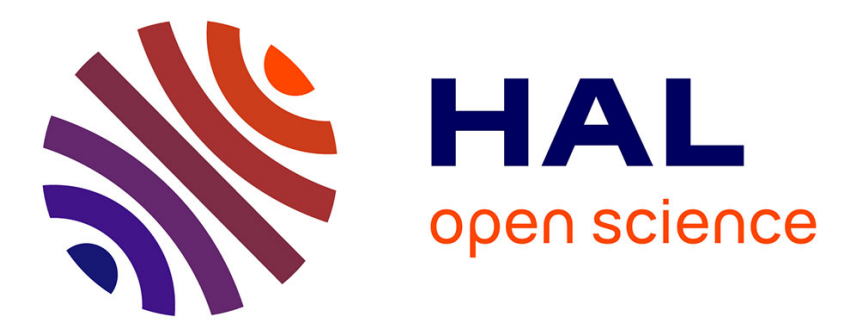

\title{
Le transfert des corps dans l'Empire romain : problèmes d'épigraphie, de religion et de droit romain
}

\author{
Nicolas Laubry
}

\section{To cite this version:}

Nicolas Laubry. Le transfert des corps dans l'Empire romain: problèmes d'épigraphie, de religion et de droit romain. Mélanges de l'Ecole française de Rome - Antiquité, 2007, 119 (1), pp.149-188. 10.3406/mefr.2007.10331 . hal-01301821

\section{HAL Id: hal-01301821 \\ https://hal.science/hal-01301821}

Submitted on 13 Apr 2016

HAL is a multi-disciplinary open access archive for the deposit and dissemination of scientific research documents, whether they are published or not. The documents may come from teaching and research institutions in France or abroad, or from public or private research centers.
L'archive ouverte pluridisciplinaire HAL, est destinée au dépôt et à la diffusion de documents scientifiques de niveau recherche, publiés ou non, émanant des établissements d'enseignement et de recherche français ou étrangers, des laboratoires publics ou privés. 
MEFRA 119/1 - 2007, p. 149-188

\title{
Le transfert des corps dans l'Empire romain : problèmes d'épigraphie, de religion et de droit romain
}

\begin{abstract}
N. LAUBRY*
Résumé : Cette étude se propose de réexaminer les modalités du transport et du transfert de cadavres sous l'Empire par la confrontation de la documentation épigraphique (21 inscriptions réunies) et des sources juridiques. Possédant parfois des conséquences rituelles qui prenaient la forme d'un piaculum mentionné par les inscriptions et que l'on peut rapprocher de l'expiation du $\S 73$ de la lex Vrsonensis, le transfert fut soumis à de stricts contrôles, dont les instances variaient selon les lieux (pontifes, empereur, gouverneurs de province). Mais, pour l'époque impériale, ces dispositions reposaient moins sur la peur de l'insepultus ou sur la crainte de la pollution par le cadavre que sur des soucis d'ordre administratif ou sur la persistance d'une forme de tabou. Même si l'on ne peut reconstituer qu'imparfaitement les conditions matérielles de ces déplacements, la mise en perspective de la documentation permet de dégager des logiques différentes, variables avec le temps, entre le discours du droit, les pratiques religieuses ou encore les croyances qui se recoupent sans toujours coïncider.
\end{abstract}

[149] Il existe dans l'ensemble de la documentation épigraphique latine un petit nombre d'inscriptions funéraires qui signalent que le corps du défunt a été rapatrié ou qu'il a été transféré de sa sépulture d'origine. Si cet usage épigraphique est très sporadique, ces textes constituent un ensemble intéressant dans la mesure où ils permettent de confronter la pratique à d'autres sources, essentiellement juridiques pour le Haut-Empire, qui fournissent des cadres à ce que les savants modernes ont pris l'habitude de dénommer la translatio cadaueris. Les premiers à avoir proposé une synthèse sur ce petit dossier furent J. Marquardt et G. Wissowa, qui se sont efforcés de reconstituer les modalités du passage d'un corps d'une sépulture à l'autre ${ }^{1}$. La question fut abordée également, mais de manière plus allusive, par des historiens du droit romain comme F. de Visscher et M. Kaser qui, néanmoins, avaient réuni une bonne partie des sources ${ }^{2}$. Les deux dernières études en date sont celles de L. Cracco-Ruggini et Fr. van Haeperen ${ }^{3}$. La première cependant adopte une perspective qui ne sera pas la mienne ici. Choisissant un cadre chronologique plus large, elle s'attache en effet principalement aux implications idéologiques de ces rapatriements ou de ces transferts. De ce fait, dans un article au demeurant très complet, elle s'intéresse essentiellement aux funérailles des empereurs morts hors de Rome, puis aux ruptures ou aux continuités entre le Haut-Empire et l'Antiquité tardive afin de montrer les spécificités de ces transferts dans le culte des martyrs. Fr. van Haeperen, dans sa thèse sur le collège pontifical, a également repris une partie de cette question, mais en se concentrant sur la délimitation du rôle des pontifes en ces matières dont elle a proposé une belle mise au

Doctorant, Université Lyon III / UMR 8546 CNRS-ENS. Ce texte est la version développée d'un travail présenté en juin 2005 à l'EHESS dans le cadre du séminaire de Y. Rivière, à qui je dois d'avoir poussé plus avant mes investigations sur cette question. Mes plus vifs remerciements vont aussi à J. Andreau, Fr. Bérard, N. Monteix, J. Pölönen, J. Scheid et Y. Thomas qui ont accepté de relire cette étude et m'ont fourni à bien des égards de précieux conseils.

${ }^{1}$ Marquardt 1881-1886, III, p. 309-310 ; Wissowa 1912, p. 393 n. 5 et p. 479, n. 4.

${ }^{2}$ De Visscher 1963. Kaser 1978.

${ }^{3}$ Cracco-Ruggini 1995 et Van Haeperen 2002. 
point. En réalité, seul O. Estiez a abordé cette question de front, mais, justement, en laissant de côté la documentation épigraphique ${ }^{4}$.

Je voudrais ici reprendre ce dossier en insistant un peu plus sur ce qui fait son intérêt : la confrontation entre la documentation épigraphique et les sources juridiques voire, le cas échéant, littéraires. Certes, dans la lignée des précédents travaux - dont la liste ne se veut pas exhaustive, on cherchera à établir les modalités exactes du transport et du transfert des corps ${ }^{5}$, les contrôles auxquels ils donnaient lieu et les autorités qui en avaient la charge. La documentation n'étant pas nouvelle, il s'agira plus de précisions ou de compléments que de conclusions inédites. Mais le problème de la translatio cadaueris possède à l'examen des implications beaucoup plus larges qu'il n'y paraît à l'abord. Touchant à la mort ainsi qu'aux rites et aux interdits qui l'entourent, le déplacement d'un [150] corps avait nécessairement des conséquences sur le plan religieux mais, de manière un peu paradoxale, nous saisissons cette pratique essentiellement par les textes de droit. Or, la mise en perspective de l'ensemble des sources permet plus qu'une simple reconstitution de la pratique : elle rend possible une comparaison entre les prescriptions et les exigences de la religion d'une part, et le discours de la jurisprudence impériale de l'autre, dont on parvient ainsi à discerner les spécificités. C'est là un fait que les études de Y. Thomas ont récemment mis en lumière, mais sur lequel on n'a pas toujours suffisamment insisté en utilisant parfois les textes juridiques comme sources pour établir les croyances et les pratiques religieuses romaines - et inversement ${ }^{6}$. D'autre part, le problème de la translatio dépassait bien évidemment les frontières de Rome et de l'Italie. Or, la documentation, que l'on aimerait plus fournie, permet de l'envisager également pour la plus grande partie de l'Empire. Elle donne ainsi un aperçu sur les modalités d'application du droit (civil et sacré) dans les provinces. On le voit, les interrogations soulevées sont multiples. Aussi cette étude prétend-elle moins apporter des solutions que suggérer quelques hypothèses.

\section{Remarques sur la documentation épigraphique}

Quelques remarques préalables de méthode sur la nature de la documentation envisagée ne seront peut-être pas superflues. Les inscriptions, au nombre de 20 pour une période de trois ou quatre siècles, sont peu nombreuses ${ }^{7}$. Ce sont presque exclusivement des épitaphes ${ }^{8}$. Mais cette rareté ne signifie pas que l'usage de transférer les corps ait été également peu répandu. Il faut prendre conscience avant toute chose que c'est le fait de rappeler ce geste sur une épitaphe qui ne va pas de soi. Ainsi, en partant d'un tel échantillon, on ne peut s'attendre à parvenir à une vision précise de cette pratique et sa fréquence véritable nous échappe définitivement. Il n'est cependant pas inutile de relever que, si l'essentiel des attestations a été découvert comme on pouvait le présager en Italie et surtout à Rome, quelques documents viennent des provinces : ainsi, une femme fait revenir

\footnotetext{
${ }^{4}$ Estiez 1995.

${ }^{5}$ Dans la suite de cette étude, comme nous le verrons dans le détail, je parlerai de « transfert » dans les cas où le corps passe d'une sépulture à une autre. J'emploierai le terme de «transport » pour les autres genres de déplacement d'un cadavre (rapatriement, etc.).

6 Thomas 1999 et 2002.

${ }^{7}$ Voir l'appendice épigraphique où sont réunis en tout 21 textes, dont l'un ne se réfère pas au transport de la dépouille d'un défunt. Néanmoins, la liste n'est peut-être pas totalement exhaustive.

${ }^{8}$ Sauf peut-être $C I L$ VI, $2120\left(n^{\circ} 2\right.$ : sur la nature du support et le contexte originel, voir l'appendice épigraphique).
} 
les restes de son époux de Dacie jusqu'à Lambèse $\left(n^{\circ} 19=C I L\right.$ VIII, 2772); une autre de Gaule jusqu'en Byzacène ( ${ }^{\circ} 16=C I L$ VIII, 12128); à Lyon, deux femmes font rapatrier de Rome le corps de leur sœur $\left(\mathrm{n}^{\circ} 14=C I L\right.$ XIII, 2181); de même, un père avec la dépouille de son fils, mort à Rome, et recevant une sépulture à Saint-Maurice, dans les Alpes Pennines $\left(n^{\circ} 13=C I L\right.$ XII, 155) ${ }^{9}$. La destination la plus fréquente reste toutefois Rome, mais cela est sans doute lié en partie au fait que les inscriptions sont beaucoup plus nombreuses dans la capitale de l'Empire $^{10}$. En effet, les épitaphes de cet ensemble proviennent presque systématiquement du lieu où la dépouille a finalement reçu une sépulture $^{11}$. Seules deux inscriptions semblent avoir appartenu à un cénotaphe. L'inscription du purpurarius Publius Murrius Zetus, encastrée dans un mur de l'abbaye de Montecassino, provient vraisemblablement du territoire d'Aquinum. Or, le texte dit explicitement que le corps a été transporté à Plaisance, même si la formule hic situs est y figure en toutes lettres ${ }^{12}$. De même, un monument funéraire retrouvé dans les environs de Zlatna (l'antique Ampelum), précise que la dépouille d'un affranchi impérial procurateur des mines d'or d'Alburnus Maior a été reconduite à Rome ${ }^{13}$.

[151] Les distances couvertes sont très variables. Nous avons des exemples où le déplacement n'a concerné que quelques centaines de mètres, ou quelques kilomètres tout au plus $^{14}$. Il peut s'agir alors de simples transferts. Cependant, on est frappé par les distances que ces dépouilles ont pu être amenées à parcourir et il ne fut pas rare que des montagnes ou des mers fussent traversées. Le temps de trajet devait être d'autant plus long si l'on songe aux conditions de transport dans l'Antiquité. Il n'est pas question de reprendre ici chacun de ces trajets pour en fournir une estimation qui restera toujours arbitraire. On peut toutefois, à titre d'exemple, rappeler les calculs d'E. Gabba et de G. Tibiletti pour le rapatriement à Pavie d'une femme morte à Trèves, sans doute au IV $\mathrm{IV}^{\mathrm{e}}$ siècle. ${ }^{15} \mathrm{Si}$ l'on s'en tient au réseau fourni par l'Itinéraire Antonin, et en passant par Strasbourg, Avenches, le Grand Saint-Bernard puis Aoste et Verceil, la distance couverte est d'un peu plus de 800 $\mathrm{km}$. À une moyenne de 30 milles romains par jour (soit $45 \mathrm{~km}$ ), le transport a pu durer 1520 jours. De même, la distance du voyage par voie de terre entre Carthage et Thubursicum Numidarum équivalait à quelques $800 \mathrm{~km}^{16}$. Il n'est guère besoin de préciser que tout le monde ne pouvait pas assumer les frais d'un tel voyage.

\footnotetext{
${ }^{9}$ Voir également le $\mathrm{n}^{\circ} 18$ (ILAlg, I, 1363) de Carthage à Thubursicum Numidarum; $\mathrm{n}^{\circ} 20\left(\right.$ ILAlg, II ${ }^{3}$, 9109) : peut-être de Bretagne en Numidie (cf. l'appendice épigraphique) ; $n^{\circ} 12$ (CIL XII, 118) : de la vallée Pennine à Aime en Tarentaise.

${ }^{10}$ Cinq cas : $n^{\circ} 15$ (CIL III, 1312 : d’Ampelum à Rome); ${ }^{\circ} 1$ (CIL VI, 1884 : de Selinonte à Rome); $n^{\circ} 2$ (CIL VI, 2120 : de Rome à Rome); n 3 (CIL VI, 2464: de Bretagne à Rome); $\mathrm{n}^{\circ} 5$ (CIL VI, 8878 : de Carnuntum à Rome) et enfin $n^{\circ} 6$ (CIL VI, 20863, sans doute de Rome à Rome, moins un rapatriement qu'un transfert).

${ }^{11}$ Voir l'appendice épigraphique, où l'on pourra comparer les lieux de découverte avec celui du tombeau signalé par l'épitaphe.

12 AE 1972, $74\left(\mathrm{n}^{\circ}\right.$ 8) : hoc monumentum fecit ossaque transtulit Placentiam. Sur les raisons de ce retour, voir les hypothèses formulées par Virno Bugno 1971.

${ }^{13}$ CIL III, $1312\left(\mathrm{n}^{\circ} 15\right)$. Voir l'appendice pour le détail. Mommsen préfère attribuer le texte à Ampelum, plutôt qu'à Apulum, car l'administration des mines y possédait ses bureaux. Il n'est pas impossible également que l'épitaphe du centurion mort en Bretagne, mais trouvée en Afrique, soit également un cénotaphe. Sur ce type de monument, voir dernièrement Ricci 2001 et 2006.

${ }^{14}$ Par exemple, très certainement, $\mathrm{n}^{\circ} 2$ et 6 (CIL VI, 2120 et 20863).

$15 A E$ 1992, 813 (n 11). Cf. Gabba - Tibiletti 1960.

${ }^{16}$ ILAlg, I, 1363 (appendice épigraphique, $\mathrm{n}^{\circ} 18$ ).
} 
De fait, nous ignorons pratiquement tout des conditions matérielles de ce transport qui, au moins d'un point de vue sanitaire, devait poser de multiples problèmes, surtout dans le cas des morts destinés à être inhumés - même si la pratique de l'embaumement n'était pas inconnue. Les termes employés pour désigner le défunt sont, le plus souvent, soit reliquiae, soit corpus. On aurait tort d'y voir une dichotomie entre incinération d'une part et inhumation d'autre part. Certes, quand nous possédons encore le monument portant l'épitaphe, on constate que corpus apparaît sur un sarcophage ${ }^{17}$. Inversement, le terme reliquiae semble désigner ce qui résulte de l'incinération. Mais cette distinction est loin d'être systématique. Dans l'inscription d'Aime en Tarentaise, ce sont des reliquiae qui sont enfermées dans un sarcophage ${ }^{18}$. En réalité, ces noms ne renvoient pas à des pratiques funéraires précises, mais à des " manières métonymiques de dire ${ }^{19}$. Ils ne possèdent pas systématiquement une valeur référentielle, même dans les textes épigraphiques. Comme l'a bien montré A. Allara, corpus n'est pas la façon de nommer le point d'aboutissement d'un rite funéraire spécifique. Ce terme est la projection d'une intégrité et renvoie à une identité qui est nécessaire à la constitution du tombeau définissant lui-même l'espace propre des morts au sein de la cité ${ }^{20}$. Autrement dit, corpus désigne le corps qui a reçu ou doit recevoir une sépulture, par opposition au cadauer. Dans deux épitaphes qui utilisent le terme ossa, la situation n'est pas plus claire, car les ossements peuvent être aussi bien le reliquat de l'incinération que celui de la décomposition ${ }^{21}$. En somme, si aucun autre indice, notamment archéologique, ne vient apporter une confirmation, il est très malaisé de déterminer l'état de la dépouille qui a été transportée. Il est tout aussi difficile de saisir, en cas d'incinération, le moment précis où elle a pu avoir lieu : avant le transport ou, dans la continuité de la série de rites donnant au défunt sa dernière demeure, au moment des funérailles ?

Il est probable que des sociétés de pompes funèbres, payées par l'héritier, se soient chargées de l'organisation matérielle du transport. On sait par exemple que, après la mort des consuls Aulus Hirtius et Vibius Pansa au cours de la guerre de Modène, les libitinarii de Rome assurèrent gratuitement les obsèques et donc, probablement, l'acheminement de leurs dépouilles vers Rome où ils reçurent une sépulture ${ }^{22}$. Une partie mutilée du texte de la première colonne du fameux règlement de pompes funèbres de Pouzzoles fournit peut-être quelques précisions à ce sujet. En cas de [152] transport du corps, l'entrepreneur facturait le coût de sa prestation en fonction de la distance parcourue. Le tarif paraît ainsi avoir augmenté au-delà du cinquième mille ${ }^{23}$. En revanche, la lex Cumana libitinaria, malheureusement extrêmement fragmentaire, semble avoir abordé la question du transport des dépouilles et de son coût de manière plus systématique ${ }^{24}$. L'étude des termes employés

\footnotetext{
${ }_{17}^{17}$ Ainsi $A E 1992,813\left(\mathrm{n}^{\circ} 11\right)$; CIL VI, $2120\left(\mathrm{n}^{\circ} 2\right)$; cf. CIL XIII $2181\left(\mathrm{n}^{\circ} 14\right)$, précisé par le texte.

${ }^{18}$ CIL XII, $118\left(\mathrm{n}^{\circ} 12\right)$.

19 Thomas 1999 , p. 89.

${ }^{20}$ Allara 1995 et Thomas 1999, surtout p. 88 sq.

${ }^{21}$ En revanche, $C I L$ VI, $2938\left(n^{\circ} 4\right)$ ne présente aucune ambiguïté, car le terme est associé aux cendres.

22 VAl.-MaX, V, 2, 10 : M. Cornuto praetore funus Hirti et Pansae iussu senatus locante, qui tunc libitinam exercebant, cum rerum suarum usum, tum ministerium suum gratuiti polliciti sunt etc. Il va de soi que la qualité des défunts empêche cependant toute généralisation.

${ }^{23}$ Voir Libitina 2004, p. 47, col. I, 5-6 et le commentaire dans Hinard - Dumont 2003, p. 98-99.

${ }^{24}$ Sur la lex Cumana libitinaria, voir maintenant Camodeca 2004 et le commentaire donné par Castagnetti 2004. Le texte a connu deux rédactions successives, la première probablement sous le règne d'Auguste. La mention d'un pons (col. II de la face A, 1. 7 et 10) a fait supposer que ce passage du règlement établissait qui, du client ou de l'entrepreneur, devait payer le droit de franchissement en cas de transport d'un cadavre (Hinard - Dumont 2003, p. 98-99). Toutefois, je crois qu'il faut rester prudent sur l'interprétation de ce
} 
laisse penser que la première colonne et le début de la deuxième colonne de la face $\mathrm{A}$ concernaient le transport des défunts et la sépulture, sans que l'on puisse en savoir beaucoup plus. Enfin, les statuts du collège de Diane et Antinous, fondé en 136 à Lanuvium, prévoient les mesures à prendre en cas de mort d'un membre à l'extérieur du municipe $^{25}$. Le décès dans la limite de 20 milles (environ $35 \mathrm{~km}$ ) à l'extérieur du municipe conduisait à l'envoi de trois collegiati désignés et chargés d'accomplir les funérailles. On leur confiait à cet effet le montant de la prime funéraire et une somme de 20 sesterces devant couvrir les frais du voyage ${ }^{26}$. Mais lorsqu'un membre de l'association mourait audelà des 20 milles, l'individu qui s'était chargé de ses funérailles devait, témoins à l'appui, réclamer la somme du funeraticium au collège, après déduction des indemnités et du prix des funérailles ${ }^{27}$. On ignore cependant à quel montant pouvaient s'élever ces obsèques, d'autant qu'il n'est pas assuré que le corps était rapatrié systématiquement.

Les dépenses occasionnées par le transport ou le rapatriement du corps d'un défunt étaient comptées par la jurisprudence impériale au nombre des frais funéraires, ainsi que nous l'apprend Ulpien dans un commentaire à l'édit du préteur conservé par le Digeste :

La dépense engagée pour le rapatriement du corps d'un individu mort à l'étranger relève des funérailles, même si l'individu n'a pas encore reçu de funérailles ${ }^{28}$.

Le retour du corps d'un défunt dans sa patrie n'était donc pas considéré comme un luxe superflu par le droit, mais comme une étape à part entière des funérailles et un moment indispensable du funus qui conduit le corps jusqu'au tombeau devenant locus religiosus. Toutefois, il faut bien saisir la portée de l'affirmation d'Ulpien et la logique qui guide l'ensemble du passage. Elle repose en effet sur l'idée que tout un chacun doit recevoir une sépulture, qui peut trouver son fondement aussi bien dans un tabou religieux que dans une exigence d'ordre administratif, et que, d'autre part, tout individu qui a dépensé de l'argent pour ensevelir un défunt dont il n'était pas légalement chargé d'assurer les funérailles peut recouvrer la somme qu'il a engagée pour la tombe ${ }^{29}$. En général, le défunt désignait

fragment. Le mot pons se trouve en effet dans un contexte de la loi où il ne s'agit plus du transport et de la sépulture (qui semble s'arrêter en II, A, 2), mais dans la partie qui traite plus spécifiquement des supplices (cf. Castagnetti 2004, p. 134, qui adopte une position raisonnable).

${ }^{25}$ CIL XIV, 2112 (ILS 7212).

${ }^{26}$ L. 26-30: quisquis a municipio ultra milliar(um uicesimum) decesserit, et nuntiatum fuerit, eo exire debebunt / electi ex corpore n(ostro) homines tres, qui funeris eius curam agant, et rationem populo reddere debebunt / sine dolo ma[lo] ; [...] Quibus / [funeraticium] eius dabitur, hoc amplius uiatici nomine ultro citro sing(ulis) HS (uiceni) (nummi). La somme allouée aux collegiati à jour dans leur cotisation pour leurs funérailles était de 300 sesterces (1. 25). Voir Flambard 1987.

${ }^{27}$ CIL XIV, 2112, 1. 30 sq. : quodsi longius / [a municipio su]pra (miliarium vicesimum) decesserit et nuntiari non poterit, tum is qui eum funerauerit, testa/[tor rem tabu]lis signatis sigillis ciuium Romanor(um) VII, et probata causa funeraticium eius, sa/[tis dato ampli]us neminem petiturum, deductis commodis et exequario, e lege collegi dari [ei debebit]. Commoda signifie manifestement " indemnités », comme le traduit J.-M. Flambard (1987, p. 230). Th. Mommsen pensait qu'il s'agissait d'un dédommagement pour le président et son secrétaire, chargés de gérer la caisse du collège. La destination de cette somme reste néanmoins problématique.

${ }^{28}$ D., 11, 7, 14, 4 (ULPIEN, Ad Ed., 25) : impensa peregre mortui quae facta est ut corpus perferetur, funeris est, licet nondum homo funeretur. Sauf mention particulière, les traductions des textes latins et grecs sont personnelles.

${ }^{29}$ D., 11, 7, 12, 3 (ULPIEN) : Hoc edictum (sc. praetoris) iusta ex causa propositum est, ut qui funerauit persequatur id quod impendit : sic enim fieri, ne insepulta corpora iacerent neue quis de alieno funeretur. 
personnellement un individu chargé de pourvoir à ses obsèques, mais, par défaut, il s'agissait soit de l'heres scriptus, soit des heredes legitimi, soit des cognats ${ }^{30}$. Cependant, il [153] pouvait arriver qu'il y ait des conflits ou des réclamations. En ce cas, le préteur accordait une actio funeraria permettant à celui qui avait accompli les funérailles à ses frais de recevoir un dédommagement de la part des héritiers. Il était par conséquent nécessaire de délimiter précisément quelles dépenses pouvaient être revendiquées devant la justice ${ }^{31}$. $\mathrm{Au}$ nombre de ces dépenses, on compte notamment, à côté des frais matériels, le péage de droit de passage (uectigalia) dont on devait parfois s'acquitter lors du transport ${ }^{32}$.

L'examen des épitaphes montre, assez naturellement, que les défunts dont les corps sont rapatriés sont des individus qui ont été conduits par leurs fonctions ou leurs activités à séjourner loin de leur patrie ou de leurs attaches. Ce sont donc majoritairement des soldats (CIL VI, $2464=\mathrm{n}^{\circ} 3$; VI, $2938=\mathrm{n}^{\circ} 4$; VIII, $12128=\mathrm{n}^{\circ} 16 ; I L A l g, \mathrm{II}^{3}, 9109=\mathrm{n}^{\circ} 20$, à quoi on peut ajouter $C I L$ VIII, $2772=\mathrm{n}^{\circ} 19$, un individu ayant accompli les milices équestres) ou des affranchis impériaux (CIL III, $1312=\mathrm{n}^{\circ} 15 ; \mathrm{VI}, 1884=\mathrm{n}^{\circ} 1$ ). On compte également deux voire trois étudiants ainsi qu'une Africaine qui avait été conduite à Rome pour affaires ${ }^{33}$. Il faut cependant bien distinguer, stricto sensu, le rapatriement du transfert d'une sépulture à une autre $\left(C I L\right.$ VI, $2120=\mathrm{n}^{\circ} 2$, sans doute VI, $20863=\mathrm{n}^{\circ} 6$ et peut-être $C I L$ IX, $4881=\mathrm{n}^{\circ}$ 9). Dans les deux cas il y a transport mais, comme nous le verrons, les modalités étaient probablement différentes.

Les motifs qui ont conduit au rapatriement nous échappent généralement dans le détail, mais il ne faut pas aller les chercher très loin. L'affection des proches ou la pietas jouent un rôle déterminant. En outre, un individu amené à voyager, sachant que la mort pouvait le surprendre loin de chez lui, avait la possibilité d'émettre de son vivant le souhait d'être rapatrié en cas de décès lointain. Un cas conservé dans le Digeste montre que ce souhait pouvait être exprimé par testament:

Il avait demandé à ses héritiers, au cas où il mourrait en province, que l'on donne à Lucius Titius la somme de tant de sesterces pour qu'il se charge de faire rapatrier son corps, et il avait ajouté ces mots : «je veux qu'on lui cède l'argent qui en restera ». Le même jour, il avait écrit des codicilles à ses héritiers en ces termes : «je vous demande, si quelque accident conforme à la nature de l'homme me surprend dans une province ou sur la route, de vous charger de rapporter mon corps en Campanie, dans le tombeau de mes fils $»{ }^{34}$.

${ }^{30}$ D., 11, 7, 12, 4 (ULPIEN).

${ }^{31}$ L'interprétation donnée par O. Estiez (1995, p. 107) est erronée. Absolument rien ne dit dans le texte d'Ulpien qu'un "premier enterrement a été fait». La concessive introduite par licet qui termine le propos indique seulement que, même si ce n'est pas un geste qui relève à proprement parler des funérailles, le droit considère que le rapatriement en fait véritablement partie.

${ }^{32}$ D., 11, 7, 37 pr. (MACER, Ad libr. uices. hered., 1). Peut-être doit-on également comprendre en ce sens le terme de uectura employé par Macer, à moins qu'il ne désigne plus concrètement le coût des moyens matériels du transport (cf. $O L D$, s.v., pour les deux sens possibles). Le tarif du péage de Coptos, ouvrant sur la route vers la Mer Rouge et daté de 90, mentionne une taxe d'une drachme et 4 oboles réservée aux convois funéraires $(O G I S, 674,31)$. Il semble que ce genre de taxe ait été supprimé à une époque plus tardive (cf. $C J$., $3,44,15)$.

${ }^{33}$ CIL XII, $118\left(\mathrm{n}^{\circ} 12\right)$; ILAlg, I, 1363 (n $\left.{ }^{\circ} 18\right)$, à quoi on ajoutera peut-être l'inscription perdue de SaintMaurice (CIL XII, $\left.155=\mathrm{n}^{\circ} 13\right)$. CIL VIII, $152\left(\mathrm{n}^{\circ} 17\right)$.

${ }^{34}$ D., 34, 4, 30, 2 : Ab heredibus petierat, ut, si in prouincia decessisset, sexaginta Lucio Titio darentur, ut is corpus eius curaret in patriam reportari, et adiecerat haec uerba : "cui concedi uolo, si quid ex ea pecunia supererit 》. eadem die codicillos ad heredes suos ita scripserat : " peto a uobis, ut, siue in prouincia siue in 
Dans le cas de transfert de corps, les motifs peuvent varier. L'inscription de Rome contenant le décret des pontifes (CIL VI, $2120=\mathrm{n}^{\circ} 2$ ) met en avant le désir de l'auteur de la requête d'être réuni avec ses proches jusque dans la mort. Elle rejoint en cela le texte précédent et l'épitaphe du sarcophage de Pavie, la défunte devant reposer après son rapatriement at maiorum sepulcra. Mais la demande est faite également sous couvert de la necessitas, la contrainte impérieuse. Arrius Alphius s'est vu obligé de confier le corps de son épouse et de son fils à une sépulture provisoire, car leur mort est survenue avant l'achèvement du tombeau qu'il projetait pour réunir les dépouilles de sa famille. Comme nous le verrons dans les textes juridiques, la necessitas est effectivement une des causes qui rendent possible le transfert d'un corps.

Mais plus que les raisons qui conduisent à transférer ou rapatrier le corps d'un proche, ce sont surtout les motivations qui poussent à [154] inscrire cette précision sur la pierre de l'épitaphe qui demanderaient une explication. La plupart des textes regroupés ici ne se démarquent des autres épitaphes que par cette seule caractéristique. Ils sont d'un ton très sobre, à peine relevé parfois par un discret éloge du mort. Quelques autres contiennent des tentatives de versification. Toutefois, la mention du rapatriement des restes peut être une manière de souligner la pietas et l'affection portée au défunt. Ainsi, M. Seruilius Fortunatus a rapporté la dépouille de son épouse "par mers et par terres ». La pauvre femme était morte en Dacie et reçut une sépulture à Lambèse, et il est certain qu'il ne s'agit pas d'une exagération rhétorique. Le pluriel, toutefois, reste suggestif ${ }^{35}$. On constate par ailleurs que, parmi les inscriptions qui nous sont parvenues, seuls les affranchis impériaux signalent que l'autorisation leur fut délivrée par l'empereur en personne ${ }^{36}$. Sans doute estce là le hasard des découvertes, mais on peut se demander si cette précision ne cherchait pas à insister sur la proximité avec le prince - proximité qui, il est vrai, rendait plus aisée la démarche pour accomplir une translatio. Il n'est pas innocent que, sur l'épitaphe de M. Vlpius Hermias (CIL III, $1312=\mathrm{n}^{\circ} 15$ ), le terme d'indulgentia se substitue au traditionnel et plus neutre permissus, soulignant à la fois l'égard et le privilège reçu du prince. L'inscription d'Arrius Alphius, si elle était funéraire - ce que nous ne pouvons déterminer avec certitude - pourrait également aller dans le sens d'un désir d'afficher ses liens avec les puissants $^{37}$. Mais tout ne saurait être expliqué par la volonté de se distinguer en cherchant par tous les moyens à faire valoir sa réussite et ses relations. Ainsi, dans l'épitaphe des Claudii de Rome, la mention de l'autorisation des tribuns de la plèbe est tout ce qu'il y a de plus neutre ${ }^{38}$. Il faut se rendre à l'évidence : si les épitaphes romaines servaient d'abord à commémorer le défunt, elles pouvaient également attester de l'accomplissement des devoirs funéraires selon les formes et valoir parfois, en quelque sorte, comme certificat de légalité.

uia aliquid mihi humanitus acciderit, corpus meum curetis et in Campania et in monumentum filiorum meorum reportare ». Je remercie J. Pölönen de m'avoir signalé cette référence.

${ }^{35}$ CIL VIII, 2772, le $\mathrm{n}^{\circ} 19$ de l'appendice épigraphique.

${ }^{36}$ CIL III, $1312\left(\mathrm{n}^{\circ} 15\right)$ : ex indulgentia Augusti nostri; CIL VI, 8878 ( $\mathrm{n}^{\circ}$ 5) : permissu imperatoris.

${ }^{37} C I L$ VI, 2120. Voir l'appendice épigraphique $\left(\mathrm{n}^{\circ} 2\right)$ pour un commentaire plus détaillé.

${ }^{38}$ CIL VI, 20863 (n 6). 
MEFRA $119 / 1-2007$, p. $149-188$

\section{Le transport des corps dans les sources juridiques}

À côté de cette documentation épigraphique, quelques textes juridiques abordent la réglementation du transport et du transfert des corps. Malgré l'attention constante portée par la jurisprudence à ce problème, les données sont cependant peu nombreuses, et d'une interprétation qui n'est pas toujours facile. Rares sont les textes qui traitent directement cette question. Elle est le plus souvent évoquée de manière allusive. En outre, il ne faut pas négliger la distance chronologique qui s'intercale parfois entre les différents témoignages. Par conséquent, plutôt que de tenter de reconstituer une norme cohérente que présupposerait l'ensemble de ces textes, il est préférable, au moins dans un premier temps, de les examiner dans le détail.

Le passage le plus explicite sur l'autorisation du transport des corps se trouve dans le Digeste de Justinien. Il apparaît dans le titre consacré à la définition des cas qui peuvent donner lieu à l'action de sepulchro uiolato ${ }^{39}$. Il s'insère dans un commentaire d'Ulpien sur l'édit du préteur qui définit et délimite les lieux de sépulture ainsi que leurs usages et les interdits dont la transgression peut conduire à l'action en justice (ensevelir un mort contre la volonté du fondateur du tombeau, habiter dans un sépulcre, etc.). Le texte qui nous intéresse est le suivant :

Les corps qui n'ont pas été confiés à une sépulture définitive peuvent être transportés, selon le contenu d'un édit du divin Sévère qui interdit que l'on retienne, que l'on malmène des corps, ou qu'on les empêche d'être transportés de par les territoires des villes. Par ailleurs, le divin Marc a établi par rescrit que ceux qui, en menant un défunt à sa tombe, ont transporté un corps dans une ville ou ses quartiers n'ont mérité aucune peine, même si de tels actes ne doivent pas être accomplis sans la permission de ceux qui ont le droit de les permettre $^{40}$.

[155] Ces décisions impériales concernent donc le transport des corps. Le verbe employé est - comme bien souvent - transferre, avec la variante de transuehere dans le rescrit de Marc-Aurèle, termes que reprennent également les inscriptions ${ }^{41}$. Il faut comprendre à la fois le trajet parcouru par une dépouille lors de la pompa funebris, mais également, selon toute vraisemblance, le transport en cas de rapatriement qui, comme nous l'avons vu, était considéré comme une partie intégrante du funus. En reprenant l'ordre chronologique inversé dans le commentaire d'Ulpien, on constate que la décision de Marc-Aurèle autorise

${ }^{39}$ D., 47, 12. Sur celle-ci, voir essentiellement De Visscher 1963, p. 139 sq.

${ }^{40} D ., 47,12,3,4$ (ULPIEN, Ad Ed., 25) : Non perpetuae sepulturae tradita corpora posse transferri edicto Diui Seueri continetur, quo mandatur, ne corpora detinerentur aut uexarentur aut prohiberentur per oppidorum territoria transferri. Diuus tamen Marcus rescripsit nullam poenam meruisse eos, qui corpus in itinere defuncti per uicos aut oppidum transuexerunt, quamuis talia fieri sine permissu eorum, quibus permittendi ius est, non debeant. Je ne m'étends pas sur la traduction de uici ou d'oppidum, qui pourrait être discutée : on pourrait lui préférer village : en traduisant par «quartier», j'ai cherché à souligner le lien entre les deux ensembles urbains. Imaginons donc le quartier d'une ville qui serait transplanté sur le territoire de la cité (cf. Tarpin 2002, p. 28 sq.).

${ }^{41}$ Par exemple CIL VI, 20863 ( $\mathrm{n}^{\circ}$ 6) : corporibus tralatis ; CIL IX, 4881 ( $\mathrm{n}^{\circ}$ 9) : corpus...tralatum est ; $\mathrm{XIV}, 3777\left(\mathrm{n}^{\circ} 7\right)$ : ossa...translata sunt. On trouve également des variantes : referre, deferre, adferre, etc. (voir l'appendice épigraphique). 
sans équivoque un tel transport. On peut se demander pourquoi elle concerne en tout premier lieu les uici et l'oppidum, et pourquoi le problème se posait justement pour ces espaces territoriaux. Cette décision est en effet un rescrit, et l'empereur avait donc été consulté sur ce point précis. Dans les textes littéraires, uici et oppida sont à la fois complémentaires et antagonistes. L'oppidum semble répondre à des critères de nature civique et religieuse (notamment le rite de fondation), qui sont, inversement, absents du uicus. Les uici, cependant, sont des structures au cadre juridique défini et qui, très souvent, bien que situés sur le territoire d'une cité, sont étroitement liés au chef-lieu ${ }^{42}$. Est-ce parce que ces espaces urbains étaient définis par un statut particulier les opposant au reste du territoire que le transport de dépouilles posait problème ? Ou bien, plus simplement, dans des espaces caractérisés également par la vie urbaine, déplacer un corps risquait-il de produire différents types de nuisances, qui sont également invoqués dans la législation prohibant la sépulture à l'intérieur des villes ? Si cette dernière hypothèse semble la plus recevable, il reste difficile d'apporter une réponse définitive à ces interrogations : il est très possible que nous ayons affaire à une forme de tabou repris et systématisé par la norme administrative, sans que le sens originel de l'interdit ait été véritablement retenu ${ }^{43}$.

Le point important reste ici que le transport était permis mais soumis à une autorisation préalable des autorités compétentes. Nous aurons à y revenir plus bas. On notera cependant que le rescrit ne désigne pas spécifiquement et nommément les magistrats pouvant délivrer une telle permission. Le caractère vague et englobant de la formule est un indice en faveur de la multiplicité des instances reconnues par le droit romain et capables de fournir l'autorisation de transport.

La décision de Septime-Sévère, rapportée en premier lieu par Ulpien, est un édit, et possède donc une valeur plus générale. Cette décision est divisée en deux parties. Le premier membre de la phrase reprend en substance le rescrit de Marc-Aurèle, en y ajoutant une condition préalable dont l'importance est de taille et qui ne figurait pas dans le texte précédent. Le transport est en effet autorisé dans la mesure où le corps n'a pas reçu de sépulture définitive. Théoriquement, il interdit donc l'exhumation d'une dépouille pour la transférer. La restriction est notable et nous allons y revenir tout de suite.

En revanche, la seconde partie de l'édit (qui, si on s'en tient à la formulation, rapporte en réalité la question principale sur laquelle portait la décision) tient plus du maintien de l'ordre public. Il est en effet interdit de malmener ou de retenir une dépouille transportée. Cette interdiction se retrouve dans un passage du De omnibus tribunalibus d'Ulpien conservé au livre XI du Digeste:

Il est du devoir du gouverneur de province d'assurer que les corps ou les ossements des morts ne sont ni retenus, ni malmenés, et qu'on ne les empêche pas d'être transportés sur la voie publique ou de recevoir une sépulture. ${ }^{44}$

\footnotetext{
${ }^{42}$ Voir Tarpin 2002, p. 28 sq. et 84 sq.

43 Sur ce problème, voir infra, p. 20 sq. Signalons que le terme d'oppidum est employé dans la lex coloniae Genetiuae (73), ainsi que dans le règlement sur les pompes funèbres de Pouzzoles (II, 5 ; cf. Libitina 2004, p. 48).

${ }^{44}$ D., 11, 7, 38 (ULPIEN, De omn. trib., 9) : Ne corpora aut ossa mortuorum detinerentur aut uexarentur neue prohiberentur quominus uia publica transferrentur aut quominus sepelirentur, praesidis prouinciae officium est. Sur l'emploi de corpus et ossa, voir supra, n. 20.
} 
[156] La répétition des termes (detinere, uexare, prohibere) incite à penser qu'Ulpien reprend l'édit de Septime-Sévère pour l'appliquer plus spécifiquement aux situations provinciales. On apprend par la même occasion que le gouverneur était tenu pour responsable de l'acheminement des dépouilles jusqu'à leur dernière demeure. Le rapprochement permet en outre de définir avec plus de précision les cas de transports envisagés. Il s'agit essentiellement de corps n'ayant pas encore reçu de sépulture. On peut donc songer aux cas de rapatriement de défunts, qui nous intéressent plus particulièrement, mais également, et plus simplement, aux processions qui se déroulaient lors des funérailles, comme le laissait déjà pressentir le rescrit de Marc-Aurèle. Ces deux textes ne concernent donc pas le transfert d'une sépulture à une autre. Ils cherchent avant tout à assurer le bon déroulement des funérailles, qui pouvaient donner lieu à des troubles de l'ordre public. L'interprétation proposée par O. Estiez ne me semble donc pas recevable. Il estime en effet que ce passage concerne le transfert de sépulture, et que ces mesures viseraient à éviter le réveil des Mânes brutalisés ${ }^{45}$. Comme nous aurons l'occasion de le constater à plusieurs reprises, le domaine du droit et celui des croyances ou du folklore sont bien plus séparés que cela. Certes, on sait que les cadavres étaient des proies convoitées pour les amateurs de nécromancie, mais on voit mal que ces derniers aient cherché à accomplir leur forfait pendant le transport même de la dépouille ${ }^{46}$. En réalité, les considérations qui guident ici l'empereur et les juristes sont tout à fait prosaïques. Il arrivait en effet que le corps d'un défunt soit retenu par ses créanciers pour forcer les héritiers à s'acquitter des dettes ${ }^{47}$. Suétone, dans la vie consacrée à Tibère, relate un fait du même genre. Énumérant les mesures prises par l'empereur pour le maintien de l'ordre public, et particulièrement les désordres populaires (populares tumultus), il rapporte la cohue qui se produisit à Pollentia dans le Picenum autour du convoi funéraire d'un centurion primipile pour extorquer à ses héritiers des jeux de gladiateurs ${ }^{48}$. Ainsi, deux ordres d'idées paraissent animer la jurisprudence impériale : d'une part, retenir la dépouille d'un défunt est lui faire injure. Or l'iniuria est moins une atteinte au cadavre objet de tabous religieux qu'un acte déshonorant susceptible d'entacher la dignitas de l'héritier, auquel une action en justice est donc accordée en conséquence. D'autre part, cet acte pouvait tomber sous le coup de la lex Iulia de $u i$, parce que, comme le montre avec emphase l'anecdote rapportée par Suétone, il pouvait conduire à des troubles de l'ordre public ${ }^{49}$. Plus donc que le repos des Mânes, c'est le désir d'éviter ce genre de manifestation ou la rétention du corps en gage qui ont guidé ces mesures. Le droit ne se soucie pas ici de la pollution que peut engendrer le contact avec

\footnotetext{
${ }^{45}$ Estiez 1995, p. 107. On remarquera en outre que, si nous sommes avant les funérailles, le mort ne peut être malfaisant, car il n'a pas encore reçu de sépulture, et donc n'est pas encore insepultus ni susceptible de se montrer malveillant parce que mal enseveli.

${ }^{46}$ Voir entre autres APUL., Met., II, 21 sq.

${ }^{47}$ Par exemple D., 47, 10, 1, 6 et surtout, mais plus tardif, CJ., 9, 19, 6 (526 ap. J.-C.). Cf. AMBR, Tob., 10 : quotiens uidi a faeneratoribus teneri defunctos pro pignore et negari tumulum, dum faenus exposcitur?

${ }^{48}$ SuÉT., Tib., 37. La répression fut lourde. Une grande partie des habitants et les décurions furent réduits aux travaux forcés. Ce trait de folklore a été bien mis en lumière par P. Veyne (1983 [1991], notamment p. 80-81).

49 D., 48, 6, 5 (MARCIEN, Inst., 14) : quiue fecerit, quo minus sepeliatur, quo magis funus diripiatur distrahatur etc. Cf. MACER, D., 47, 12, 8 et surtout Sent. Paul., 5, 26, 3 : Lege Iulia de ui priuata tenetur, qui [...] coetum, concursum, turbam, seditionem, incendium fecerit, funerari sepeliriue aliquem prohibuerit funusque eripuerit, turbauerit, etc. Soulignons que, si l'auteur des Sentences indique que cet acte est sanctionné par la lex Iulia de ui priuata, Marcien le range parmi ceux qui tombent sous le coup de la lex Iulia de ui publica. Ce n'est pas le lieu ici de s'interroger sur cette divergence.
} 
le corps, mais du bon déroulement et de la continuité du processus dont la dernière phase est l'ensevelissement et la constitution du locus religiosus. Cette mesure rejoint donc en quelque sorte la logique qui a fait inclure dans les frais funéraires les dépenses occasionnées par le rapatriement d'une dépouille $\mathrm{e}^{50}$.

\section{La perpetua sepultura et le transfert}

Il faut donc aller chercher ailleurs pour trouver des mesures qui ont pu concerner plus directement et plus spécifiquement le transfert de corps. On a constaté en effet que l'édit promulgué par Septime-Sévère qui autorise le transport d'un défunt impose au préalable la condition que le corps n'ait pas reçu une sépulture définitive, ou perpetua [157] sepultura. La même restriction est imposée de nouveau quelques dizaines d'années plus tard par Dioclétien et Maximien, dans un rescrit de 287 :

Si le corps n'a pas encore reçu une sépulture définitive, on ne t'interdit pas de le transférer ${ }^{51}$.

Le cas du transfert est soulevé également dans un texte important des Sententiae Pauli. Ce manuel de droit romain, composé sans doute vers la fin du $\mathrm{III}^{\mathrm{e}}$ s., peut-être en Afrique, est un recueil de sentences juridiques consacrées par l'usage et qui propose des séries de préceptes dépourvus de commentaires détaillés ${ }^{52}$. Le passage qui nous intéresse plus particulièrement se trouve, tout naturellement, dans la rubrique De sepulchris et lugendis :

En cas de crue d'un cours d'eau ou par crainte d'un écroulement, on peut, après avoir accompli les sacrifices rituels, transférer de nuit dans un autre lieu un corps qui a déjà été confié à une sépulture définitive ${ }^{53}$.

L'auteur des Sentences reprend ici presque textuellement un rescrit de 213 adressé par Caracalla à une certaine Dionysia et conservé par le Code Justinien :

Si les restes de ton fils sont menacés par la violence d'un cours d'eau ou qu'il se présente une autre raison, juste et impérieuse, tu peux, après avis du gouverneur de la province, les transférer en un autre lieu ${ }^{54}$.

Dans ce dernier texte, il n'est pas explicitement question de sépulture définitive, mais la proximité terminologique incite à le rapprocher du précédent. La première idée importante est donc que le transfert de corps (entendu comme un changement de sépulture) pouvait

\footnotetext{
${ }^{50}$ Cf. en ce sens également les remarques de Thomas 1999, p. 96-97.

${ }^{51}$ CJ., 3, 44, 10 : Si necdum perpetuae sepulturae corpus traditum est, translationem eius facere non prohiberis. On ne peut suivre F. Millar lorsqu'il affirme que «Dioclétien et Maximien ont donné une interprétation moins stricte que celle qui avait prévalu par le passé dans le déplacement des corps » (Millar 1977, p. 361).

${ }_{53}^{52}$ Pour une mise au point récente et raisonnée sur ce compendium, voir Herzog 1993, p. 73-74.

${ }^{53}$ Sent. Paul., 1, 21, 1 : ob incursum fluminis uel metum ruinae corpus iam perpetuae sepulturae traditum sollemnibus redditis sacrificiis per noctem in alium locum transferri potest.

${ }^{54}$ CJ., 3, 44, 1 : si ui fluminis reliquiae filii tui continguntur uel alia iusta causa et necessaria internenit, aestimatione rectoris prouinciae transferre eas in alium locum poteris.
} 
être autorisé dans des conditions extraordinaires et légitimes, ce que résumerait adéquatement le terme latin de necessitas qu'Arrius Alphius emploie dans le libelle qu'il confie au collège pontifical ${ }^{55}$. Concrètement, il s'agit principalement de la menace de destruction de la sépulture lors de crues. Il est frappant de constater que cette éventualité revient par deux fois, Caracalla se contentant par la suite de généraliser en invoquant un motif « légitime et impérieux ». Plus intéressant encore, les motifs de déplacement évoqués dans les Sentences se rencontraient déjà dans la fameuse lettre de Pline à Trajan sur des sépultures de Bithynie ${ }^{56}$. Il se dégage ainsi une forme de continuité dans les principes qui ont guidé cette législation, au moins pour les $\mathrm{II}^{\mathrm{e}}$ et $\mathrm{III}^{\mathrm{e}} \mathrm{s}$.

En conséquence, il est manifeste que l'auteur des Sententiae Pauli s'est inspiré des décisions antérieures pour composer sa maxime. Le transfert de corps était autorisé dans des cas exceptionnels, en particulier de catastrophes naturelles, mais dont l'appréciation était nécessairement confiée à une autorité compétente. Cette autorisation était rendue nécessaire précisément parce que la sépulture avait un caractère définitif ${ }^{57}$.

La notion de perpetua sepultura, attestée dans les sources juridiques au moins à partir du début du III $^{\mathrm{e}}$ s., n'est jamais définie en tant que telle. Toutefois, un passage des Quaestiones de Paul permet au moins de la cerner indirectement :

En effet, si quelqu'un ensevelit un corps quelque part dans l'intention de le déplacer par la suite et estime le déposer en raison des circonstances plutôt que dans l'idée d'y ensevelir un mort et de lui donner pour ainsi dire une demeure éternelle, le lieu restera profane ${ }^{58}$.

[158] Du point de vue du droit, l'emplacement d'une sépulture temporaire restait un locus profanus. Il est donc évident que la perpetua sepultura est une autre façon de dire que cette sépulture est, comme toute tombe à Rome, un locus religiosus ${ }^{59}$. La condition essentielle de la constitution d'un lieu « religieux » est, selon le droit classique, la présence effective du

${ }^{55}$ CIL VI, $2120\left(\mathrm{n}^{\circ}\right.$ 2). On notera néanmoins que dans ce cas, la necessitas est différente, car il s'agit moins de la menace de la destruction de la sépulture que d'un coup du sort qui a emporté l'épouse et le fils d'Arrius Alphius avant l'achèvement du monument funéraire.

${ }^{56}$ PLIN., X, 68 : Petentibus quibusdam, ut sibi reliquias suorum aut propter iniuriam uetustatis aut propter fluminis incursum aliaque his similia quocumque secundum exemplum proconsulum transferre permitterem etc. Voir infra.

57 Dans la fameuse « inscription de Nazareth » qui a donné lieu à de nombreux commentaires (voir Cumont 1930, ainsi que, dernièrement, Tsalampouni 2001 avec l'ensemble de la bibliographie antérieure), il faut souligner que la décision impériale (édit ou rescrit) n'interdit pas absolument le transfert de corps, mais seulement s'il est fait dans une intention dolosive: Eij" eJtevrou" tovpou" dwvlw/ (!) ponhrw/' metateqeikovta ejp' ajdikiva/ th'/ tw'n kekhdeumevnwn.

${ }^{58}$ D., 11, 7, 40 (PAUL, Quaest., 3) : Si quis enim eo animo corpus intulerit, quod cogitaret inde alio postea transferre magisque temporis gratia deponere, quam quod ibi sepeliret mortuum et quasi aeterna sede dare destinauerit, manebit locus profanus. On date généralement cet ouvrage après 210 (voir la notice de D. Liebs, dans Herzog 2000, notamment p. 194).

${ }^{59}$ En réalité, l'antonyme de profanus est sacer (cf. D., I, 8, 6, 3 ; Wagenvoort 1949 et Benveniste 1960) et celui de religiosus, purus (D., 11, 7, 2, 2). Mais la distinction n'était pas toujours systématique : Purus autem locus dicitur, qui neque sacer neque sanctus est neque religiosus, sed ab omnibus huiusmodi nominibus uacare uidetur (D., 11, 7, 4, 4). Sur des épitaphes, voir CIL VI, 23838 ; CIL X, 2015 (Pouzzoles) : tabernula autem cum suis superioribus / nullo modo ab hoc loco sacro et religio/so ob tutelam obitorum separari poterit, etc. 
$\operatorname{corps}^{60}$. La codification juridique se distingue ici des prescriptions religieuses telles qu'elles avaient été édictées par les pontifes et qui, semble-t-il, étaient encore en usage à la fin de la République. Dans le Traité des Lois, Cicéron insiste en effet sur les gestes rituels qui, selon le droit sacré dont les pontifes ont la charge, conduisaient à la fondation d'une tombe en bonne et due forme, le sepulchrum. Le passage le plus explicite indique qu'un lieu ne devient religieux qu'à partir du moment où l'on a procédé à l'inhumation symbolique de l'os resectum retranché au cadavre ${ }^{61}$. À ces prescriptions rituelles, on pourra confronter la définition donnée par la jurisprudence impériale du $\mathrm{II}^{\mathrm{e}} \mathrm{s}$. telle qu'on la rencontre par exemple chez Gaius ${ }^{62}$. Le droit n'exige finalement que l'ensevelissement du corps et ne se préoccupe même pas de la forme du rituel. Comme l'a écrit Y. Thomas, « le droit simplifie, rationalise, autonomise les critères de définition du religieux », et, de la sorte, se dégage des exigences rituelles qu'il n'abolit évidemment pas $^{63}$. En conséquence, pour cette époque, même si le droit des tombeaux a pu être influencé par la religion ou d'antiques prescriptions pontificales, il semble que son discours connaisse une autonomie assez grande par rapport à elles. Si le régime des tombeaux dépendait à la fois du droit civil et du droit sacré comme on le lit très souvent, droit et religion ne jouaient apparemment pas exactement sur le même plan.

Un édit de Marc-Aurèle et Lucius Verus montre bien que les juristes ne reprenaient pas complètement la logique des pratiques religieuses. Ce texte, en outre, concerne lui aussi le déplacement de corps ayant déjà reçu une sépulture :

Les divins frères ont rappelé dans un édit que la tranquillité d'un corps confié à une sépulture constituée selon les règles - c'est-à-dire un corps recouvert de terre - ne doit pas être troublée ; on estime qu'il est recouvert de terre également dans le cas où il est enfermé dans un cercueil, sans qu'on ait l'intention de le transporter ailleurs. Mais pour le cercueil même, si les circonstances l'exigent, on ne doit pas refuser la possibilité de le transporter dans un lieu plus adapté ${ }^{64}$.

Il est possible que les termes de l'édit fassent allusion aux rites évoqués dans le $D e$ Legibus par Cicéron. Ainsi, la mention de la terre (terra conditum) renvoie peut-être à l'importance symbolique attribuée à l'inhumation et sur laquelle insistent les sources

\footnotetext{
${ }^{60}$ Voir sur ce point, parmi d'autres, De Visscher 1963 ; Longo 1964 ; Ducos 1995 ; Thomas 1999.

${ }^{61}$ CIC., De Leg., II, 57 : nec tamen eorum ante sepulcrum est quam iusta facta et porcus caesus est. [...] nam priusquam in os iniecta gleba est, locus ille ubi crematum est corpus nihil habet religionis. Sur l'os resectum ou exceptum, voir aussi VAR., LL, V, 23 et FESTUS, p. 135 L. On notera au passage que les interprétations de Cicéron et de Varron sont, stricto sensu, différentes : tandis que le premier insiste sur le caractère religieux du tombeau, le second voit dans ce rite le moyen de purifier la famille de la souillure occasionnée par la mort du proche, ce qui n'a pas toujours été souligné dans l'exégèse moderne de ces textes. Sur l'inhumation symbolique, voir Salvadore 1996 (que je ne suis pas cependant dans ses dernières conclusions) et pour les rites en général, Scheid 1984 et Scheid 2005, ainsi que Belayche 1995.

${ }^{62}$ GAIUS, Inst., II, 6 : Religiosum uero nostra uoluntate facimus mortuum inferentes in locum nostrum, si modo eius mortui funus ad nos pertineat.

63 Thomas 1999, p. 79. Sur le droit comme construction consciente dont l'une des idées maîtresses est la sortie de la religion, voir Thomas 2002.

${ }^{64}$ D., 11, 7, 39 (MARC., Inst., III) : diui Fratres edicto admonuerunt, ne iustae sepulturae traditum, id est terra conditum, corpus inquietetur; uidetur autem terra conditum et si in arcula conditum hoc animo sit, ut non alibi transferatur. Sed arculam ipsam, si res exigat, in locum commodiorem licere transferre non denegandum. Le verbe inquietare est peut-être à mettre en relation avec la quies du défunt qui est un thème fréquent sur les épitaphes.
} 
littéraires. Qualifier la sépulture de iusta serait une façon de dire que les rites nécessaires ont été accomplis pour conférer au lieu son caractère religieux ${ }^{65}$. Pourtant, ce texte s'éloigne de la stricte prescription rituelle en considérant comme inhumé [159] un corps reposant dans un cercueil ou un sarcophage ${ }^{66}$. Mais surtout, il semble en fin de compte que ce soit le caractère définitif du dépôt qui importe (hoc animo... ut alibi non transferatur). Nous retrouvons alors l'idée que tout corps qui n'est pas livré à une perpetua sepultura peut, selon les juristes, être déplacé. Ainsi, dans le cas du déplacement d'un cercueil, il n'y avait peut-être pas de problème religieux, dans la mesure où le corps n'était pas exhumé. En revanche, la question se posait pour le droit, puisque l'on a vu que seule la présence effective du corps fondait le locus religiosus. La disparition entraînait ipso facto la « mise à mort du tombeau » comme l'a écrit joliment Y. Thomas et une remise en cause de la nature du sol affecté à la sépulture qui constituait « une parcelle d'éternité dans un paysage en mouvement $\gg{ }^{67}$. Cette question est d'ailleurs envisagée par le juriste Paul dans une sorte de fiction de droit. À un corps ne peut correspondre qu'un seul sépulcre, c'est-à-dire un unique locus religiosus ${ }^{68}$. S'il y a dispersion des restes, seul le lieu où est ensevelie la tête, qui est comme la métonymie du corps tout entier, prendra un caractère religieux. En cas de transfert et de regroupement des restes, bien sûr soumis à une autorisation préalable (impetratur), le lieu où se trouvait la tête cessait d'être religieux si on avait dû la déplacer ${ }^{69}$. Par conséquent, bien que la jurisprudence impériale sur les tombeaux repose en partie sur la nécessité religieuse de protéger la propriété des dieux Mânes, elle se détache des rites ou de la croyance en la vindicte des insepulti et répond essentiellement à sa propre logique ${ }^{70}$.

Dans le passage du livre III des Quaestiones de Paul dont nous étions partis, il faut souligner que, pour la définition de la sépulture provisoire, l'intention de celui qui opère l'ensevelissement est décisive pour décider du statut religieux ou non de la parcelle de terrain concernée. Ce trait, on vient de le voir, transparaît également dans l'édit de MarcAurèle et Lucius Verus. Si l'on s'en tient en effet à la définition donnée par Gaius au début du livre II des Institutes, le simple fait d'inferre mortuum fait passer un lieu de statut de purus à celui de religiosus. Mais la comparaison avec le texte de Paul montre qu'il faut

${ }^{65}$ Néanmoins, Papinien emploie également l'expression de iustum sepulchrum (D., 11, 7, 43). Dans le contexte du passage, il est manifeste que c'est un synonyme de locus religiosus défini selon les critères du droit, dans la mesure où, justement, il souligne l'impossibilité de la constitution d'un iustum sepulchrum en cas de déposition d'un défunt sur la propriété d'autrui.

${ }^{66}$ J'ai choisi de traduire arcula par « cercueil », sens qui est attesté (voir $T L L$, s.v.), mais on pourrait tout aussi bien envisager une urne, dans la mesure où ce mot, en latin, concerne toute sorte de réceptacle ou de coffre. Comme nous l'avons vu plus haut, le terme corpus ne saurait présumer du rite funéraire utilisé. La date du texte laisse cependant penser que le législateur pense plutôt à une inhumation.

${ }^{67} \mathrm{Au}$ point que les tombeaux peuvent être pris comme points de repère dans la cadastration (Grom. uet., p. 271-272, éd. Lachmann). L'expression citée entre guillemets est de M. de Souza (2004, p. 95).

${ }^{68}$ D., 11, 7, 44 (PAUL, Quaest., III) : Cum in diuersis locis sepultum est, uterque quidem locus religiosus non fit, quia una sepultura plura sepulchra efficere non potest : mihi autem uidetur illum religiosum esse, ubi quod est principale conditum est, id est caput, cuius imago fit, inde cognoscimur. Cum autem impetratur, ut reliquiae transferrantur, desinit locus religiosus esse.

${ }^{69} 11$ semble évident que reliquiae désigne ici la tête, dans la mesure où, en cas de dispersion, Paul vient justement d'émettre l'avis que seul le lieu où se trouvait la tête était considéré comme religiosus. Sur cette fiction juridique, voir également Thomas 1999, p. 102.

${ }^{70}$ Contra, toute une partie de la démonstration d'O. Estiez (1995) et notamment, dans la conclusion : « on voit combien la peur de l'insepultus a construit certains domaines particuliers du droit en le modelant». (p. 108). 
également qu'il y ait une intention. Gaius, d'ailleurs, précise bien que la création d'un locus religiosus dépend de la volonté de l'individu qui est chargé des funérailles (nostra uoluntate facimus). La distinction entre sépulture définitive et sépulture provisoire esquissée par les jurisprudents implique donc un engagement clair de la part de l'exécutant au moment où la tombe est mise en place. On retrouve en passant une idée fondamentale du droit romain, où l'intentionnalité est essentielle pour déterminer le statut des choses. Fr. Van Haeperen, en étudiant les attributions du collège pontifical en matière de droit des tombeaux, a bien vu que l'inscription d'Arrius Alphius était un indice qui suggérait que cette distinction se rencontrait dans la pratique dès le milieu du $\mathrm{II}^{\mathrm{e}}$ siècle. ${ }^{71}$ Le collège pontifical en effet reconnaît que la sépulture est provisoire et donc autorise le transfert et, qui plus est, sans exécution d'une expiation.

[160] Dans la pratique cependant, il est difficile d'imaginer un contrôle systématique sur l'ensemble des sépultures et tombeaux ${ }^{72}$. L'hypothèse d'une déclaration préalable systématique n'est confortée par aucune source et, de fait, est peu vraisemblable. Il est plus probable que toute sépulture qui remplissait les conditions légales établies par la jurisprudence (présence du corps, possession du ius sepulchri et du terrain contenant la tombe) ait donné lieu par défaut à un locus religiosus reconnu par le droit. C'est peut-être seulement dans les cas problématiques que l'on avait recours à l'avis des autorités compétentes, notamment les pontifes.

La définition du religiosus, malgré des points communs, diffère donc selon que l'on se place du côté de Cicéron et du droit sacré ou de celui des juristes impériaux. Pour le droit, le transfert à partir d'une sépulture provisoire n'est plus un problème car il ne conduit pas à la remise en cause du statut de la chose ou du lieu (tombeau ou sépulture) qui, en cas de sépulture définitive, sortent du commerce des biens et appartiennent aux dieux Mânes. Néanmoins, on peut s'interroger sur ce qu'il en était concrètement du point de vue du rituel en cas de sépulture provisoire. Le défunt avait-il reçu les iusta? La famille était-elle purifiée ? Il est probable que oui, mais on ne peut esquisser de réponse sans tomber dans la spéculation, faute de sources. Notons simplement que la sépulture provisoire ne peut théoriquement se concevoir d'un point de vue religieux, dans la mesure où le mort pourrait alors être regardé comme un insepultus et la famille considérée comme encore souillée. Ainsi, il semble que nous ayons un indice solide montrant que la peur de la colère du mort mal enterré n'est pas ce qui a déterminé la logique du discours de la jurisprudence impériale sur le transfert des corps. Dès lors, à partir des sources juridiques, et sans vouloir raffiner dans la typologie, on peut distinguer, outre le simple transport du corps (y compris le rapatriement) avant les funérailles, deux genres de transferts : celui qui fait passer le corps d'une sépulture provisoire (car voulue comme telle) à une sépulture définitive (locus religiosus) et le transfert véritable, qui fait passer le corps d'un locus religiosus à un autre.

71 Van Haeperen 2002, p. 325. Toutefois, elle semble rejeter l'hypothèse d'un transfert véritable en supposant que le sarcophage resterait dans le même monument. Cette interprétation me semble liée à une mauvaise compréhension de la conjonction donique (=donec). Elle traduit en effet le passage ainsi : « comme (...) j'avais confié leurs corps à un sarcophage de terre cuite, et que, donc, ce lieu que j'avais acheté était construit sur la via Flaminia etc. » Il faut à mon avis comprendre : «comme (...) j'avais confié leurs corps à un sarcophage de terre cuite en attendant que le lieu que j'avais acheté sur la via Flaminia reçoive une construction... » L'auteur reprend d'ailleurs l'idée d'un véritable transfert quelques pages plus loin (p. 332).

${ }^{72}$ Cf. Kaser 1978, p. 26 sq. 
Ce dernier cas de figure devait être le plus exceptionnel : c'est pourquoi la jurisprudence parle en ce cas de nécessité, ou de motif impérieux ${ }^{73}$.

\section{Droit et religion : les sacrificia des Sentences de Paul}

Revenons maintenant au texte du premier livre des Sententiae Pauli. S'il reprend une partie de la jurisprudence antérieure, on remarque deux innovations par rapport aux textes précédents - notamment le rescrit de Caracalla : il s'agit de la mention des sacrifices à effectuer lors du transfert du corps et de la nécessité d'opérer le transport de nuit (sollemnibus redditis sacrificiis per noctem in alium locum transferri [sc. corpus] potest). Nous venons de constater, à la suite de Y. Thomas, que les croyances, les peurs n'étaient généralement pas prises en compte par les juristes du Haut-Empire dans la définition du locus religiosus et les conditions du transfert. De même, toute mention de pratique rituelle est généralement écartée, sauf de manière allusive. L'auteur des Sentences, à l'inverse, inclut dans un précepte de droit la nécessité d'accomplir des rites pour le bon déroulement (selon le ius et, visiblement, selon le mos) du transfert d'un corps. En moins d'un siècle de temps, le contenu du discours normatif, tout en conservant un noyau identique, semble avoir quelque peu évolué.

La référence aux rites religieux revient dans la suite du même chapitre 21 sur les tombeaux et le deuil. L'auteur du manuel reprend l'antique prescription, remontant à la loi des XII tables, interdisant tout type de sépulture in Vrbe, c'est-à-dire, au sens étroit, dans l'enceinte du pomerium. Un rescrit d'Hadrien, conservé dans le Digeste, condamnait déjà à une amende tout individu instaurant une sépulture dans la ciuitas $^{74}$. Mais le compilateur du manuel y ajoute un motif, d'ordre [161] à la fois religieux et rituel : l'interdiction est faite pour éviter de polluer les rites de la cité par contact avec la mort (funestare) - idée qui était absente du rescrit d'Hadrien ${ }^{75}$. Quelques lignes plus bas, il est de nouveau fait allusion à la nécessité d'un rituel religieux, une expiation cette fois. Il vaut la peine de citer le passage, car il nous intéresse à plusieurs égards :

Quiconque met à nu un corps qui a reçu une sépulture définitive ou qui a été placé temporairement en un lieu, et l'expose aux rayons du soleil, commet un acte qui exige une

\footnotetext{
${ }^{73}$ Aussi, je dois avouer avoir du mal à comprendre la casuistique mise en œuvre par O. Estiez, selon qui le « dédicant» (sic) serait placé devant ses responsabilités lors d'un choix entre sépulture provisoire qui lui laisserait la possibilité du transfert et d'une sépulture définitive, plus satisfaisante sur le plan religieux (Estiez 1995, p. 102-103). Il me semble que, lorsque quelqu'un choisissait de ne pas donner une sépulture définitive à un défunt, il le faisait par nécessité, c'est-à-dire qu'il avait de bonnes raisons de ne pas lui donner sur-lechamp une tombe «religieuse». Les «mesures de responsabilisation» sont plutôt des mesures de prévoyance, pour éviter les conséquences de l'abolition d'un lieu religieux et qui prouvent, dans une certaine mesure, la souplesse du droit en cette matière.

${ }^{74}$ D., 47, 12, 3, 5 (ULP., Ad Ed., 25) : Diuus Hadrianus rescripto poenam statuit quadraginta aureorum in eos qui in ciuitate sepeliunt, et locum publicari iussit et corpus transferri. Il est manifeste que ciuitas désigne ici l'espace urbain. On retrouve le transfert de corps, cette fois sur décision publique. Nous y reviendrons plus bas. L'Histoire Auguste nous apprend qu'Antonin le Pieux avait lui aussi pris des mesures en ce sens (Vit. Ant., 12, 3 ; cf. également Vit. Marc., 13, 4).

${ }^{75}$ Sent. Paul., 1, 21, 2 : Corpus in ciuitatem inferri non licet, ne funestentur sacra ciuitatis : et qui contra ea fecerit, extra ordinem punitur.
} 
expiation ; et, de ce fait, si cet individu est de rang élevé, on l'envoie en général sur une île ; s'il est de rang humble, on l'envoie aux mines ${ }^{76}$.

On retrouve ici, dans un contexte quelque peu différent, la distinction entre sépulture provisoire et sépulture définitive. Comme l'a constaté Y. Thomas, l'une des nouveautés est que l'acte sanctionné ici n'est pas la violation du tombeau par l'intermédiaire d'une atteinte au cadavre : c'est le corps lui-même qui est visé, dans la mesure où l'on envisage tout aussi bien le locus religiosus que le locus profanus ${ }^{77}$. Toutefois, pour s'en tenir à la lettre de la formulation, le véritable délit semble être ici l'exposition aux rayons du soleil. Cette précision est curieuse, et s'explique difficilement ${ }^{78}$. Cependant, le fait est que, dans l'énoncé de la maxime, la faute réside dans l'accomplissement d'un acte qui exige expiation. C'est aussi parce que l'exhumation appelle une compensation expiatoire (est un délit religieux donc) qu'elle est punie par la déportation ou par les travaux forcés dans les mines.

Par rapport aux règles énoncées dans le Digeste, les modalités d'énonciation et les présupposés qu'elles impliquent ne peuvent manquer de frapper. Dans l'ensemble de la compilation justinienne, on ne rencontre qu'une seule et unique occurrence du terme piaculum $^{79}$. Mais le contexte n'a absolument aucun rapport avec une sanction induite par une action réclamant l'expiation. On constate incidemment que les Sententiae Pauli ne sont pas simplement la reprise de règles de droit antérieures, mais que, dans une certaine mesure, elles marquent dans ces domaines sinon une pratique, au moins un discours différent de celui de la jurisprudence classique. La place de considérations religieuses, et notamment l'idée de pollution ou d'impureté, reviendra par la suite, au $\mathrm{IV}^{\mathrm{e}}$ s., plus particulièrement dans des décisions impériales conservées dans le Code Justinien ${ }^{80}$. Mais ce problème dépasse très largement le cadre de cette étude.

Le fait que seul un manuel de la fin du $\operatorname{III}^{\mathrm{e}} \mathrm{s}$. évoque des rites à accomplir ne signifie bien évidemment pas qu'on ne les accomplissait pas auparavant ni, bien sûr, que le droit ne punissait pas des actes exigeant une expiation. Il indique simplement que des domaines qui étaient séparés se sont alors recoupés. C'est aussi, sur un autre plan, un intéressant indice de la pérennité de certaines obligations rituelles. A-t-on des moyens de cerner un peu mieux ces sacrifices accomplis selon les rites ? Sans que son exposé soit très clair, O. Estiez semble suggérer que, à l'occasion d'un transfert, il y avait renouvellement des rites accomplis lors des funérailles, et, notamment, de la pratique de l'os resectum ${ }^{81}$.

\footnotetext{
${ }^{76}$ Sent. Paul., 1, 21, 4 : qui corpus perpetuae sepulturae traditum uel ad tempus alicui loco commendatum nudauerit, et solis radiis ostenderit, piaculum committit ; atque ideo, si honestior sit, in insulam, si humilior, in metallum dari solet.

77 Thomas 1999, p. 103-104 ; cf. Rebillard 2003, p. 78-79.

${ }^{78}$ On trouvera quelques éléments de réflexion infra, p. 24 sq.

${ }^{79}$ D., 28, 8, 7, 3 (ULPIEN, Ad Ed., 60) : in causae autem cognitione hoc uertetur, an iusta causa sit, ut deminuere praetor permittat. Ergo et funeris causa deminui permittet, item eorum quae sine piaculo non possunt praeteriri.

${ }^{80}$ Voir par exemple, de Constance II, CJ., IX, 19, 4. Cf. Thomas 1999, p. 104.

${ }^{81}$ Estiez 1995, notamment p. 104-105. Laissons-nous aller à quelques légères spéculations : en imaginant qu'il faille transférer les restes d'un individu qui a reçu une sépulture selon les rites romains, comprenant la pratique de l'os resectum puis une incinération, on se demande bien comment les proches, soucieux de renouveler le rite, pourront trouver un doigt (si c'est bien de cela dont il s'agit) à couper sur un cadavre
} 
Cela est très improbable. En fait, comme la plupart des auteurs précédents l'avaient vu, il semble bien que les sollemnia sacrificia dont parle l'auteur des Sententiae Pauli soient des sacrifices expiatoires. Le seul document qui vient sans [162] équivoque confirmer cette hypothèse est l'inscription funéraire de l'affranchi impérial M. Vlpius Phaedimus. Son épitaphe nous apprend en effet qu'il décéda auprès de Trajan, le 12 août 117, à Sélinonte, en Cilicie, et que son corps fut rapporté à Rome un peu moins de treize ans plus tard, le 11 février 130, sur autorisation du collège des pontifes et après l'exécution d'un sacrifice expiatoire (piaculo facto) ${ }^{82}$.

Une seconde inscription découverte à Terracine évoque aussi l'exécution d'un piaculum dans un contexte funéraire. Le texte est malheureusement fragmentaire, mais les restitutions sont, pour la plupart, très probables ${ }^{83}$. Les premiers éditeurs du texte, R. de la Blanchère et Th. Mommsen, avaient estimé, en s'appuyant sur l'épitaphe de M. Vlpius Phaedimus et sur une partie des textes juridiques que nous avons étudiés, que cette inscription faisait allusion au transfert d'un corps. En réalité, rien ne permet de l'affirmer catégoriquement. On pourrait tout aussi bien envisager une réfection du monument funéraire suffisamment importante pour exiger l'exhumation du corps. La formule tituli at pristinam formam restituere à la fin de la seconde colonne pourrait aller dans ce sens ${ }^{84}$.

De fait, le problème de la restauration des monuments funéraires, res religiosae, recoupe, par bien des aspects, celui du transfert des corps ${ }^{85}$. Les sources juridiques et épigraphiques nous apprennent qu'une approbation préalable du collège pontifical était nécessaire. Deux textes du Digeste abordent cette question. Le premier est un passage d'Ulpien, qui pose quelques problèmes d'interprétation que A. Manfredini a cherché à élucider :

Si des restes ont été ensevelis dans un monument qui est dit inachevé, rien n'interdit qu'il soit achevé. Mais si le lieu religieux est déjà construit, les pontifes doivent rechercher dans quelle mesure on peut satisfaire au désir de reconstruction en préservant les règles religieuses ${ }^{86}$.

Ce texte recoupe partiellement un passage de Marcien conservé au titre 12 du livre 47 du Digeste concernant la violation de tombeau :

Il est interdit de détériorer un tombeau ; mais il est permis de restaurer un monument endommagé ou croulant sans toucher aux corps ${ }^{87}$.

désormais réduit en cendres. Quant à la reprise des autres rites accomplis lors des funérailles, aucun document ne vient la confirmer.

${ }^{82} C I L$ VI, 1884 ( ${ }^{\circ} 1$ de l'appendice épigraphique). Cf. infra, p. 24.

${ }^{83} C I L \mathrm{X}, 8259\left(\mathrm{n}^{\circ} 21\right)$. Voir l'appendice épigraphique pour les problèmes posés par le texte. Je suis ici la restitution proposée par Th. Mommsen au volume X du CIL.

${ }^{84}$ Opinion partagée par Fr. Van Haeperen (2002, p. 317-318).

${ }^{85}$ De Visscher 1963, p. 70 et 145 sq.

${ }^{86}$ D., 11, 8, 5 (Ulpien, Opin., 1) : Si in eo monumento, quod imperfectum esse dicitur, reliquiae hominis conditae sunt, nihil impedit quominus id perficiatur. Sed si religiosus locus iam factus sit, pontifices explorare debent, quatenus salua religione desiderio reficiendi operis medendum sit. Voir Manfredini 1987.

${ }^{87}$ D., 47, 12, 7 (MARCIAN., Inst., III) : Sepulchri deteriorem condicionem fieri prohibitum est : sed corruptum et lapsum monumentum corporibus non contactis licet reficere. L'interdiction de toucher aux corps peut s'expliquer par la crainte de la souillure qui en découlerait mais correspond sans doute avant tout, dans la perspective juridique, à la volonté de garantir ce qui fait la religiosité du tombeau (cf. supra). 
A. Manfredini s'est demandé pourquoi Ulpien exigeait une autorisation pontificale pour reficere un tombeau, tandis que Marcien passe cette permission sous silence. Il est parvenu à la conclusion que reficere n'a pas le même sens dans les deux passages: Ulpien envisagerait une reconstruction totale, tandis que Marcien penserait à une restauration de moindre ampleur. Il s'agirait donc d'une question de degré des travaux ${ }^{88}$. Pour séduisante que soit cette hypothèse sur le plan doctrinal, elle n'est pas totalement satisfaisante. En effet, une petite série d'inscriptions funéraires témoigne de la restauration de tombeaux. Il s'avère que l'autorisation pontificale était demandée à la fois pour la reconstruction, mais également pour la réparation et même, enfin, pour l'achèvement d'un tombeau ${ }^{89}$. La pratique dépassait donc les simples cadres repris par le droit, et le scrupule religieux a pu inciter à s'assurer du bien fondé de l'entreprise, au-delà des froides codifications juridiques - dont les contours, au demeurant, ne sont pas si nets que cela. Il n'est peut-être pas nécessaire de chercher à tout prix une cohérence totale entre les [163] deux passages, et Marcien a très bien pu passer sous silence la nécessité de consulter le collège pontifical - à moins que cette absence ne soit due aux compilateurs byzantins.

L'intérêt majeur de l'inscription de Terracine est qu'elle indique très explicitement et, puisque ces lignes sont intégralement conservées, sans aucune équivoque, la nature de l'expiation. Il s'agit en effet d'un piaculum operis faciendi. La victime recommandée par le collège pontifical est tout naturellement une brebis noire, car le sacrifice a pour destinataire des divinités souterraines qu'il s'agit d'apaiser, les Mânes. Ainsi, sur les decreta pisana qui ont conservé les honneurs funéraires des princes Lucius et Caius César, le sacrifice annuel de commémoration comprend un bœuf et une brebis noirs ${ }^{90}$. L'expiation operis faciundi était en principe requise lorsque l'on s'apprêtait à commettre une infraction religieuse en intervenant sur un bien appartenant à la divinité. Elle anticipait les conséquences d'un acte qui pouvait remettre en cause la pax deorum ${ }^{91}$. Ce type d'expiation est relativement bien connu par un témoignage de Pline l'Ancien et un autre de Caton, auxquels on peut ajouter les actes du collège des frères arvales ${ }^{92}$. Il s'agit très souvent d'opérations d'émondage dans un bois sacré. Dans le cas du sanctuaire de Dea Dia, le piaculum operis faciundi était requis en cas de dommages exceptionnels nécessitant une intervention dans le bois de la déesse ou, annuellement, pour des nécessités cultuelles ${ }^{93}$. Par conséquent, le sacrifice mentionné par l'inscription de Terracine s'explique très certainement par les travaux entrepris sur le tombeau. Ce témoignage rejoint ceux, plus laconiques, que nous avons cités et qui précisent

\footnotetext{
${ }^{88}$ Manfredini 1987, notamment p. 225 sq.

${ }^{89}$ CIL VI, 2963 (ILS 8382) : petit a ponti/fices ut sibi permitterent / reficere n(ouum ?) monumentum ; CIL VI, 22120 (ILS 8383): sepul/crum parentum suorum / uetustate conrup/tum permissu pontificum / c(larissimorum) u(irorum) restituit; CIL VI, 35068 : permissu pontific(um) refec(erunt); CIL IX, 1729 à Bénévent (ILS, 8110) : tribunal ex permissu pontif(icum) perfecit. Cf. aussi Panciera et alii 1987, $\mathrm{n}^{\circ} 82$ : L(ucius) Domitius Hilarusus / et Clodia Helpis, quod / maciria disruita, ex suscriptione collegi pon $<$ ti $>$ ficum, / patronis benemerentibus / refecerun (!) suis. En revanche, il est des inscriptions où l'intervention des pontifes n'est pas précisée: CIL VI, 13188: D(is) M(anibus) / M(arcus) Aurelius Primosus Aug(usti) lib(ertus) / memoriolam uetustate delapsam / refecit sibi, etc. Ce texte illustre donc parfaitement le propos de Marcien.

90 CIL XI, 1420 (ILS 139), 1. 20 : bosque ouis atri infulis caerulis infulati diis Manibus eiu[s] (sc. L. Caesaris) mactentur...

${ }^{91}$ Tromp 1921, p. 90 sq. ; Scheid 1981.

92 Plin., HN, 17, 267 ; CAT., De Agr., 139.

${ }^{93}$ Broise - Scheid 1993 contient une mise au point particulièrement claire à ce propos.
} 
qu'une autorisation pontificale fut délivrée pour achever ou reconstruire un monument funéraire.

Cependant, le problème se pose de savoir si c'est le simple fait d'intervenir sur une res religiosa qui entraîne la nécessité de l'expiation, ou si c'est l'exhumation du corps qui est le motif principal ${ }^{94}$. Ainsi, le texte des Sententiae Pauli que nous avons commenté plus haut établit clairement que l'exposition d'un corps à l'air libre est un acte qui demande expiation. Il est intéressant de constater au passage que l'auteur ne s'occupe guère des remèdes religieux à une telle impiété. Le délit qui est qualifié de manière religieuse est sanctionné par une peine de droit pénal. Il faut noter en outre que dans l'inscription de Terracine, le terme eximere est une restitution complète que l'on doit à Th. Mommsen. Elle convient pour le sens et le nombre de lettres, mais il est extrêmement rare de trouver le verbe eximo dans le sens d' « exhumer » un cadavre ${ }^{95}$. Par ailleurs - et l'argument paraît plus décisif, si les pontifes ont estimé que l'expiation qualifiée dans cette situation était un sacrifice operis faciundi, c'est que la faute à prévoir était une atteinte portée au monument même. C'est de là qu'aurait résulté l'impureté potentielle, plutôt que de la souillure véhiculée par le cadavre, même si les deux aspects, en un sens, sont liés.

\section{Le piaculum de la lex coloniae Genetiuae}

Dans la loi de la colonie espagnole d'Urso, gravée à l'époque flavienne mais dont la composition remonte aux dernières années de la République, on rencontre également la mention d'un sacrifice expiatoire en relation avec la démolition de tombeaux. Le chapitre 73 de la charte interdit en effet d'introduire un corps dans l'enceinte de la ville, ainsi que de l'incinérer, de l'inhumer ou de lui construire un monument funéraire ${ }^{96}$. Cette disposition trouve un écho direct dans une interdiction qui était énoncée dans la loi des XII tables, transmise par Cicéron dans son Traité des Lois et que nous avons déjà eu l'occasion d'évoquer : hominem mortuum in Vrbe neue sepelito neue urito ${ }^{97}$. Les [164] motivations de cet interdit ne sont pas entièrement claires. En effet, Cicéron, dissertant sur le contenu respectif du droit pontifical (ius pontificium) et des lois (leges), estime qu'il s'agit d'une disposition de droit civil, et l'exclut donc du droit sacré. L'explication qu'il donne, d'ailleurs un peu en passant, est la volonté d'éviter les incendies ${ }^{98}$. Le droit en somme aurait interdit les sépultures dans les villes pour des raisons de sécurité et peut-être également sanitaires. Quelques siècles plus tard, Isidore de Séville, s'appuyant sur une tradition que l'on retrouve chez Servius, attribuera également l'exclusion des tombes à l'intérieur des villes aux risques d'infection dont les cadavres sont le foyer ${ }^{99}$. Cette

\footnotetext{
${ }^{94}$ S. Tromp (1921, p. 95) estime ainsi que les deux raisons expliquent l'expiation.

${ }^{95}$ Voir TLL, s.v. Il apparaît toutefois sur une inscription de Rome : CIL VI, 36467 : ossa eximere.

${ }^{96}$ Lex coloniae Genetiuae, 73 : ne quis intra finem oppidi colon(iae)ue , qua aratro / circumductum erit, hominem mortuom / inferto neue ibi humato neue urito neue homi/nis mortui monimentum aedificato. si quis / aduersus ea fecerit, is c(olonis) c(oloniae) G(enetiuae) Iul(iae) (sestertium) (quinque milia) dare damnas esto, / eius que pecuniae cui uolet petitio persecu/tio $†$ exactioq(ue) $†$ esto, itque quot inaedificatum / erit IIuir aedil(is)ue dimoliendum curanto. si / aduersus ea mortuus inlatus positusue erit, expianto uti oportebit. Voir $R S, \mathrm{I}, \mathrm{n}^{\circ} 25$. Sur les chapitres 73 et 74 de la lex Ursonensis, voir Lopéz Melero 1997 et Rüpke 2006.

${ }^{97}$ CiC., De Leg., II, 58. Voir RS., II, p. 704.

${ }^{98}$ CIC., De Leg., II, 58 : credo uel propter ignis periculum.

${ }^{99}$ IsID., Etym., XV, 11, 1 : prius autem quisque in domo sua sepeliebatur. Postea uetitum est legibus, ne foetore ipso corpora uiuentium contacta inficerentur. Sur la coutume des anciens Romains d'ensevelir leurs morts dans leur maison, voir SERV., Ad Aen., VI, 152.
} 
explication rationaliste ne doit pas être négligée. La lecture du Digeste montre en effet que le souci de l'ordre et du bien public ont très souvent guidé la législation prohibant l'abandon de cadavre et l'interdiction de sépulture dans l'enceinte des villes ${ }^{100}$. Toutefois, la préoccupation sanitaire ou la sécurité contre les incendies ne rendent pas totalement compte de la formulation de cette prescription. D'abord parce qu'il y a une différence entre introduire un cadavre puis l'abandonner et lui donner une sépulture. Par ailleurs, l'interprétation de la loi des XII tables par Cicéron n'est pas entièrement satisfaisante, car elle ne justifie pas l'interdiction d'incinérer et d'inhumer. Enfin, la volonté de prévenir les risques d'incendie se trouve explicitement dans le chapitre 74 de la charte d'Urso qui prohibe l'édification de bûchers funéraires à moins de 500 pas de la limite de la colonie ${ }^{101}$.

L'hypothèse alternative, souvent invoquée, est que l'interdit repose sur des motifs d'ordre religieux. Le premier point à souligner est que la limite de l'espace prohibé est précisément définie, dans la lex coloniae Genetiuae, par le sillon qui renvoie au rite de fondation de la colonie ${ }^{102}$. Le sulcus primigenius délimitait ainsi l'espace qualifié de la future ville, sur le modèle du rite accompli selon la tradition par Romulus à Rome, et que l'on assimile généralement au pomerium ${ }^{103}$. Toutefois, on ne rencontre nulle part de témoignages explicites sur la nature proprement religieuse de l'interdit d'ensevelir des morts intra pomerium, sauf dans le texte des Sententiae Pauli que nous avons cité plus haut et dans un passage du Code Justinien ${ }^{104}$. Le premier texte ne fait pas véritablement allusion au caractère sacré de l'espace intra pomérial, mais plutôt au risque de souillure qu'encourent les rites qui se déroulent dans les sanctuaires urbains. De la même façon, Julien, comme nous le reverrons plus bas, imposa dans son fameux édit d'Antioche les funérailles nocturnes afin de ne pas polluer les cérémonies religieuses qui avaient lieu dans les villes. Le passage du Code Justinien est un peu plus problématique car il est difficile d'établir précisément ce que recouvre le ius sanctum municipiorum. Je laisserai de côté cette question qui dépasse mon propos, mais le souci de ménager un espace propre aux morts reste évident. Néanmoins, il est intéressant de rappeler que le rescrit d'Hadrien conservé dans le Digeste ne fait aucune allusion à ces motifs religieux pour interdire les

${ }^{100}$ Par exemple D., 43, 10, 1, 5 (PAPIN., De cur. urb.) : mh; ejavtwsan de; mhde; mavcesqai ejn tai'" oJdoi'" mhde; kovrpon ejkbavllein mhde; nekra; mhde; devrmata rJiptein (mais nekrav pourrait désigner des carcasses d'animaux ; cf. Panciera 2000, p. 98). Voir également le règlement de munere publico libitinario de Pouzzoles (Libitina 2004), II, 1 et les remarques de J. Bodel 1986 [1994], p. 33 sq. qui réunit une bonne partie des pièces du dossier. Cf. notamment MART., 10, 5, 11 sq., SuÉT., Ner., 48 et PÉTR., Satir., 134. Sur l'abandon des cadavres, on pourra consulter également Panciera 2000, p. 96 sq.

101 Lex coloniae Genetiuae, 74 : Ne quis ustrinam nouam, ubi homo mortuus / combustus non erit, prop\{r\}ius oppidum pas/sus (quingentos) facito. Le contrevenant s'expose à une amende de 5000 sesterces payables à la colonie. Voir Lopéz Melero 1997, p. 117. On notera qu'il s'agit de l'interdiction de construire de nouveaux bûchers (cf. CIC., De Leg., II, 61). Cf. également Mommsen 1877 [1905], p. 262 et comparer aux cippes du préteur L. Sentius : neiqui intra terminos propius urbem ustrinam fecisse uelit neiue stercus cadauer iniecisse uelit (CIL I², 838 et 839 ; ILS 8208).

102 Qua aratro circumductum erit. Ainsi à Capoue, ILLRP 482 ; cf. VAR., LL, V, 143 ; PlUT., Quaest. Rom. 27.

${ }^{103}$ La bibliographie sur le pomerium est relativement abondante. Voir, entre autres, Mommsen 1876, Magdelain 1976 [1990] et Simonelli 2001.

${ }^{104}$ Sent. Paul., 1, 21, 2 : Corpus in ciuitatem inferri non licet, ne funestentur sacra ciuitatis : et qui contra ea fecerit, extra ordinem punitur. Intra muros ciuitatis corpus sepulturae dari non potest uel ustrina fieri. CJ., 3, 44, 12 : Mortuorum reliquias, ne sanctum municipiorum ius polluatur, intra ciuitatem condi iam pridem uetitum est (290 ap. J.-C.). 
sépultures dans les villes ${ }^{105}$. Ici encore, il n'est pas impossible que nous assistions vers la fin $\mathrm{du} \mathrm{III}^{\mathrm{e}}$ s. à un infléchissement du discours du droit, accompagné, en outre, d'un [165] durcissement de la peine, car là où le rescrit d'Hadrien (comme la loi d'Urso) ne prévoyait qu'une amende, le texte des Sentences de Paul requiert une sanction extraordinaire (extra ordinem punitur) ${ }^{106}$.

Le piaculum exigé par la lex coloniae Genetiuae a donné lieu à deux types d'explication. Il faut au préalable rejeter l'hypothèse qui était celle de G. Wissowa et qui voulait que l'expiation fût exécutée par le contrevenant. Elle aurait été redoublée, sur le plan profane, par une amende considérée comme une forme d'adoucissement ou de laïcisation de la peine ${ }^{107}$. Ainsi que S. Tromp l'a bien vu, cette interprétation n'est pas recevable et, suivant la lettre du texte de la charte (expianto uti oportebit), il faut bien comprendre que ce sont les magistrats, duumvirs ou édiles, qui doivent se charger du sacrifice expiatoire. La première explication fut donc formulée par $\mathrm{S}$. Tromp, qui a été suivi plus récemment par J. Scheid ${ }^{108}$. Le sacrifice expiatoire serait rendu indispensable en raison de la démolition par les magistrats du tombeau édifié malgré l'interdit de la loi de la colonie. À côté de la sanction purement profane qui prenait la forme d'une amende et, peutêtre, si l'on suit Th. Mommsen qui s'appuie sur le rescrit d'Hadrien, d'une publication du lieu, l'expiation est prise en charge non pas par le contrevenant, mais par les responsables de la communauté qui abolissent un locus religiosus et, très certainement, doivent exhumer le corps pour le déplacer. Le rite expiatoire serait donc, en somme, un sacrifice assimilable au sacrifice operis faciundi prescrit par le décret du collège pontifical sur l'inscription découverte à Terracine, mais conduisant à la destruction définitive du tombeau.

Dans un article récent, R. Lopéz Melero a proposé une autre interprétation de ce sacrifice piaculaire $^{109}$. Pour elle, l'expiation operis faciundi formulée par S. Tromp ne correspond pas exactement à la lettre du texte de la colonie. Celui-ci dit en effet : si aduersus ea mortuus inlatus positusue erit, expianto uti oportebit. Le sacrifice piaculaire n'apparaît pas, dans cette logique, comme la conséquence de la destruction, de l'exhumation puis du transfert, mais de la transgression de l'interdit en général, c'est-à-dire l'introduction et l'ensevelissement intra oppidum. Ce serait donc, en réalité, la présence du cadavre dans un espace sacré (comme elle l'écrit) et dont il faut préserver la pureté, qui justifierait cette expiation. Pour étayer cette interprétation, elle reprend la démonstration de S. Tromp sur la loi sacrée du lucus de Spolète ${ }^{110}$. Tandis que le contrevenant sur le plan profane est puni pour avoir bravé la loi en cas d'infraction volontaire, la souillure qu'il a occasionnée retombe sur l'ensemble de la communauté. Alors qu'il est laissé à son sort, les magistrats doivent expier la faute commise indirectement par la cité vis-à-vis de la divinité $^{111}$. Ainsi, l'expiation est conçue comme la réparation d'un dommage causé par la

${ }^{105}$ D., 47, 12, 5. Il est vrai que les décisions impériales sont assez rarement motivées dans la compilation justinienne.

${ }^{106}$ L'hypothèse de R. Lopéz Melero (1997, p. 110), reprenant une suggestion de Casavola (1958, p. 79

sq.) pour qui ce silence de la jurisprudence classique serait à mettre sur le compte d'une secret jalousement gardé par le collège pontifical n'a pas de fondement solide.

${ }_{107}$ Wissowa 1912 , p. 393 et n. 4.

108 Tromp 1921, p. 92 ; Scheid 1981, p. 135 sq. Cette idée avait déjà été suggérée par Mommsen 1877 [1905], p. 110 [262].

${ }^{109}$ Lopéz Melero 1997, p. 114-115.

${ }^{110}$ CIL XI, 4766 (ILLRP 504 ; ILS 4911). Cf. Tromp 1921, p. 85 sq.

${ }^{111} \mathrm{Cf}$. aussi Scheid 1981, p. 130 sq. 
présence impure du cadavre et non comme l'anticipation d'une atteinte portée à l'encontre d'un lieu religieux. Pour R. Lopéz Melero, le transfert du corps n'a pas lieu car il n'est pas explicitement requis par la charte, et le sacrifice piaculaire aurait même pour but de neutraliser la souillure émanant de ce cadavre enseveli dans un espace de nature sacrée.

L'alternative est donc la suivante : soit l'expiation est causée par la violation d'un espace considéré comme sacré et exigée pour mettre un terme à la contagion occasionnée par le corps impur, soit elle est la conséquence de la destruction d'un locus religiosus, voire, si l'on s'appuie sur le texte des Sententiae Pauli, de l'exhumation du corps. Il est difficile de trancher définitivement sur ce point car nos sources sont disparates et laconiques. Néanmoins, on peut ajouter quelques remarques complémentaires qui permettent d'aller un peu plus loin. En premier lieu, comme l'a rappelé récemment J. Scheid, on ne doit pas confondre le cas de figure illustré par les lois des bois sacrés de Spolète avec celui qui est envisagé par la loi de la colonie d'Urso ${ }^{112}$. Techniquement, d'un point de vue religieux ou juridique, comme l'a montré jadis A. Magdelain, l'espace délimité par le pomerium [166] n'est pas sacré comme le sol d'un lucus ou celui d'un sanctuaire ou encore d'un temple, mais qualifié pour les inaugurations ${ }^{113}$. L'expiation ne peut donc s'expliquer par la violation ou l'atteinte portée à l'intégrité religieuse d'un espace consacré. Par ailleurs, un passage du Traité des Lois de Cicéron nous apprend que le sol public de Rome ne pouvait être contraint par la religion privée, c'est-à-dire que la présence de tombes ne pouvait le rendre religiosus. Cette impossibilité fut formulée et sanctionnée par un décret pontifical, en vertu d'un principe qui rejoint la nécessité d'être propriétaire du sol pour constituer un locus religiosus aux yeux d'une grande partie de la jurisprudence classique $^{114}$. Dans ces conditions, dans la mesure où, au moins partiellement, le contenu de la charte d'Urso était calqué sur des normes d'origine romaine, les sépultures installées dans un locus publicus n'avaient probablement aucune valeur et étaient considérées comme nulles. L'anecdote du temple d'Honos hors la porte Colline à Rome citée par Cicéron montre qu'elles étaient purement et simplement détruites (exarata) et que le lieu redevenait pur, c'est-à-dire libéré de tout interdit religieux. Cette règle semble trouver un écho dans le fragment d'une charte municipale qui date peut-être du règne d'Auguste ${ }^{115}$. Il n'est pas précisé si, dans ce cas, une expiation était nécessaire. Dans la mesure où le locus religiosus n'existait pas, on n'y avait peut-être pas recours, comme pourrait le confirmer le silence de Cicéron $^{116}$.

112 Scheid 2006, 23-24.

113 Voir Magdelain 1976 [1990].

${ }^{114}$ CIC., De Leg., II, 58 : Sed ut in urbe sepeliri lex uetat, sic decretum a pontificum collegio, non esse ius in loco publico fieri sepulcrum [...] quom multa in eo loco sepulcra fuissent, exarata sunt. Statuit enim collegium locum publicum non potuisse priuata religione obligari. Cependant, on s'attendrait plutôt ici à un locus sacer, dans la mesure où c'est la découverte d'une tablette au nom de la divinité Honos qui justifie la destruction des tombeaux. C'est sans doute aussi ce qui justifie plus particulièrement l'intervention du collège pontifical.

${ }^{115}$ Il s'agit du «fragment Ricardi » : RS, I, 489-491, $\mathrm{n}^{\circ} 34$ : [- - -] In res singulas (sestertium) (decem milia) c(olonis) e(ius) c(oloniae) d(are) d(amnas) e(sto) isque locus, ubi / quis aduersus ea humatus sepultusue erit, / purus et religione solutus esto, eumque s(ine) f(raude) $s($ ua) / qui uolet exarato. Cf. Thomas 2002, p. 1446-1447.

${ }^{116}$ C'est la position adoptée par Y. Thomas (1999, p. 110). Mais il n'est pas exclu qu'un lieu qui n'était pas religiosus selon le droit ait entraîné des obligations rituelles et cela reste un argument a silentio. 
Assurément, les sépultures dans les lieux publics devaient être des cas sinon inexistants, du moins fort rares, pour des raisons assez évidentes ${ }^{117}$. En réalité, il est bien possible que la législation, en interdisant les sépultures dans l'enceinte des villes, ait visé principalement la construction de tombes sur des terrains privés. La confiscation par les autorités (publicatio) du lieu où le corps a été enseveli qui est prescrite dans le rescrit d'Hadrien cité plus haut va dans ce sens ${ }^{118}$. Dans cette situation précise en effet, il pouvait y avoir constitution d'un locus religiosus. Par conséquent, pour l'abolir, il y avait nécessairement un transfert du corps qui, au moins du point de vue du droit, était le fondement du caractère religieux de ce lieu. Quelle que fût donc la cause de l'interdiction, il est tout à fait vraisemblable, malgré le silence de la loi, que le corps litigieux ait été expulsé, soit qu'on l'ait purement et simplement éliminé, soit qu'il ait reçu une nouvelle sépulture en dehors de la ville - auquel cas nous retrouvons la question des transferts à proprement parler ${ }^{19}$. C'est l'abolition du locus religiosus qui est la propriété perpétuelle des Mânes, plus même que l'exhumation, qui aurait ainsi entraîné le sacrifice expiatoire.

Dans le cas du règlement d'Urso, l'expiation, exécutée par les magistrats, concerne indirectement l'ensemble de la communauté, engagée par le geste de destruction du tombeau. Mais, à partir de ces témoignages, on comprend mieux pourquoi l'inscription de M. Vlpius Phaedimus mentionne l'exécution d'un sacrifice expiatoire avant le transfert des restes $^{120}$. Cet affranchi impérial, en effet, est mort la veille des Ides d'août de l'année 117, soit quelques heures avant Trajan, à Sélinonte, en Cilicie. Il est évident qu'il reçut là-bas une première sépulture. Puis, treize ans plus tard, l'un de ses anciens esclaves passés dans la propriété de Trajan et affranchi par cet empereur a fait rapatrier sa dépouille à Rome, où l'épitaphe fut découverte. C'est probablement la longueur de l'intervalle qui [167] a nécessité le sacrifice expiatoire, qui n'engageait toutefois que celui qui se chargeait du transfert. Le collège pontifical a dû estimer que le défunt affranchi avait reçu une sépulture définitive (perpetua sepultura), constituant sans doute un véritable locus religiosus, et que le déplacement de la dépouille exigeait une expiation en bonne et due forme. L'intervention des pontifes dans ce cas prouve également que leur autorité pouvait être requise, même dans le cas où le transfert ne se faisait pas uniquement dans les limites de Rome ou de l'Italie. Ou, plus exactement, c'est probablement parce que Rome est le lieu d'arrivée du corps que le collège a dû être saisi. Nous envisagerons de nouveau cette question par la suite.

\section{Le transfert de nuit}

La seconde originalité du texte des Sententiae Pauli qui a fourni un point de départ à ces réflexions est l'obligation d'effectuer le transfert de nuit (per noctem in alium locum transferri potest). Cette exigence en effet n'apparaît nulle part ailleurs dans la

\footnotetext{
${ }^{117}$ En cas de sépulture sur un lieu public, l'édit du préteur accordait un procès (UlPIEN, $D ., 11,7,8,2$ ) : Si in locum publicis usibus destinatum intulerit quis mortuum, praetor in eum iudicium dat, si dolo fecerit et erit extra ordinem plectendus, modica tamen coercitione : sed si sine dolo, absoluendus est.

${ }^{118}$ D., 47, 12, 5 : et locum publicari iussit et corpus transferri.

${ }^{119}$ Le transfert du corps est explicitement requis par le rescrit d'Hadrien du titre 12 du livre 47 du Digeste. Cela ne signifie pas, contrairement à ce que semble penser R. Lopéz Melero (1997, p. 117), que la loi n'a imposé le transfert qu'à partir d'Hadrien.

${ }^{120} C I L$ VI, 1884 (appendice épigraphique, $n^{\circ} 1$ ).
} 
documentation relative aux déplacements de dépouilles. Pourquoi le transfert doit-il se faire de nuit? On se souvient que, quelques lignes plus bas, l'auteur des Sentences, insiste sur le fait que l'exposition d'un cadavre aux rayons du soleil est un acte qui demande une expiation. On peut dès lors se demander si les deux idées ne sont pas liées, et si le transfert doit être accompli nuitamment pour éviter que le corps n'apparaisse à la lumière du soleil. Dans son étude sur le droit des tombeaux, F. de Visscher s'appuyait justement sur ce texte pour étayer la théorie selon laquelle la nécessité d'enfouir les cadavres, si prégnante dans la législation et le rituel romain, relèverait en définitive de la volonté d'épargner toute souillure à l'astre solaire ${ }^{121}$. De son côté, $O$. Estiez reprend partiellement cette hypothèse et l'élargit en suggérant que la nuit opère comme un substitut de la terre pour cacher le corps au soleil. La translatio nocturne serait une fiction visant en outre à empêcher que le mort soit, même temporairement, un insepultus, et devienne de ce fait malfaisant ${ }^{122}$.

Nous touchons là à un problème épineux, et je me contenterai de quelques remarques. La thèse de $\mathrm{F}$. de Visscher repose sur deux arguments: le premier est l'attestation par plusieurs sources du caractère nocturne des funérailles romaines à l'époque ancienne, et le second qui, logiquement et chronologiquement explique le précédent, est le sentiment religieux touchant la lumière solaire. Il n'est pas douteux qu'il a existé anciennement à Rome un culte au dieu Sol qui avait une origine italique et non grecque ou orientale $^{123}$. Mais il est très malaisé d'en mesurer la portée exacte qui, dans tous les cas, semble avoir été relativement réduite dans les anciens temps. Si l'on en croit une notice de Festus qui remonte peut-être à Varron ${ }^{124}$, ce culte aurait pu avoir une origine sabine. Il aurait été introduit par la famille des Aurelii, et aurait donc, au moins au départ, pris la forme d'un culte gentilice ${ }^{125}$. Il semble donc bien hypothétique de faire reposer un ensemble de rites et croyances, et notamment en matière funéraire, sur ces seuls éléments. S'il fallait rattacher cet usage à d'anciennes coutumes, on peut se demander pourquoi aucune mention n'en est faite dans les sources républicaines. Plus essentiellement, le problème de l'argument de F. de Visscher est qu'il cherche à retrouver les origines de pratiques attestées textuellement plus tardivement, en sorte que le recours au texte des Sentences pour appuyer l'argumentation me paraît risqué, puisqu'il fut composé à une époque où le culte traditionnel de Sol a été éclipsé ou modifié par l'apport de ses avatars orientaux $^{126}$. Même s'il existe des continuités, il n'est pas de bonne méthode de négliger la chronologie des documents.

Or, en replaçant ce texte dans un contexte historique plus large, on pourrait au moins proposer une hypothèse alternative pour expliquer la prescription du texte des Sententiae. On sait en effet qu'après sa victoire sur la reine Zénobie, l'empereur Aurélien instaura en 274 à Rome un culte officiel de Sol, avec un temple qui se trouvait près des castra urbana, sur les pentes du Quirinal et une fête, le Solis Agon, qui avait lieu le 25 décembre $^{127}$. Ce culte connu un succès non démenti au moins jusqu'à la seconde partie du règne de Constantin. Or, si la rédaction du texte des Sententiae Pauli date bien de la fin du

${ }^{121}$ De Visscher 1963, p. 32 sq. et notamment p. 38.

122 Estiez 1995, p. 106-107.

${ }^{123}$ Cumont 1910 ; Wissowa 1912, p. 315 sq. ; Marbach 1927 ; Berrens 2004, p. 17-19.

124 Festus, p. 22 L.

${ }^{125}$ C'est la position adoptée par G. Dumézil (2000, p. 432 et 609).

126 Voir Cumont 1910.

127 Sur ce culte, voir, outre Cumont 1910, Wissowa 1912, p. 365 sq., Marbach 1927, l'étude de G. Halsberghe (1984, notamment p. 2195 sq.) et la récente synthèse de St. Berrens (2004). 
III $^{\text {e }}$ s., il est assez tentant de mettre en relation la mention des rayons solaires et la religion de Sol. Ce n'est là qu'une hypothèse, mais elle serait plus satisfaisante que celle d'une continuité avec d'antiques croyances dont nous n'avons pas de trace sous le Haut-Empire. Toutefois, une autre solution est peut-être envisageable.

En effet, un édit de l'empereur Julien promulgué à Antioche en février 363 et intégré dans le Code Théodosien éclaire un peu mieux la prescription contenue dans les Sententiae :

En second lieu, nous avons appris que l'on transporte les cadavres des morts à travers les rassemblements compacts du peuple et quand la circulation est très intense, de façon que l'on souille les yeux des hommes par un spectacle de mauvais augure. Un jour commencé par des funérailles l'est-il sous de bons auspices? Et comment après cela osera-t-on s'approcher des temples des dieux ? Pour ces motifs, considérant que la douleur, dans les obsèques, aime le secret et qu'il est indifférent aux défunts qu'on les transporte pendant la nuit ou pendant le jour, il convient de les soustraire à la vue du peuple tout entier; ainsi, la douleur accompagnera leurs convois, au lieu d'une pompe de deuil et d'ostentation ${ }^{128}$.

Comme dans le texte des Sentences, à côté de motifs de salubrité ou d'ordre public (les cortèges funéraires au beau milieu de la foule affairée), surgissent ici également des raisons religieuses, à savoir la pollution que véhiculent le corps et la famille endeuillée, risquant de mettre en péril l'accomplissement des rites religieux de la cité. Or nous avons la chance d'avoir conservé un texte grec, publié dans la correspondance de l'empereur, mais qui est peut-être l'original de l'édit que les compilateurs byzantins auraient condensé. Julien, de la même manière, y invoque les nuisances occasionnées par les funérailles diurnes. Cependant, l'accent est mis sur l'impiété (dussevbeia), le risque de contamination, même involontaire, des temples et des cultes. Il est intéressant de constater qu'il n'est pas fait allusion ici à l'astre solaire, alors que, comme on sait, Julien était un dévot du dieu Hélios. L'empereur appuie sa décision en cherchant à se placer dans la continuité d'une tradition dont il essaie de reconstruire les motifs et qu'il souhaite rétablir (to;n palai;on e[qo" ajnalabei'n).

Nous rejoignons alors ici le premier argument avancé par F. de Visscher qui, on s'en souvient, reposait sur les quelques attestations du caractère nocturne des funérailles à Rome. L'un des textes les plus importants est un commentaire de Servius à l'Énéide, qui nous apprend qu'à une époque reculée, les Romains célébraient effectivement leurs funérailles la nuit. Cette pratique en tout cas, dans la logique de son développement (les funérailles de Pallas), expliquerait l'usage de torches lors de la procession des obsèques ${ }^{129}$.

128 CTh., 9, 17, 5. (= Epistulae, Euvres complètes, I, 2 [éd. et trad. J. Bidez], Paris, CUF, 1960) : Secundum illud quod efferi cognouimus cadauera mortuorum per confertam populi frequentiam et per maximam insistentium densitatem, quod quidem oculos hominum infaustis incestat aspectibus. Qui enim dies est bene auspicatus a funere? Aut quomodo ad deos et templa uenietur? Ideoque quoniam et dolor in exsequiis secretum amat et diem functis nihil interest utrum per noctes an per dies efferentur, liberari conuenit populi totius aspectus, ut dolor esse in funeribus, non pompa exsequiarum nec ostentatio uideatur. Sur ce texte, voir les remarques de J. Bidez dans l'introduction de l'édition citée, p. 129 sq. On trouvera une mise au point récente dans Rebillard 2003, p.80-81.

${ }^{129}$ SERV., Ad Aen., 11, 143 : 'rapuere faces' (...) apud Romanos moris fuit, ut noctis tempore efferentur ad funalia - unde etiam funus dictum est. Cf. également Ad. Aen., 6, 224 et FESTUS 506 L. 
Dans ce passage du grammairien, c'est la volonté de préserver la pureté des magistrats et prêtres, impliqués directement dans les rites de la religion publique et qui auraient pu croiser le cortège, qui rend compte de cette coutume ${ }^{130}$. On connaît en effet par d'autres sources les interdits qui pesaient sur les prêtres, pontifes ou flamines, au regard de la mort et des cadavres ${ }^{131}$. On peut ainsi s'expliquer un peu mieux que l'usage des torches ait perduré lors même que les funérailles se déroulaient le jour. Leur fonction n'était sans doute pas apotropaïque comme le voulaient P. Boyancé et H. Rose avant lui ${ }^{132}$. Si le témoignage de Servius, qui semble remonter à Varron, est digne de foi, la présence de [169] torches est tout naturellement explicable par des raisons pratiques : elles guidaient le cortège. Mais, comme les branches de cyprès fixées aux portes des demeures endeuillées ou comme les clochettes des employés des pompes funèbres de Pouzzoles, elles ont pu posséder une valeur prémonitoire, et ce de nuit comme de jour - même si leur efficacité dans ce dernier cas a pu être réduite ${ }^{133}$. Par ailleurs, il y a quelques années, J. Scheid a, dans une démonstration convaincante, mis en doute la thèse de $\mathrm{P}$. Boyancé pour qui, à l'époque historique, seules les funérailles d'enfants morts prématurément (les funera acerba) auraient été célébrées à la lueur des torches. Il a ainsi insisté à juste titre sur la valeur symbolique de ces flambeaux - comme celle des lampes que l'on allumait lors des célébrations commémoratives pour les défunts - signifiant par métonymie la nuit qui est proprement ou métaphoriquement le lieu et le temps des morts ${ }^{134}$. Même en pleine journée, les torches matérialisent l'altérité du mort qui, bien évidemment, est au centre du cortège, mais également celle de l'entourage qui est frappé par le deuil et que la contamination contractée par le décès met temporairement au ban du reste de la communauté. Cette symbolique montre bien que la nuit était donc considérée comme le lieu des morts et des Mânes. Après tout, même en admettant avec H. Rose que la tradition rapportée par Varron est une forme de rationalisation a posteriori dont rien n'indique le caractère antique, et que c'était bien de jour que les funérailles des anciens temps étaient normalement célébrées affirmation bien difficile à démontrer dans la mesure où les sources à ce sujet ne sont pas si nombreuses, cette pratique affirme malgré tout avec force le lien symbolique entre la mort et la nuit, dont on pourrait citer bien d'autres exemples. Or, cette hypothèse rejoint incidemment les justifications données par Julien et qu'il présente comme une restauration des plus anciennes traditions afin d'interdire les cortèges funéraires diurnes. La nuit est le moment naturel pour les cérémonies destinées aux divinités d'en bas ${ }^{135}$.

De tout cela, on peut retenir deux choses. D'une part, que la mesure prise par Julien apparaît, comme le soulignait déjà J. Bidez, comme une « disposition toute nouvelle par sa généralité ». En effet, pour l'époque « classique », disons la fin de la République et le Haut-

${ }^{130}$ SERV., Ad Aen., 11, 143 : qui in religiosa ciuitate cauebant, ne aut magistratibus occurrerent aut sacerdotibus, quorum oculos nolebant aliena funera uiolari.

${ }^{131}$ Par exemple interdits concernant le flamen Dialis: AULU-GELLE, NA, 10, 15 ; Tibère, grand pontife assistant le visage voilé aux funérailles de Drusus : SÉN., Ad Marc., 15.

${ }^{132}$ Rose 1923 et Boyancé 1952 [1972], p. 79 sq.

${ }^{133}$ Branche de cyprès : SERV., Ad Aen., III, 64 : moris autem Romani fuerat ramum cupressi ante domum funestam poni, ne quisquam pontifex per ignorantiam pollueretur ingressus; à Pouzzoles : règlement de munere publico libitinario (Libitina 2004), col. II, 1. 13-14. Cf. le commentaire ad loc. dans Hinard - Dumont 2003, p. 122. Dans le même genre d'idée, on peut ajouter les trompettes de la sonnerie funèbre jouée lors du banquet de Trimalcion (PÉTR., Satir., 78).

${ }^{134}$ Ce n'est pas le lieu de reprendre ici l'ensemble de la démonstration : voir Boyancé 1952 [1972] et surtout Scheid 1984, p. 122 sq. Pour les lampes sur les tombes, la documentation est réunie par Cumont 1946.

135 JuliEN, Epist., 77 (=136b, p. 200, 1.11 sq., éd. Bidez). 
Empire, nous n'avons qu'un nombre très restreint d'attestations de funérailles nocturnes. Il semble assez significatif en revanche que toute activité des pompes funèbres de Pouzzoles ait été suspendue pendant la nuit ${ }^{136}$. D'autre part - et ce point nous intéresse plus directement - on ne peut conclure à partir du texte des Sententiae Pauli que le caractère nocturne du transfert ait été systématique à toute époque. Ainsi, il me semble que l'hypothèse de la fiction mise en place par le transfert nocturne pour éviter que le mort ne soit un insepultus est extrêmement fragile. Il est probable cependant qu'elle exprime une mesure de précaution pour empêcher la pollution de passants, surtout de ceux qui, d'une façon ou d'une autre, avaient affaire avec le sacré et les rites de la cité. Il s'agit ainsi de l'ébauche d'une mesure systématisée par Julien qui conduira à exclure (avec quel succès ?) le déroulement de funérailles de jour, avec cette idée que la nuit est le temps réservé à la mort et aux morts.

Le dernier avatar de la législation sur le transport et le transfert des corps se rencontre dans le Code Théodosien. Il s'agit d'une constitution des empereurs Gratien, Valentinien et Théodose datée du 26 février 386 :

Que personne ne transfère dans un autre lieu un corps inhumé ${ }^{137}$.

La continuité avec la documentation précédente est patente, même s'il semble y avoir une radicalisation - à moins que ce ne soit une simplification dans la formulation - car tout transfert est prohibé ${ }^{138}$. Le contexte de cette constitution est en [170] réalité bien différent. La suite du texte interdit en effet le dépècement et la vente du corps des martyrs, mais permet en revanche l'intervention sur leurs tombeaux pour les aménager en lieux de culte $^{139}$. C'est donc à la lumière de ces nouvelles pratiques que ce texte doit être lu, et non à l'aune de la législation traditionnelle telle que nous l'avons entrevue par les extraits du Digeste de Justinien reprenant la jurisprudence impériale.

\section{Quibus ius permittendi est}

Dans le cas du simple transport, pompa funebris ou rapatriement, nous avons vu qu'il existait des contrôles relativement stricts, rendus indispensables par le souci du maintien de l'ordre public autant que par le respect de la religio qui entoure les tombeaux. L'autorisation préalable est a fortiori nécessaire dans le cas d'un transfert, parce que ce dernier est une atteinte au locus religiosus propriété des Mânes et que, le cas échéant, la présence d'un cadavre est ressentie comme un danger pour les rites de la cité. La documentation épigraphique et juridique que nous avons réunie cite quatre autorités

${ }^{136}$ De munere publico libitinario, notamment II, 3-4, et le commentaire dans Hinard - Dumont 2003, p. 110-111 qui contient la plupart des références.

${ }^{137}$ CTh., 9, 17, 7 : humatum corpus nemo ad alterum locum transferat.Cf. CJ., 3, 44, 14 et 1, 2, 3.

${ }^{138}$ Voir De Visscher 1963, p. 158 et p. 311 sq., mais avec une perspective différente de celle qui est ici la mienne.

139 ibid.: nemo martyrem distrahat, nemo mercetur. habeant uero in potestate, si quolibet in loco sanctorum est aliquis conditus, pro eius ueneratione quod martyrium uocandum sit addant quod uoluerint fabricarum. Voir Rebillard 2003, p. 81. 
compétentes en ces matières : les pontifes, l'empereur, les gouverneurs de province et enfin les tribuns de la plèbe. Est-il possible de délimiter plus précisément leurs modalités d'intervention et leurs sphères d'action respectives ?

Les pontifes sont naturellement tout désignés en raison de leurs compétences dans les affaires touchant à la religio et aux sacra priuata dont les rites funéraires sont une partie $^{140}$. L'intervention du collège pontifical dans le transfert de corps apparait sur quatre des inscriptions que nous avons réunies. Dans deux cas, l'épitaphe de M. Vlpius Phaedimus $\left(C I L\right.$ VI, $\left.1884=\mathrm{n}^{\circ} 1\right)$ et l'inscription funéraire de Terracine $\left(C I L \mathrm{X}, 8259=\mathrm{n}^{\circ} 21\right)$, il est fait mention explicite d'un piaculum. Dans le troisième document nous avons la chance de posséder l'intégralité de la requête formulée auprès des pontifes $\left(C I L\right.$ VI, $\left.2120=\mathrm{n}^{\circ} 2\right)$. Dans ce cas cependant, aucun sacrifice expiatoire ne semble avoir été prescrit. Cette conclusion repose sur un argument a silentio, mais un texte si détaillé qui fait figurer la réponse du promagister du collège n'aurait pas manqué de le signaler s'il avait été requis. Il est tout à fait probable que l'absence d'expiation soit à expliquer par le caractère explicitement provisoire des sépultures de l'épouse et du fils d'Arrius Alphius, comme je 1'ai déjà suggéré ${ }^{141}$. Dans la dernière inscription enfin, qui provient de Trebula Mutuesca, le texte est plus laconique et ne mentionne que la permission des pontifes (CIL IX, $4881=\mathrm{n}^{\circ}$ 8). Il faudrait ajouter à cette liste l'ensemble des inscriptions rappelant l'autorisation des pontifes pour la réfection d'un monument funéraire. Je n'y reviendrai pas ${ }^{142}$.

D'après ces textes, les pontifes jouent le rôle de consultants, bien attesté dans les sources littéraires, tant pour les cérémonies publiques que pour les rites privés ${ }^{143}$. On ignore les détails de la procédure, mais l'inscription d'Arrius Alphius, corroborée par l'étude de Fr. Van Haeperen sur deux passages du De Legibus de Cicéron, laisse penser que la démarche était volontaire de la part des particuliers qui s'adressaient d'eux-mêmes au collège pontifical $^{144}$. La question était soumise au collège sous la forme d'un libelle, retranscrit par exemple dans l'inscription d'Arrius Alphius, et qui est également mentionné dans l'inscription de Terracine portant sur la réfection d'un monument funéraire. Cette démarche semble avoir été générale, et elle est encore attestée dans une constitution impériale de mars 349 portant sur la destruction de tombeaux ${ }^{145}$.

Le droit civil a donc ménagé une place au droit sacré et au collège pontifical dans son dispositif régissant et protégeant les res religiosae. On trouve ainsi inséré dans le Digeste le commentaire suivant d'Ulpien :

${ }^{140}$ Sur le rôle du collège pontifical, voir Bouché-Leclerq 1871, notamment p. 149 sq., ainsi que Wissowa 1912, p. 503 sq. et maintenant, Van Haeperen 2002, p. 72 sq. qui passe en revue les différents témoignages.

${ }^{141}$ Cf. également Van Haeperen 2002, p. 324-325. Ce qui pourrait signifier que le droit sacré a pris en compte une notion élaborée par la jurisprudence civile.

${ }^{142}$ Voir supra p. 18 sq.

143 Par exemple : Liv., I, 20, 6 ; Den. Hal., Ant. Rom., 2, 73 ; Plut., Numa, 12, 7. Cf. Van Haeperen 2002, p. 74 sq.

${ }^{144}$ CIL VI, 2120 (n 2). Voir Van Haeperen 2002, p. 309-311 sur CiC., De Leg., 2,55 (sur la réponse d'A. Torquatus à la famille Popilia) et 2, 57 (réponse de $\mathrm{P}$. Mucius à une famille dont un membre était mort en mer).

${ }^{145}$ CTh., 9, 17, 2 pr. (sur la destruction de tombeaux) : qui uero, libellis datis, a pontificibus impetrarunt ut reparationis gratia labentia sepulchra deponerent, si uera docuerunt, ab illatione multae separentur. Dans l'inscription CIL VI, 2120, le verbe rogo (1. 23), ainsi que la subscriptio sont typiques du formulaire des libelles. Sur les libelli, voir Premerstein 1926. 
[171] On se demande s'il est permis au propriétaire d'un lieu de déterrer ou d'exhumer sans décret des pontifes [ni ordre du prince] des os ou un corps qui y ont été enterrés par un tiers ; Labéon dit qu'il faut attendre l'autorisation pontificale [ou l'ordre du prince], ou bien celui qui les aura expulsés sera passible d'une actio iniuriarum ${ }^{146}$.

Selon un texte de Gaius sur l'édit provincial, l'ensevelissement d'un défunt sur la propriété d'autrui conduisait à l'ouverture d'une actio in factum contre l'auteur de la sépulture ${ }^{147}$. Mais le propriétaire lésé ne pouvait pas se débarrasser purement et simplement du corps. Comme dans le cas de la restauration de monuments, le collège pontifical était saisi pour déterminer dans quelle mesure la destruction de la sépulture pouvait être accomplie salua religione. Il est très vraisemblable en outre que le corps enseveli illégalement était transféré ailleurs ${ }^{148}$. En cas de non respect de cette procédure, le propriétaire lésé aurait pu se rendre coupable d'un acte réprimé par l'actio iniuriarum et, sur le plan religieux, d'une impiété. Après consultation et examen de la question, la réponse des prêtres prenait la forme d'un décret, comme d'ailleurs dans la subscriptio au libelle d'Arrius Alphius ou encore dans l'inscription retrouvée à Terracine ${ }^{149}$. Pour reprendre les termes employés par Macrobe, le propre des décrets pontificaux était bien de définir, entre autres choses, ce qui était ou non religiosus ${ }^{150}$.

Denys d'Halicarnasse, dans sa présentation des prêtres, est le seul à leur attribuer un droit de sanction (zhmiou'n), peut-être sous la forme d'une amende, en cas de non respect des rites et des prescriptions traditionnels ${ }^{151}$. Cependant, dans l'état actuel de nos sources, aucun témoignage décisif ne vient étayer cette affirmation. En tout cas, pour le problème du transfert des corps (ou même pour la restauration des monuments), il ne semble pas que le collège ait eu le droit d'infliger des sanctions d'ordre pénal. Il apparaît assez nettement dans le texte d'Ulpien cité plus haut, reprenant lui-même un propos de M. Antistius Labeo,

${ }^{146}$ D., 11, 7, 8 (ULP., Ad Ed., 25) : Ossa quae ab alio illata sunt uel corpus an liceat domino loci effodere [uel] eruere sine decreto pontificum [seu iussu principis], quaestionis est : et ait Labeo exspectandum [uel] permissum pontificale [seu iussionem principis], alioquin iniuriarum fore actionem adversus eum qui eiecit. Il est intéressant de noter la nature de l'action accordée par le préteur en ce cas.

${ }^{147}$ D., 11, 7, 6. Sur cette procédure, voir De Visscher 1963, p. 62-63 et Ducos 1995, p. 140.

${ }^{148}$ Ce passage, ainsi que le commentaire de Gaius sur l'édit provincial évoqué plus haut, est au cœur d'une discussion entre les spécialistes de droit pour établir si le simple dépôt du corps suffit ipso facto à rendre un lieu religieux ou si, comme paraissent le soutenir en général les autres textes de la jurisprudence classique, il faut être propriétaire du sol où est fondée la sépulture. Aux arguments de F. de Visscher (1963, p. 62-63) partisan de la première solution, on opposera ceux de G. Longo (1964, notamment p. 139-140). Sans rentrer dans la complexité du débat, on fera cependant une remarque sur le texte d'Ulpien. Il n'est pas impossible que l'on entrevoie ici une dissonance entre la définition strictement juridique de la tombe (présence du corps sur un terrain dont on possède le dominium) et la dimension religieuse de toute sépulture constituée selon les rites. C'est pour cette dernière raison que les pontifes seraient consultés, dans la mesure où le corps doit être exclu. Pour le dire autrement, là où le droit civil ne reconnaît pas le caractère religieux du sol, le droit sacré peut être en mesure de l'accepter.

${ }^{149}$ CIL VI, 2120 : decretum : fieri placet ; CIL X, 8259 : collegium pontificum decreuit (restitution quasi assurée). Les autres inscriptions utilisent les termes de permissus (CIL VI, 1884 et 4881 ) qui n'est qu'un synonyme moins technique et se rencontre aussi pour des restaurations de monuments funéraires (cf. supra).

${ }^{150}$ MACR., Sat., III, 3, 1 : inter decreta pontificum hoc maxime quaeritur, quid sacrum, quid sanctum, quid religiosum.

151 DEN. HAL., 2, 73 : kai; ei[ tina" ai[sqonto mh; peiqomevnou" tai'" ejpitagai'", zhmiou'si pro;" e\{kaston crh'ma oJrw'nte"... Denys est le seul auteur à fournir cet précision dans l'ensemble des notices antiques conservées sur les pontifes. Sa remarque est donc sujette à caution, même s'il est possible que Varron ait été sa source (voir Van Haeperen 2002, notamment p. 59-61 et p. 74). 
que les pontifes n'étaient qu'un rouage dans la procédure et que la sanction, en définitive, relevait du magistrat devant qui l'affaire était conduite. On peut ainsi suggérer que le dispositif légal contraignant mis en place autour des tombeaux, mais aussi, plus simplement le scrupule religieux entourant les sépultures furent, au moins à partir du principat, les deux motifs qui conduisaient des particuliers à requérir l'avis du collège pontifical ${ }^{152}$. Comme l'avait déjà souligné F. de Visscher, les [172] pontifes n'avaient sans doute aucune compétence en matière de juridiction pénale pour le droit des tombeaux ${ }^{153}$. De même, comme nous l'avons déjà remarqué, il n'est pas vraisemblable ni même nécessaire que le collège ait exercé un contrôle lors de la fondation de chaque tombe dans le but de vérifier la conformité aux exigences de la religio. Néanmoins, même si la logique juridique cherche en ces matières à s'émanciper des pratiques religieuses, la jurisprudence classique ne pouvait évidemment pas exclure entièrement les compétences conférées traditionnellement aux pontifes et relevant du droit sacré.

Le passage précédemment cité d'Ulpien évoque, à côté de la permission des pontifes, la possibilité d'une autorisation délivrée par l'empereur. Or, Ulpien citant Labéon, il est manifeste que cette mention est une interpolation tardive ajoutée par le commentateur sévérien $^{154}$. Néanmoins, l'intervention du Prince dans les transferts ou transports de corps est explicitement attestée par deux inscriptions, dont l'une date du second quart du $\mathrm{II}^{\mathrm{e}} \mathrm{s}$ de n. è. (CIL III, $1312=\mathrm{n}^{\circ} 15$ : ex indulgentia Augusti nostri) et la seconde, des années 170 (CIL VI, $8878=\mathrm{n}^{\circ} 5$ : permissu imperatoris). Les sources juridiques livrent d'autres témoignages de permission accordée par l'empereur en personne. Nous avons déjà cité deux rescrits conservés dans le Code Justinien, l'un de Caracalla adressé en 213 à une certaine Dionysia dans un contexte manifestement provincial et un second de la fin du III $\mathrm{s}^{\mathrm{e}}$. rédigé par Dioclétien et Maximien et destiné à une Aquilina ${ }^{155}$. L'explication traditionnelle veut que le prince soit intervenu en qualité de grand pontife comme le suggère explicitement la lettre de Pline à Trajan sur le déplacement de sépultures bithyniennes ${ }^{156}$. Pourtant, F. Millar et M. Kaser, dans des perspectives différentes mais qui se rejoignent, ont conjointement proposé une autre interprétation au rôle de l'empereur. Pour F. Millar, l'intervention par rescrit au $\mathrm{III}^{\mathrm{e}} \mathrm{s}$. illustrerait la façon dont, progressivement, la figure de l'empereur se dégage des institutions traditionnelles et montrerait comment il devient l'interlocuteur naturel et privilégié des habitants de l'Empire dans un domaine où, à l'origine, il partageait ses compétences avec le collège pontifical ${ }^{157}$. M. Kaser, en revanche, explique que le rôle croissant du prince aurait pour toile de fond la concurrence entre son

152 On ne doit pas oublier que l'action accordée par le préteur (de sepulchro uiolato) est une action populaire, et peut donc, théoriquement, être engagée par n'importe qui : le titulaire du ius sepulchri, mais aussi un tiers. Ainsi, tout le monde pouvait être touché par cette action si on estimait qu'il avait porté atteinte à un sepulchrum, c'est-à-dire, comme le disent Cicéron et Ulpien, ce que nous appellerions une " sépulture » et non, comme on le traduit généralement, simplement un « tombeau » (CIC., De Leg., II, 57 et UlPIEN dans D., 47, 12, 3, 2). Sur cette action, voir Casavola 1958, p. 24 sq. et De Visscher 1963, p. 139 sq.

${ }^{153}$ De Visscher 1963, p. 145 sq. Cf. Marquardt 1881-1886, III, p. 313.

154 L'interpolation est signalée par De Visscher 1963, p. 62-63, n. 5, suivant en cela P. Bonfante. Sur l'opposition de M. Antistius Labeo au régime instauré par Auguste, voir GELL., NA, 13, 12 ; TAC., Ann., 3, 75 et PORPHYR., Ad Horat Sat., 1, 3, 82 (cf. la mise au point de Jörs 1894).

${ }^{155}$ CJ., 3, 44, 1 et 10 (supra, p. 11).

156 Plin., Epist., X, 68 : te, domine, maximum pontificem consulendum putaui. Cf. Marquardt 1881-1886, III, p. 310. Plus récemment, Cracco-Ruggini 1995, p. 121 n. 1.

${ }^{157}$ Millar 1977, notamment p. 359 sq. 
pouvoir grandissant en matière de droit civil et pénal d'un côté et le droit sacré traditionnellement aux mains du collège pontifical de l'autre. Le droit régissant les choses funéraires étant à la croisée des deux, il serait le lieu de tensions où l'empereur et les jurisprudents finiraient par imposer leurs vues. À cela pourraient s'ajouter des querelles d'autorité entre le souverain et le prestige social et politique du collège ${ }^{158}$. Ces hypothèses ne sont pas sans intérêt, mais on peut formuler quelques remarques à leur encontre. En premier lieu, sans oublier que l'empereur porta le titre de pontifex maximus jusqu'au règne de Gratien, on peut se demander si les tensions et divergences ne sont pas à mettre au compte des différences de logique entre les normes induites par le droit et par la religion telles que nous avons pu les entrevoir, plutôt que de les rapporter à des rivalités entre les jurisprudents et l'empereur d'une part et les pontifes de l'autre. Quant à l'interprétation proposée par F. Millar, il me semble que Fr. Van Haeperen l'a nuancée de manière décisive $^{159}$. Il faut souligner au préalable que le fonctionnement du collège pontifical a en général été respecté par l'empereur, malgré la prééminence de son avis ${ }^{160}$. On peut établir avec une relative certitude que, dans les limites géographiques des compétences des pontifes, c'est-à-dire Rome et l'Italie, l'empereur agissait de concert avec le collège, au moins au $\mathrm{II}^{\mathrm{e}}$ et au début du $\mathrm{III}^{\mathrm{e}}$ siècle. La riche inscription d'Arrius Alphius est à cet égard éclairante. Il semble bien en effet que la requête de l'affranchi ait été en premier lieu destinée à Antonin qui, soit par manque de temps dans une affaire qui demandait diligence, soit par volonté de laisser le collège statuer sur la question, n'y a pas répondu ${ }^{161}$. C'est finalement le promagister [173] P. Iuuentius Celsus qui accorda la permission du transfert, soit seul, soit après avoir réuni le collège. On ignore les attributions exactes de cette charge et ses modalités précises d'exercice, mais on s'accorde à penser que ce personnage jouait en quelque sorte le rôle de vice-président du collège normalement dirigé par le prince, grand pontife. Nous avons avec cette inscription l'attestation la plus ancienne de cette fonction, et le cas d'Arrius Alphius montre que le prêtre qui la remplissait devait expédier les affaires courantes qui ne nécessitaient pas obligatoirement la consultation de l'empereur en personne ${ }^{162}$. On ajoutera aux arguments de Fr. Van Haeperen que l'évolution décelée en ces matières par F. Millar pourrait tout aussi bien découler de la nature de notre documentation: tandis que l'activité des pontifes est connue essentiellement par des inscriptions dont le nombre décroît à partir de la seconde moitié du III $^{\mathrm{e}}$ s., les sources juridiques, et notamment le Code Justinien, mettent en avant les rescrits impériaux et comblent donc nos lacunes sur ce sujet pour cette période. Enfin, on peut noter qu'une constitution de Constance datée de 349 rappelle les prérogatives du collège pontifical pour l'autorisation de restauration de monuments, preuve qu'un rôle leur était encore reconnu en plein IV $^{\text {e }}$ s. ${ }^{163}$ Mais il est vrai que nous n'avons dans nos sources aucune attestation de

${ }^{158}$ Kaser 1978, p. 90-91.

${ }^{159}$ Van Haeperen 2002, p. 331-333.

${ }^{160}$ Van Haeperen 2002, p. 195 sq. et 213 sq.

${ }^{161} C I L$ VI, $2120\left(n^{\circ}\right.$ 2). L'interprétation de F. Millar (1977, p. 360 n. 30) selon qui l'empereur n'aurait pas été le destinataire originel n'est pas recevable. Il estime en effet que l'apostrophe domine du libelle désigne le promagister du collège, Iuuentius Celsus. Toutefois, si l'on se reporte quelques lignes plus haut, dans la lettre de Velius Fidus décrivant la tentative d'Arrius Alphius pour obtenir une réponse de l'empereur, toute équivoque disparaît (1. $10:$ a domino nostro imperatore impetrasse).

${ }^{162}$ Cette théorie classique est exposée par Wissowa 1912, p. 509, reprise par Latte 1960, p. 401. Cf. également Scheid 1990, p. 266 et surtout Van Haeperen 2002, p. 197.

${ }^{163}$ CTh., 9, 17, 2, cité plus haut n. 139 ; cf. Van Haeperen 2002, p. 333. 
l'intervention de l'empereur en matière de restauration des tombeaux et que celle-ci n'est connue que pour le transport ou le transfert de corps.

La compétence des gouverneurs de province est attestée par nos sources à la fois pour l'autorisation de transport des corps et pour le transfert d'une sépulture à une autre. Selon un texte d'Ulpien que nous avons déjà cité, ils devaient s'assurer de l'ordre en cas de transport sur la voie publique et garantir l'ensevelissement de la dépouille ${ }^{164}$. L'inscription $\mathrm{du}$ jeune étudiant mort à Carthage montre que les prérogatives des gouverneurs ne se limitaient pas à la sécurité des processions des funérailles, mais qu'elles pouvaient également s'étendre aux autorisations de rapatriement ${ }^{165}$. Un rescrit de Caracalla indique aussi qu'ils possédaient la capacité d'autoriser le transfert de sépulture ${ }^{166}$. Le témoignage le plus explicite à ce sujet est la lettre de Pline à Trajan dont nous avons déjà eu l'occasion de parler à plusieurs reprises. Pline, légat de l'empereur en Bithynie, a reçu une requête d'habitants de la province - on ignore d'où exactement - réclamant l'autorisation de déplacer des sépultures menacées de destruction. Il demande donc conseil à l'empereur, en qualité de grand pontife ${ }^{167}$. La réponse de Trajan, teintée d'ironie, indique sans ambiguïté que ce domaine est du ressort des gouverneurs de province, et non du collège pontifical ${ }^{168}$. Elle est justifiée avant tout par des raisons pratiques : la requête en bonne et due forme auprès des pontifes aurait été évidemment bien longue, onéreuse et en contradiction avec la contrainte impérieuse de la necessitas. Pline, comme dans la lettre 49, cherche à appliquer à un problème provincial la législation pontificale propre à Rome et à l'Italie ${ }^{169}$. À sa décharge, on pourra cependant faire remarquer, à la suite de A. Sherwin White, que le légat cherche moins à demander une autorisation au collège pontifical qu'à obtenir des conseils de l'empereur sur la démarche à suivre ${ }^{170}$.

[174] Le texte nous apprend que cette prérogative était du ressort des gouverneurs de province déjà au début du $\mathrm{II}^{\mathrm{e}}$ s. Pline, comme Trajan, évoque en effet l'exemple des proconsuls précédents. En outre, il ne s'agit sans doute pas, ainsi qu'on l'a parfois suggéré, d'une requête ponctuelle de la part des Bithyniens qui auraient ainsi cherché à flatter le légat nouvellement arrivé ${ }^{171}$. Les motifs invoqués dans la lettre de Pline sont de natures multiples: menace d'un cours d'eau, ruine par le temps, et d'autres, qui ne sont pas développés. On n'a pas l'impression d'une réclamation précise liée à des circonstances

${ }^{164}$ D., 11, 7, 38 (supra, p. 9).

${ }^{165}$ ILAlg, I, $1363\left(\mathrm{n}^{\circ} 18\right)$ : permissu praesidis a Karthagine de studio relatis reliquiis. Rien ne dit que le jeune homme avait reçu une sépulture à Carthage, ce qui me fait préférer l'hypothèse d'un rapatriement à celle d'un transfert.

${ }^{166}$ CJ., 3, 44, 1 (supra p. 11).

167 Plin., X, 68: Petentibus quibusdam, ut sibi reliquias suorum aut propter iniuriam uetustatis aut propter fluminis incursum aliaque his similia quocumque secundum exemplum proconsulum transferre permitterem, quia sciebam in urbe nostra ex eius modi causa collegium pontificum adiri solere, te, domine, maximum pontificem consulendum putaui, quid obseruare me uelis. Sur les aspects juridiques de la correspondance entre Pline et Trajan, voir Gaudemet 1964.

${ }^{168}$ PLIN., X, 69 : Durum est iniungere necessitatem prouincialibus pontificum adeundorum, si reliquias suorum propter aliquas iustas causas transferre ex loco in alium locum uelint. Sequenda ergo potius tibi exempla sunt eorum, qui isti prouinciae praefuerunt, et ut causa cuique, ita aut permittendum aut negandum.

169 Il s'agit alors du transfert d'un temple de la Mater Magna à Nicomédie, et la possibilité d'un déplacement salua religione, malgré l'absence de lex dicta (PLIN., X, 49).

${ }^{170} \mathrm{La}$ formule exacte employée par Pline est en effet : quid obseruare me uelis. Voir Sherwin-White 1985, p. 655-656.

${ }^{171}$ Hypothèse de Vidman 1960, p. 76, s'appuyant sur PLUT., Rei publ. ger., 19. 
définies, mais d'une accumulation de doléances que Pline a enfin consenti à traiter. Il n'est même pas impossible d'envisager qu'elles aient été regroupées par les services accompagnant le légat afin d'être examinées ensemble. Dans une certaine mesure, c'est le recours au gouverneur ou au légat qui, notamment dans le cas de ciuitates liberae, peut paraître surprenant. On apprend en effet incidemment dans un discours de Dion de Pruse que des cités pouvaient prendre des décrets pour déplacer des sépultures ${ }^{172}$. Ce que le texte ne dit malheureusement pas, c'est si ces décrets étaient ou non soumis à l'approbation des autorités romaines. Mais nous touchons là à un problème bien plus large qui est celui de la nature et des modalités de l'intervention du pouvoir romain dans la vie des cités théoriquement libres - problème qui dépasse largement mon propos ici. Soulignons simplement que la démarche des habitants de Bithynie implique une reconnaissance des compétences des autorités romaines en cette matière. Toutefois, le fameux « rescrit de Nazareth » publié jadis par Fr. Cumont et qui était peut-être en réalité un édit, pourrait montrer que dès l'époque augustéenne, le pouvoir romain se souciait du respect des tombes et des monuments funéraires dans les provinces, probablement en prenant la continuité de droits locaux plus anciens ${ }^{173}$.

Théoriquement, les attributions des proconsuls ou des légats en matière religieuse ne sont en rien comparables à celles des pontifes romains. Mais G. Wissowa a fait l'hypothèse que c'est la nature du sol provincial qui rend possible la délégation et l'intervention des gouverneurs pour des affaires touchant aux res religiosae ${ }^{174}$. On sait en effet par un passage des Institutes de Gaius que le sol des provinces, propriété de l'empereur ou du peuple romain, ne peut devenir religiosus, dans la mesure où l'une des conditions pour rendre un lieu religieux est d'en être le propriétaire ${ }^{175}$. Toutefois, s'il n'est pas religiosus à proprement parler, il est considéré comme tel (pro religioso). C'est peutêtre ce caractère fictivement religieux qui rendait possible la délégation aux gouverneurs de provinces de la capacité à autoriser le transfert de corps et le déplacement de sépultures ${ }^{176}$. Quoi qu'il en soit, il ne faut pas non plus négliger un certain pragmatisme dans la gestion romaine de ces questions. La documentation est malheureusement trop fragmentaire pour apporter des réponses précises à ces interrogations. En outre, bien que nous n'en ayons aucune trace, il n'est pas exclu que les magistrats locaux aient pu délivrer ce genre d'autorisation.

172 Dio. CHR., Or., 47, 16 : à Tarse et Nicomédie, un décret de l'assemblée a autorisé de déplacer des tombeaux (oiJ ejyhfivsanto ta; mnhvmata metaivrein).

${ }^{173}$ Les questions soulevées par cette inscription sont nombreuses et loin d'être toutes élucidées. Pour le texte, voir Cumont 1930, qui donna le premier commentaire. La bibliographie est réunie par Tsalampouni 2001 (qui n’apporte aucune élément nouveau). Les arguments les plus sérieux font pencher pour une datation augustéenne. Le lieu où se trouvait originellement ce texte n'est pas assuré, malgré l'indication de provenance qu'on lui attribue en général par commodité. L'hypothèse d'un édit (comme semblent l'indiquer le terme diavtagma et le ton du texte) paraît la plus vraisemblable, mais est loin de répondre à toutes les interrogations. On trouvera une mise au point récente dans Giovannini - Hirt 1999.

174 Wissowa 1912, p. 479, n. 4.

${ }^{175}$ GAIUS, Inst., II, 7 : Sed in prouinciali solo placet plerisque solum religiosum non fieri, quia in eo solo dominium populi Romani est uel Caesaris, nos autem possessionem tantum et usumfructum habere uidemur ; utique tamen, etiamsi non sit religiosum, pro religioso habetur.

${ }^{176}$ Le problème se posait également pour les loca sacra et le statut des temples : GAIUS, Inst., II, 8 (cf. PLIN., X, 49 et 50 : solum peregrinae ciuitatis capax non sit dedicationis, quae fit nostro iure). 
Tel semble donc avoir été le schéma général que l'on peut établir à partir de nos sources : à Rome et probablement sur l'ager Italicus, c'est le collège pontifical qui délivrait une autorisation pour le transfert de corps ${ }^{177}$. Dans les provinces, [175] cette compétence était du ressort des proconsuls ou des légats, qui devaient également s'assurer du bon déroulement du transport lors des funérailles et autorisaient également les rapatriements. Quant au rôle de l'empereur, il est un peu plus problématique. L'hypothèse formulée par Fr. Van Haeperen semble néanmoins la plus recevable : il agissait en tant que grand pontife et la plupart du temps en accord avec le collège pour Rome et l'Italie. On notera en outre que son intervention n'apparaît finalement que sur deux épitaphes qui rappellent le rapatriement à Rome de deux affranchis impériaux depuis la Pannonie et la Dacie. La situation est donc tout à fait similaire à celle du retour des restes de $\mathrm{M}$. Vlpius Phaedimus de Cilicie. On comprend mal alors qu'il se soit agi d'une répartition de compétences. À titre de suggestion, il n'est peut-être pas impossible de penser que l'empereur a pris la décision en tant que pontifex maximus (voire après consultation du collège), mais que les proches du défunt ont demandé au lapicide de ne faire figurer que le nom du prince, cherchant ainsi à exprimer le loyalisme bien connu des affranchis impériaux envers leur patron. Nous serions plus alors du côté des usages épigraphiques que de la transcription précise de la procédure engagée, dont l'inscription d'Arrius Alphius montre bien les détours et les contrariétés. Enfin, pour ce qui concerne les provinces, le rescrit de Caracalla montre assez nettement que, en dernier ressort, l'autorisation du transfert est laissée à l'appréciation du gouverneur, suivant en cela la logique déjà affirmée à Pline par Trajan. Le rôle du prince est ici de confirmer un principe ancien et général de droit, non de répondre administrativement à la requête en tant que telle.

Nous possédons une inscription de Rome, malheureusement perdue, où la permission de transférer des corps a été délivrée par des tribuns de la plèbe ${ }^{178}$. Ce texte pose problème, car nulle part ailleurs n'est signalée la compétence des tribuns en la matière. Déjà Th. Mommsen avait signalé le fait sans insister, l'attribuant aux capacités du collège des tribuns à jouer un rôle supplétoire ${ }^{179}$. Dans une étude sur les compétences extraordinaires des tribuns en matière juridique, B. Kübler a émis l'hypothèse qu'ils auraient eu à Rome une fonction similaire à celle des gouverneurs dans les provinces ${ }^{180}$. Cette idée ne semble pas exclue, bien qu'il faille la préciser quelque peu. En effet il n'est guère envisageable qu'il s'agisse d'un transfert d'une sépulture à l'autre entraînant une intervention sur un locus religiosus, auquel cas on aurait, à Rome, inévitablement saisi le collège pontifical. Mais on peut penser à un simple déplacement du corps, par exemple pour la mise au tombeau, avec ou sans sépulture temporaire. Le terme utilisé, transferre, se retrouve dans les inscriptions et dans les textes juridiques pour signifier un transport, et pas

${ }^{177}$ Voir Van Haeperen 2002, loc. cit. L’inscription de M. Vlpius Phaedimus (CIL VI, $\left.1884=\mathrm{n}^{\circ} 2\right)$ montre toutefois que la pratique pouvait dépasser le cadre théorique tel que nous pouvons le reconstituer. La tombe d'où l'affranchi impérial a été exhumé se trouvait sur un sol provincial, donc considéré seulement comme pro religioso. Pourtant, même si elle se trouvait hors de Rome et de l'Italie, on a jugé bon de demander l'autorisation au collège pontifical qui, en sus, a prescrit une expiation. Il n'est pas impossible que la destination de la dépouille (Rome) ait influencé la décision des prêtres, mais nous sommes plus ici dans le domaine de la spéculation.

${ }^{178}$ CIL VI, 20863 ( ${ }^{\circ}$ 6) : isdem corporibus tralatis perm(issu) trib(unorum) pl(ebis).

${ }^{179}$ Mommsen 1889-1896, III, p. 329.

${ }^{180}$ Kübler 1903, p. 58-59. 
nécessairement un transfert. La permission pourrait être de celles dont parle le rescrit de Marc-Aurèle, et les tribuns de la plèbe compter au nombre de ceux quibus ius permittendi est ${ }^{181}$.

Quelques mots de conclusion. La documentation étudiée ici n'est pas nouvelle, pas plus, sans doute, que la plupart des hypothèses que nous avons avancées. Mais l'une des intentions de cette étude était de mettre en perspective les documents afin de souligner la spécificité de chacun d'entre eux. Non seulement ils appartiennent à des moments différents, mais aussi à des discours ou à des pratiques qui, bien que présentant des relations, n'en suivent pas moins leurs logiques propres. On risque de passer à côté de beaucoup de choses en cherchant systématiquement à avoir recours à des idées clefs (la « souillure » ou la « peur des morts malfaisants ») qui seraient le fondement (logique [176] ou chronologique) des rites ou du droit en matière de transfert des corps.

La vision que nous en avons reste, malgré tout, fragmentaire. Pour les juristes, le rapatriement d'un défunt n'est finalement qu'une variante du transport qui conduit un mort au tombeau. Il nécessite simplement une autorisation, délivrée par les pouvoirs compétents qui peuvent varier selon les lieux. L'important est d'une part que ces transports ne donnent pas lieu à des troubles de l'ordre public ou ne soient pas l'occasion de l'humiliation de l'entourage du défunt et, d'autre part, qu'ils aboutissent à la constitution d'un locus religiosus qui ne sera pas remis en cause. Pour la jurisprudence classique, en cas de nécessité, le transfert d'une sépulture à une autre semble avoir été toléré, même pour une sépulture définitive (perpetua sepultura), mais, cette fois encore, sur autorisation. À Rome, il y avait alors intervention du collège pontifical qui devait sans doute rechercher si l'acte était accompli salua religione. Dans les provinces, c'étaient les gouverneurs qui assumaient l'ensemble de ces tâches. Lors de transfert d'une sépulture à une autre, à Rome et dans les territoires où les normes romaines étaient en vigueur, on exécutait une expiation qui était réclamée moins par la souillure véhiculée par le cadavre que par la destruction d'un bien qui appartenait en propre à des divinités, les Mânes. Sur ce point, la religion et le droit civil se recoupent, ou plutôt le second reprend et confirme la première : une tombe n'appartient pas aux vivants. De fait, nous avons constaté que le scrupule religieux dépassait parfois le cadre dessiné par les prescriptions juridiques - du moins tel que nous pouvons le reconstituer. La jurisprudence classique, sans ignorer les exigences de la religion, produit un discours autonome qui, à cet égard, paraît s'infléchir à partir de la fin du $\mathrm{III}^{\mathrm{e}} \mathrm{s}$. de n. è., laissant transparaître une insistance plus notable sur les motifs religieux et, en tout cas, sur l'idée de souillure et de pollution.

Le problème qui se pose en définitive pour nous est bel et bien celui de la pratique que nous n'appréhendons qu'à travers des sources possédant leur logique et leur histoire particulières. Il en va de même pour les épitaphes qui, bien que laissant timidement

${ }^{181}$ D., 47, 12, 3, 4 (supra, p. 8). J. Scheid me suggère que l'on pourrait également développer $\operatorname{tr}($ ibunus) pl(ebis), et que la décision aurait pu avoir été prise dans le cadre d'une région de Rome admistrée alors par un tribun, selon les habitudes de l'Empire. On notera que nous possédons une autre inscription funéraire de Rome, dont le texte se termine par la formule : in hoc monumento siue sepul(cro) corp(us) per aedil(es) inferri licebit (CIL VI, 12389 ; ILS 8388). Le cas est ici différent, car il s'agit non pas d'un transfert, mais d'un contrôle des personnes admises à partager la tombe qui est soumis aux édiles (Voir Kaser 1978, p. 88, n. 333 ; contra Van Haeperen 2002, p. 323). 
MEFRA $119 / 1-2007$, p. 149-188

entrevoir les conduites des individus, possèdent une portée limitée pour reconstruire les modalités précises de la translatio corporum. Mais si l'on dépasse ce seul aspect documentaire, questionnant l'usage épigraphique, elles peuvent nous suggérer toute autre chose. La mention de ces précisions sur un texte funéraire lui donne une dimension qui n'est pas seulement commémorative: elle certifie à la communauté que l'auteur du transfert a agi dans la légalité la plus complète, face au droit et face aux dieux. On mesure alors la différence avec les autres épitaphes romaines qui avaient pour seule fonction de marquer la tombe ou conservaient une mémoire élogieuse du défunt et, tout simplement, la distance avec nos pierres tombales modernes. 


\section{Appendice épigraphique}

Il a semblé commode de réunir ici les attestations épigraphiques de transport ou de transfert de corps. Toutefois, il n'était pas question de donner une nouvelle édition de ces textes. J'ai cherché à fournir les indications, forcément partielles, qui étaient les plus utiles pour la lecture du propos principal. En outre, j'ai préféré exclure les textes signalant un décès à l'étranger, mais ne mentionnant pas explicitement un transport ou la présence de la dépouille sur le lieu de découverte de l'épitaphe. Dans ces cas en effet, il peut parfois s'agir de cénotaphes, sans que nous puissions le déterminer avec certitude à partir de la seule inscription. Enfin, il est possible que des inscriptions aient échappé à mes investigations. Les textes sont classés dans l'ordre géographique adopté par l'Année épigraphique.

1. CIL VI, 1884 ; ILS 1792 ; Walser 1993, n 13, p. 48 sq. (Photographie) ; Negroni 2001, p. 175 (avec l'essentiel de la bibliographie antérieure) ; Constant 2001. Conservée au musée du Vatican. Rome. L’inscription apparaissait sur deux plaques identiques qui semblent avoir appartenu à une base. Un troisième fragment est connu (cf. CIL).

M(arco) Vlpio Aug(usti) lib(erto) Phaedimo, / diui Traiani Aug(usti) a potione / item a laguna et tricliniarch(ae), / lictori proximo et a comment(ariis) / beneficiorum, uixit ann(os) XXVIII; / abscessit Selinunte pri(die) idus Augus(tas) / Nigro et Aproniano co(n)s(ulibus), / reliquiae treiectae (!) eius / III nonas Febr(uarias) ex permissu / collegii pontific(um) piaculo facto / Catullino et Apro co(n)s(ulibus) ; / dulcissimae memoriae eius / Valens Aug(usti) lib(ertus) Phaedimianus / a ueste ben(e) mer(enti) fecit.

Le personnage est mort le 12 août 117 et son corps fut rapatrié le 2 février 130. On rappellera que Trajan est également mort à Sélinonte en Cilicie, peu avant le 13 août 117 selon l'Histoire Auguste (Vit. Hadr., 4, 7 ; cf. CAS. Dio., 68, 33). Le cursus a été étudié par P. R. C. Weaver (1972) et, plus récemment, par M.-L. Constant (2001). Cette dernière met à juste titre l'accent sur l'ascension rapide du personnage dont témoigne la fonction de lictor proximus. Il est donc vraisemblable qu'il ait été un proche et un homme de confiance de Trajan, comme le montrent par ailleurs les fonctions précédentes d'a potione, a laguna et de tricliniarque. Elle conclut que l'affranchi a pu disparaître avec ou peu après son ancien maître, dont la mort et ses circonstances sont mal élucidées.

Le dédicant du texte est connu par une autre inscription de Rome, tout à fait semblable à celle-ci (CIL VI, 8550 ; ILS 1756). Valens était manifestement, comme le trahit son onomastique, un esclave uicarius de Phaedimus, revenu à Trajan après la mort de son maître et affranchi par lui (Weaver 1972, p. 217).

2. CIL VI, 2120 (= 32398a); ILS $8380 ; F I R A^{2}$, III, 85. Plaque de marbre avec de petites lettres et de lecture difficile, trouvée à Rome. Conservée aujourd'hui au Museo Nazionale Romano.

Velius Fidus Iubentio Celso col/legae suo salutem. Desideri fra/ter, Arri(i) Alphii Arriae Fadillae, domi/ni n(ostri) imp(eratoris) Antonini Aug(usti) matris, liberti / libellum tibi misi, cogniti mihi ex / longo tempore primae iubentutis (!). / Etiam miratus, cum ab aedibus es/sem, quot eo lo $<$ co $>$ se contulisset, a quo / didici causa se requitionis (!) set et relligionis magnope $<$ re $>$ a domino n(ostro) imp(eratore) / impetrasse. Ita, ne qua mora uidea/tur ei per nos fieri, libellum subscrip/tum per eudem (!) publicum sine mora / mihi remittas. Opto te saluon (!) et fel $/ i$ cem es $<s e>$. / 
Exe $(m)$ plu(m) libelli dati. /

Cum ante hos dies coingem et filium ami/serim et pressus necessitate corpora eorum / fictili sarcofago commendauerim, doni/qu'e' (!) is locus, quem emeram, aedificaretur ui/a Flaminia inter miliar(ia) II et III euntibus a/b urbe parte laeua custodia monumenti / Fla(uia) Thumeles, maesolae 'o' M(arci) S[i]li(i) Orcili : / rogo, domin(e), permittas mihi in eodem lo/co in marmoreo sarcofago, quem mihi mo/do comparaui, ea corpora colligere, ut cuan/done ego esse desier(o), pariter cum eis ponar. /

[D Jecretum : fieri placet. Iubentius Celsus / promagister subscripsi III nonas No $<u>$ emb(res) /Antio Pollione et Opimiano ko(n)s(ulibus) ordinar $[i] s, /[S]$ euero et Sabiniano co(n)s(ulibus).

1. 9 : se pour ipsum ; 1.10 : il faut comprendre, comme Mommsen l'a vu : miratus, cum ab aedibus meis abessem, Alphium me persecutum ad eundem locum se contulisse, ab eo didici ipsum ob causam requietionis, sed et religionis magnopere domino impetrare quid uelle. On retiendra toutefois l'interprétation de l'infinitif parfait proposée par V. Arangio Ruiz qui lui donne une valeur de conatu. 1.14 : febcem sur la pierre ; 1. 27 : fecretum sur la pierre ; 1.29 : ordinalis sur la pierre ; cevero sur la pierre.

Velius Fidius est sans doute à identifier avec D. Velius Fidus, légat d'Auguste propréteur mentionné sur une inscription du temple de Zeus Héliopolitain en Syrie (CIL III, 14387e), et consul en 148 (Camodeca 1996, p. 236 ; cf. PIR V, 225). P. Iuuentius Celsus fut consul ordinaire en $164\left(P I R^{2}, \mathrm{I}, 881\right)$. Il faut probablement comprendre Desideri comme un signum plutôt que, comme le pensait Mommsen, un qualificatif de libellum et qui aurait la signification de libellus supplex (cf. cependant le décret des décurions de Ferentinum AE 1982, 307 = SupplIt, I, 5 : libellum desideri sui). La subscriptio date du 3 novembre 155, et fournit un terminus post quem pour l'inscription.

Le texte de cette épitaphe au latin tortueux se divise en trois parties : d'une part, la reproduction de la lettre de recommandation de Velius Fidus, membre du collège pontifical, au promagister du même collège, P. Iuuentius Celsus. Cette lettre expose le contexte de la demande de l'affranchi Arrius Alphius, ainsi que les liens unissant les deux personages. Elle renforce sans la répéter la seconde partie reproduisant le libelle du dit affranchi, qui expose les motifs de sa demande (1. 16-23), puis formule sa requête (introduite comme il se doit par le verbe rogo), adressée à l'empereur. La subscriptio sous forme de décret et suivie de la datation constitue la dernière partie du texte.

Au-delà de son intérêt documentaire évident, cette inscription pose quelques problèmes, dont celui du contexte originel n'est pas le moindre. Ce texte est en effet connu depuis le $\mathrm{XVI}^{\mathrm{e}}$ siècle, mais on ignore le lieu de sa découverte (voir les notices du CIL, ainsi que Magister 1998, p. 176). La mention conjointe des consuls ordinaires et des consuls suffects pour la datation donne à ce texte une allure très officielle. On pourrait songer à la copie sur marbre d'un décret ou d'archives du collège pontifical. Ce texte rappelle également, mutatis mutandis, une plaque de marbre découverte à la fin du XIX ${ }^{\mathrm{e}}$ s. via Ostiense (CIL VI, 22840 ; Bruns 1909-1912, p. 331, n 140) : elle transcrit la requête d'un colon travaillant sur les fonds dont le revenu est affecté par Antonin et Marc-Aurèle au moment de la mort des deux Faustines à l'éducation de jeunes filles de la plèbe romaine. Ce colon s'adresse aux responsables du collège chargé de la gestion du domaine afin d'obtenir pour son monument funéraire un droit de passage et une parcelle de terrain. La requête est 
reproduite sur la pierre, ainsi que les recommandations adressées par les quinquennales aux questeurs et scribes du collège pour veiller à ce que Geminius Eutyches respecte ses engagements. On ignore également la localisation originelle de ce texte, mais le contexte funéraire est possible. De la même façon, le texte découvert à Terracine $(C I L \mathrm{X}, 8259$; infra, $\mathrm{n}^{\circ} 21$ ) et qui débute très probablement par une dédicace aux dieux Mânes montre que ce genre de décret se rencontrait à l'occasion sur des monuments funéraires. Il est donc possible que cela ait été également le cas pour l'inscription d'Arrius Alphius, qui pouvait se trouver sur le tombeau mentionné dans le libelle.

La question qui se pose alors est de savoir pourquoi ces décrets, dont la gravure devait par ailleurs être relativement coûteuse, ont été consignés sur la pierre. Le procédé se retrouve, quoique le texte soit plus concis, dans les inscriptions qui se contentent d'attester que les travaux effectués ont été faits après permission des pontifes (cf. supra). L'inscription funéraire joue alors le rôle d'une sorte d'attestation que tout a été accompli en bonne et due forme dans le respect de la loi et de la religio, sans pour autant que l'on sache si la gravure était exigée par les autorités ayant donné l'autorisation. Dans le cas de l'inscription d'Arrius Alphius, il est toutefois possible de proposer une seconde interprétation, qui n'est d'ailleurs pas exclusive de celle qui voudrait que nous ayons affaire, en somme, à l'équivalent de la formule permissu pontificum en (bien) plus développé. En effet, en admettant que ce texte se trouvait sur un monument funéraire, il a pu contribuer à rehausser la figure de cet affranchi de la mère d'Antonin le Pieux en affichant ses relations avec quelques grands du monde. Nous avons relevé en effet que Velius Fidus, déjà consul une fois en 155, insiste sur ses liens anciens avec l'auteur de la requête. La citation de cette lettre de recommandation pouvait être, un peu comme dans le cas du marbre de Thorigny (Pflaum 1948, notamment p. 30 sq.), un moyen de faire valoir ses relations et d'afficher sa position sociale. Tout cela cependant reste hypothétique, faute de précisions et de parallèles explicites.

3. CIL VI, 2464 ; ILS 2089. Provient de Rome. Sarcophage en marbre selon le CIL.

D(is) M(anibus). / C(aio) Cesennio Se/necioni, c(enturioni) c(o)hor(tis) II / pr(aetoriae) p(iae) u(indicis), exercitatori equitum pr(aetoriorum); fecit C(aius) Ce/sernius Zonysius liue/rtus (!) et heres, atfer/ente Zotico a Brittania (!).

Ce centurion est peut-être mort lors de l'expédition de 209 menée par SeptimeSévère en Bretagne. L'identification proposée prudemment par $H$. Dessau avec un centurion de la $\mathrm{V}^{\mathrm{e}}$ cohorte des vigiles nommé Caesernius Senecio et apparaissant sur une inscription datée de 205 (CIL VI, 1057, 1) n'est pas totalement certaine. Le corps du défunt a été rapatrié par les soins d'un Zoticus qui devait être son esclave, tandis que le monument a été érigé à Rome par son affranchi et héritier. L'inscription, en tout cas, peut être datée de l'époque sévérienne en raison du surnom porté par la cohorte.

4. CIL VI, 2938; CLE 1099. Rome.

Sex(to) Naeuio / L(ucii) f(ilio) Pub(lilia) / Verecundo, sign(ifero) / coh(ortis) XIIII, nato / Veronae; ossa relata domum, / cinis hic adoperta / quiescit. Heredes / titulum uersiculos / Cornelius epoi / conlegae et amico. 
Comme l'indique le texte et comme le confirme la tribu Poblilia, ce soldat de la $14^{\text {ème }}$ cohorte urbaine était originaire de Vérone, où ses restes, ou plutôt une partie d'entre eux, furent rapportés après son décès. La distinction entre les ossements, transférés, et les cendres, restées à Rome, est peu banale. On retrouve quelque chose du même genre dans un autre texte de Rome (CIL VI, 24792; cf. CLE 1062). Tandis que le corps aura été incinéré sur le lieu de sa mort, quelques ossements auront été prélevés pour être conduits dans sa patrie natale. Il n'est pas impossible de rapprocher cette curieuse mention de la pratique de l'ossilegium, attestée notamment par Varron (LL, 5, 23) et Plutarque (Quaest. Rom., 14). La question qui se pose alors est de savoir lequel de ces deux lieux de sépulture fut considéré comme abritant le véritable tombeau du soldat (cf. Paul, D., 11, 7, 4).

La fin du texte de l'épitaphe ne va pas sans poser de problème. Il s'achève sur un distique élégiaque. Les lettres EPOI (selon la lecture de Mommsen, les éditeurs précédents ayant lu EROI) sont rien moins que claires. Mommsen proposait d'y lire le surnom de Cornelius. On retiendra l'ingénieuse hypothèse de Fr. Bücheler, qui en fait une transcription du grec : ejpovei (cf. CLE 935, 13). On comprend mal cependant l'usage du pluriel pour heres.

La $14^{\text {ème }}$ cohorte urbaine est en garnison à Rome à partir de l'époque flavienne (Freis 1967, 8 sq.), ce qui fournit un terminus post quem pour la datation de ce texte qui, en raison du formulaire, ne doit pas être postérieur au milieu du $\mathrm{II}^{\mathrm{e}}$ siècle.

5. CIL VI, 8878 ; ILS 1685 ; Sinn 1987, n 638, p. 247 et pl. 94d (avec l'essentiel de la bibliographie antérieure). Urne ronde en marbre, provenant de Rome, conservée au musée de Leyde. L'inscription, à l'exception du sigle DM, est gravée dans une tabula ansata.

D(is) M(anibus). // T(ito) Aelio Aug(usti) lib(erto) Titiano, prox(imo) / a libr(is) sacerdotal(ibus), def(uncto) Carnunt(i) / annis XXXXII m(ensibus) III d(iebus) XIX, marit(o) uirgin(eo) / dulciss(imo) et incomparabili bene/que merito, quem funerauit / Fl(auia) Ampelis coniux carissima / et reliquias eius permissu imp(eratoris) / ipsa pertulit consecrauitque, / cum q(uo) u(ixit) a(nnos) XII m(enses) III d(ies) XXI sine ulla / querella.

Le défunt était un affranchi d'Antonin le Pieux et occupait une fonction importante dans l'administration impériale dont on ignore toutefois la nature exacte. Il appartenait manifestement à l'entourage proche de l'empereur et lui permettait de garder un contrôle sur les archives consignant les prescriptions rituelles (voir Wissowa 1912, p. 497 et $R E, 23$, 1 (1957), s.v., c. 1035 [Enßlin]).

Pour l'usage de funerare, «accomplir les funérailles », cf. par exemple CIL XIV, 2112. L'expression reliquias consecrare est plus inattendue. En général, la consecratio, qui peut être destinée au dieux Mânes, concerne des lieux ou des objets (TLL, s.v., c. 379 sq. ; voir par exemple $C I L$ VI, 12772, ou encore XII, 1657). Toutefois, il est possible d'y voir ici une référence à la consecratio des défunts, c'est-à-dire une forme d'héroïsation post mortem. Il n'en reste pas moins que l'insistance sur les restes est curieuse mais peut s'expliquer par le zeugma quelque peu brutal avec le verbe perferre.

Un faisceau d'indices concordants (nom de l'empereur qui lui a donné sa liberté, décès à Carnuntum, âge au moment du décès) permet de dater cette urne du règne de MarcAurèle. Il est même probable que cet affranchi soit mort lors de la campagne de l'empereur contre les Marcomans, entre 170 et 172 (EUTR., VIII, 6; cf. Weaver 1972, p. 253). 
MEFRA $119 / 1-2007$, p. 149-188

6. CIL VI, 20863 ; ILS 8389. Rome. Plaque de marbre (CIL).

Dis Man[ibus sacr(um)]. / Iuniae L(uci) f(iliae) Cele[rinae matri et auiae?], / Ti(berii duo) Claudii Euschemus et Prim[itiuus], / Claudiae Quiane Euschemus sorori, / Primitiuus matri, / Euschemus consobrinae Samiariae Arethusae;/ isdem corporibus tralatis perm(issu) trib(unorum) pl(ebis) et / Ti(berio) Claudio Epaphrodito tatae bene me(renti) fecer(unt) / et sibi et suis et libertis libertabus posterisque eorum.

1. 2 : les liens de parenté sont une restitution probable de Mommsen.

Comme l'a fait remarquer Mommsen, Quiane est probablement l'équivalent latin de Kuavnh (cf. Solin 2003, p. 601). Tata est un terme affectif désignant normalement le père (" papa »; voir MART., I, 100, 1 et CIL VI, 27258). Cette inscription est la seule attestation de l'autorisation d'un transfert de corps par les tribuns de la plèbe (voir mes remarques, supra). Il est difficile de dater ce texte. H. Solin le situe avec vraisemblance dans les deux premiers siècles de n. è. (Solin 2003, loc. cit.).

7. CIL XIV, 3777 ; InscrIt, IV, 1, 344. Autel de marbre, aujourd'hui incomplet. Provient de Tibur.

Dis manibus. / Herenniae Lampadi, / concubinae / Herenni(i) Postumi, / cuius ossa ex Sardinia / translata sunt.

Datation proposée : fin du I $\mathrm{I}^{\mathrm{er}}-\mathrm{II}^{\mathrm{e}}$ s. de n. è.

8. AE 1972, 74 ; Virno Bugno 1971, p. 691 sq. Emmurée dans le cloître de l'abbaye de Montecassino.

[P(ublius) M]urrius P(ubliorum duorum) l(ibertus) Zetus, / [Pla]centinus mercator / [pur]purarius hic situs est. / [uiator] consiste et casus hominum cogita : / [anno]rum natu $X X X V$ arbitror fuissem [-] / [quom] plurimi fui et florebam maxum [e] / [et ce]cidi longe ab domo et meis amantib[us]. I [P(ublius) M]urrius P(ubliorum duorum) l(ibertus) Eros / [con]libertus et socius uiuus / [hoc] monumentum fecit ossaque / [tran]stulit Placentiam ind [---].

Pour les restitutions, voir dans le détail Virno Bugno 1971. L. 1 et 8, Murrius est possible en raison de l'onomastique locale; 1.4 : hospes convient également pour le mètre iambique ; 1.5 : fuisse me est également possible ; 1.6 ; quom convient mieux que cum pour combler la lacune ; $1.11:$ la fin de la ligne semble entièrement indéchiffrable.

La provenance exacte de cette inscription est inconnue, mais elle fut très probablement découverte sur le territoire d'Aquinum. Il s'agit donc d'un cénotaphe car, comme le dit le texte de l'épitaphe, les ossements du défunt ont été transférés à Plaisance, d'où cet ancien esclave devait être originaire. On notera que, malgré la mention explicite du 
MEFRA 119/1 - 2007, p. 149-188

transfert, l'épitaphe comporte la formule hic situs est. La datation de ce texte est malaisée à établir avec précision.

9. CIL IX, 4881 ; ILS 8390 ; Torelli 1963, p. 245. Trouvée à Frasso Sabino, sur le territoire de l'antique Trebula Mutuesca. Elle a été déplacée à Rome (Torelli).

Egnatiae A(uli) f(iliae) Aul[inae - - -], / flaminicae in colonia C[ - - -] prouinciae Narbone[nsis]; / L(ucio) Caecilio L(uci) f(ilio) Pom(ptina) Long[o, cuius] / corpus pontificum perm[issu ex uetere?] / monimento in hoc tral[atum est]. /Egnatia Aulina mammae s[uae] / et Q(uinto) Vibio Crispi l(iberto) A[- - -].

L. 4 : long[o cuius] Dessau ; 1. 5 : perm[issu ex uetere] Dessau (peut-être un peu long pour la lacune) ; 1.6 : tral[atum est] Dessau (cf. supra, $\mathrm{n}^{\circ} 6$ ).

La restitution du nom de la colonie de Narbonnaise où Egnatia Aulina a exercé sa prêtrise n'est pas assurée. On peut penser à Carpentras (Carpentorate), si la titulature complète est omise. En revanche, avec une titulature entière et abrégée, la seule solution envisageable serait la colonia Octavanorum Pacensis Classica Forum Iulii, où l'arrondi serait en réalité la moitié d'un O. Guardabassi, l'un des premiers éditeurs du texte, avait lu non pas $\mathrm{C}$ mais I : on pourrait alors penser à l'une des nombreuses colonies de Narbonnaise dont la titulature commence par Iulia. Le gentilice Egnatius est assez rare en Narbonnaise : il n'apparaît qu'une fois à Arles (CIL XII, 112), une autre à Avignon (XII, 1037), une fois sur le territoire de Nîmes et deux fois à Narbonne (respectivement XII, 4179; 4468 et 4777 ; cf. $O P E L$, II, p. 114). On ne peut guère tirer de conclusion de tout cela.

C'est de toute façon le corps de Lucius Caecilius Longus, le second défunt, qui a été transporté. Inscrit dans la tribu Pomptina, il n'était vraisemblablement pas originaire de Trebula Mutuesca, qui était plutôt inscrite dans la Sergia (Kubitschek 1889, p. 56). Aucune communauté de la Regio IV n'est inscrite dans la Pomptina : l'origine de cet individu reste donc obscure. En outre, il n'est pas totalement exclu que cette pierre soit errante.

On a identifié le patron de l'affranchi nommé à la dernière ligne à Quintus Vibius Crispus, orateur de renom, connu entre autres par Tacite, mort sous le règne de Domitien (voir PIR, V, 379). La manière dont il apparaît dans la nomenclature de l'affranchi - par le seul cognomen - peut en effet être vue comme un indice de la notoriété du patron et donc aller dans le sens de l'identification. En ce cas, l'inscription serait à dater de la seconde moitié du $\mathrm{I}^{\mathrm{er}}$ s. environ. Ce serait alors la plus ancienne attestation d'une autorisation pontificale pour le déplacement d'un corps.

10. CIL IX, 5860 ; ILS 8234. Auximum (Picenum). Inscription perdue, mais copiée plusieurs fois à la Renaissance.

[H]ic sum posita Aurel[iana, uixi] ann(os) XXVIII, m'e'(nses) II, d(ies) XXVII. Nata in urbe sac[ra], I [pe]regrinata Italiam et [prouincias], debitum reddidi Nicomedia et hic transl[ata] / [ab] dulcissimo mihi coiu[ge Euarist]o Aug(usti) lib(erto). Vt uos, uiatores, legendo sciantis (!), q[ua] / [pi]etate ac castitate cum eo [uiuens tal]i merito hoc meruerim, in hoc sarcophag[o] / [cum] ammissus fuerit Euarist[us dulcissi]mus coniux meus, nemini licere neque aperir[e neq(ue)] / [tr] ansferre neque de con[- - m] unimenti aliquit de marmoribus minus fa[cere ;] / [c]ontra quae si qu[i]t [quis fecerit], dabit fisco 
(denarios) (decem milia), rei p(ublicae) Firmanorum [(denarios) (quinque milia ?)] / [et rei p(ublicae) RJicinensium (denarios) (quinque miliae).

Ce texte pose un certain nombre de problèmes que je ne chercherai pas à résoudre dans cette notice. Il s'agit de l'épitaphe d'une femme née à Rome, désignée par l'expression urbs sacra. Ce qualificatif, sans être très fréquent, se rencontre sur plusieurs autres inscriptions, par exemple sur la partie sévérienne du texte gravé sur l'aqua Marcia (CIL VI, $1245=I L S$ 98, datée entre 212 et 213) et sur quelques autres monuments : on pourra citer une épitaphe en vers de Préneste (CIL XIV, $2852=I L S 3696=$ CLE, 249, datée par mention des consuls de 136) et une autre de Forum Novum (CIL IX, $4796=I L S 7542=$ CLE 437). La défunte a voyagé en Italie et dans les provinces, puis est morte à Nicomédie. Ses restes ont été transférés d'Asie Mineure à Auximum, où elle avait peut-être des attaches familiales.

La place de l'éloge donne à cette épitaphe une tonalité particulière. On soulignera notamment l'expression debitum naturae reddere, qui se retrouve parfois sur des épitaphes chrétiennes (par exemple ILCV 3302 et la note), mais qui est en réalité connue dès le début du I ${ }^{\mathrm{er}}$ s. à Rome (CIL VI, 25617 : debitum reddere seul) et apparaît également sur l'épitaphe d'un centurion ayant reçu les dona militaria de l'empereur Vespasien (CIL VI, 3580= ILS 2641 : debitum naturae persoluit; cf. également, CIL VI, 15696 et 37317, plus tardives).

L'inscription se clôt sur l'interdiction d'ouvrir le sarcophage, de le déplacer ou de détériorer le monument funéraire, le contrevenant s'exposant à verser une amende pécuniaire, au fisc et aux cités voisines de Firmum Picenum ou Ricina. Ce n'est pas le lieu ici de revenir sur le problème controversé des amendes funéraires, de leur fonction et de leur fondement juridique (voir, en général et entre autres, Giorgi 1910, dont il faudrait mettre à jour les listes épigraphiques; De Visscher 1963, p. 113 sq. ; Rossi 1975). On notera ici que les instances destinataires sont multiples (Kaser 1978, p. 83 et Rossi 1975, p. 128 sq. ; cf. par exemple CIL X, 3570 et 3594), et que la cité d'Auximum où, semble-t-il, se trouvait la tombe, n'est cependant pas concernée. D'autres épitaphes montrent néanmoins que ce cas n'est pas isolé, même si la majorité des exemples mentionne une alternative plutôt qu'un redoublement. On explique souvent - quoique de manière peu probante - le décalage entre le lieu où se trouve effectivement le monument funéraire et la cité chargée de percevoir l'amende en supposant que les défunts étaient originaires de cette dernière (Rossi 1975).

La datation de ce texte est assez malaisée et une large fourchette entre le $\mathrm{II}^{\mathrm{e}}$ et le III $^{\mathrm{e}}$ s. semble la plus raisonnable.

11. AE 1992, 813 ; SupplIt, IX, 51, p. 283-294; Gabba - Tibiletti 1960. Ticinum. Sarcophage $(60$ x 211 x $81 \mathrm{~cm})$ conservé dans la cour de l'université de Pavie.

Val(eriae) Vincentiae / coiugi dulcissimae / que (!) uixit annis XXVII dieb(us) XII ; / Fabius Maianus in cuius matrimonio / fuit annis X, m(ensibus) II, d(iebus) XXV, quiusq(ue) (!) corpus / ob merita eius a Treueris at maiorum / sepulcra usque perduxit.

Cette inscription a reçu un commentaire complet dans l'étude d'E. Gabba et de G. Tibiletti. Les auteurs proposent de dater le sarcophage du $\mathrm{IV}^{\mathrm{e}}$ s., essentiellement à partir de critères onomastiques. 
MEFRA $119 / 1-2007$, p. 149-188

12. CIL XII, 118 ; IL Alpes Grées, 36. Aime en Tarentaise. Sarcophage en marbre $(84 \times 128 \times 26 \mathrm{~cm})$. L'inscription est gravée dans un cadre mouluré. Au-dessus, deux bustes dans des niches et une troisième, au centre, laissée vide.

D(is) M(anibus) / L(ucii) Exomni(i) Macrini, Rustici fili(i), hic Bri/gantione geniti, annorum XVI in studis / ualle Poenina uita functi ; reliquis eius / [huc] delatis Nigria Marca mater fili[o] / [kar]issimo et sibi uiua faciendum / curauit (hedera).

Cette épitaphe pose quelques problèmes (notamment la localisation du Brigantio nommé dans le texte) que je n'examinerai pas ici. Principalement sur des critères de formulaire et de typologie monumentale, l'inscription pourrait être datée de la seconde moitié du $\mathrm{II}^{\mathrm{e}}$ s., voire du début du III .

13. CIL XII, 155. Trouvée à Saint-Maurice. Perdue.

D(is) M(anibus) / Antoni(i) Vecetini Rome (!) delfuncti qui uixit annos XXV / menses III dies XXIIII. Antonius / Severus pater infelix corpus eius deportatum hic condidit.

Le verbe deportare signifie ici « rapporter chez soi ». Il est probable que nous ayons affaire à un étudiant mort en cours d'études à Rome. Le texte, en l'absence de tout critère décisif, est difficile à dater : la seconde moitié du $\mathrm{II}^{\mathrm{e}}$ s., voire le $\mathrm{III}^{\mathrm{e}} \mathrm{s}$., notamment en raison de l'absence de praenomen dans la nomenclature du défunt, conviennent le mieux.

14. CIL XIII, 2181 ; AD II, 146 ; ILS 8098. Grand bloc qui appartenait à un mausolée. L'inscription est gravée dans un cadre mouluré.

D(is) M(anibus) / Iuliae Heliadis / Sex(ti) Iuli(i) Callisti / et Iuliae Nices filliae, flaminic(ae) Aug(ustae), / quae uixit annis / XXV mensibus II. / Iuliae Heliane et / Callistate corpus / sororis anima sua / sibi carioris ab / Vrbe adferri / curauerunt et / sarcophago in/tra maesolum (!) / condiderunt.

Les motifs de la présence de cette flaminique lyonnaise à Rome restent obscurs. Elle était la fille d'un sévir augustal de Lyon mentionné sur une autre inscription très semblable à celle-ci (CIL XIII, 1956). Le formulaire funéraire suggère une datation dans les deux premiers tiers du $\mathrm{II}^{\mathrm{e}} \mathrm{s}$. de $\mathrm{n}$. è.

15. CIL III, 1312 ; ILS 1593 ; IDR III/3, 366. Ampelum.

D(is) m(anibus). / M(arco) Vlpio Aug(usti) / lib(erto) / Hermiae proc(uratori) / aurariarum, cuius / reliquiae ex indulgentia / Aug(usti) n(ostri) Romam latae sunt ; / Salonia Palestrice / coniunx et Diogenes /lib(ertus) benemerenti fecer(unt). / Vixit ann(is) LV.

Le défunt, affranchi de Trajan, avait la charge de l'administration des mines d'or d'Alburnus Maior, en Dacie. Cette fonction, relativement élevée, sera par la suite confiée à un procurateur de rang équestre. Cette épitaphe appartenait à un cénotaphe, car elle fut 
MEFRA $119 / 1-2007$, p. 149-188

trouvée non loin de Zlatna (Ampelum), tandis que le texte nous apprend explicitement que le corps a été transféré à Rome.

On ignore bien sûr la date et l'âge de l'affranchissement de Marcus Vlpius Hermias, mais on peut situer avec vraisemblance cette épitaphe aux alentours des années 120-140 de n. è.

16. CIL VIII, 12128 (=702); ILS 2380 ; ILTun, 582 ; CLE 522 ; Pikhaus 1994, B102. Chusira (El Kessra), en Byzacène. Plaque $(52$ x 210 x 6,5).

Iulius Ingenus obi(i)t in Gallia morte. / Coniunx patriae gremio mandat Virula corpus. / Germaniae meruit specula[t]or et cornicul[ar]ius / legionis ; initium uitis uitae fuit finis.

Le mètre employé est l'hexamètre dactylique, mais les vers sont fautifs. Sa carrière d'officier aura conduit cet Africain en Germanie puis en Gaule où il est mort, peu après avoir accédé au centurionat (ayant acquis la uitis, baguette de commandement). Le rapatriement du corps est explicite. L'épitaphe est malaisée à dater. Certains éditeurs ou commentateurs ont proposé le III ${ }^{\mathrm{e}}$ siècle.

17. CIL VIII, 152 ; ILTun, 297 ; CLE, 516 ; Pikhaus 1994, B 17. Trouvée à Sommet el Amra, au nord de Capsa (Afrique proconsulaire), sur les murs d'un mausolée.

Vrbanilla mihi coniunx uerecundia plena hic sita est, / Romae comes negotiorum, socia parcimonio (!) fulta ; / Bene gestis omnibus cum in patria (!) mecum rediret / Au ! miseram Carthago mihi eripuit sociam, / Nulla spes uiuendi mihi sine coniuge tali ; / Illa domum seruare meam, illa et consilio iuuare, / Luce priuata misera quescit (!) in marmore clusa. / Lucius ego coniunx hic te marmore texi, / Anc (!) nobis sorte(m) dedit fatu(m) cum luci daremur.

L. 2 : parcimonio Merlin : parsimonio Willmanns, Bücheler. Les initiales des vers forment un acrostiche au nom d'Vrbanilla. Ce jeu poétique explique l'orthographe de hanc à la dernière ligne. Les vers sont des hexamètres dactyliques.

Ce texte ne mentionne pas explicitement le transport de la dépouille de la défunte. Mais le poème funéraire dit qu'elle est morte à Carthage, probablement à son retour de Rome où elle s'était rendue pour affaires, et qu'elle a reçu une sépulture dans le mausolée construit à Sommet el Amra. La formule hic sita est va dans ce sens (cf. cependant notre $\left.\mathrm{n}^{\circ} 20\right)$. G. Willmanns date ce texte de la fin du $\mathrm{II}^{\mathrm{e}}$ ou du début du $\mathrm{III}^{\mathrm{e}}$ s. en raison de la paléographie, mais ce critère n'est pas contraignant.

18. ILAlg, I, 1363 ; ILS 7742a ; Merlin 1903, p. 118-119. Provient de Khamissa (Thubursicum Numidarum, Afrique proconsulaire). Cippe ou autel funéraire. L'inscription est gravée dans un cadre mouluré non saillant, surmonté d'une guirlande en relief.

Heracli. / D(is) M(anibus) s(acrum). / L(ucius) Vetidius / Maternus / Vetidianus, / eques Rom(anus), / Q(uinti) Vetidi(i) Iuuena/lis quinquen/nalici filius, / utraq(ue) lingua / eruditus, p(ius) u(ixit) a(nnos) XVIII / m(enses) IIII d(ies) XXVIII, per/missu praesidis a / Karthagine de stu/dio relatis reliquiis, / h(ic) s(itus) e(st). 
Le monument fut retrouvé avec cinq autres épitaphes appartenant à des membres de la même famille (Merlin 1903). Comme son père mentionné dans ce texte et son frère aîné, L. Vetidius Maternus est désigné par son signum, Heraclius, au début de l'inscription. La famille des Vetidii est connue par un certain nombre d'attestations épigraphiques dans la région qui permettent de suivre son ascension sociale sur cinq générations.

Le trajet entre Carthage et Thubursicum Numidarum était assez considérable : environ $800 \mathrm{~km}$ par voie de terre. Pour un autre étudiant mort à Carthage en cours d'études, voir CIL VIII, 12152. La date est difficile à déterminer $\left(\right.$ II $^{\mathrm{e}}-\mathrm{III}^{\mathrm{e}}$ s.).

19. CIL VIII, 2772. Bloc ayant peut-être fait partie d'un autel $(120 \times 62 \mathrm{~cm})$ et provenant de Lambèse, dans une "ruine byzantine sur la rive droite de l'oued Cheb » (Renier).

D(is) M(anibus) s(acrum). / Flauiae Iuli/osae coniugi ; / uix(it) an(nos) XXVII. / M(arcus) Seruilius For/tunatus a militi(i)s / qui per maria et ter/ras retulit reliquias / coniugis ex prouinci/a Dacia.

Voir CIL VIII, 2973, où le dédicant est l'auteur d'une épitaphe destinée à son frère, Marcus Seruilius Rusticus, librarius de la légion III Auguste. Les deux monuments ont été découverts au même endroit, ce qui semble confirmer l'identification des deux individus homonymes. M. Seruilius Fortunatus était chevalier romain et il avait accompli les trois milices équestres.

On peut se demander pourquoi son épouse est morte en Dacie : peut-être son mari avait-il été conduit à y exercer un commandement. Originaire de Lambèse, il y aurait fait rapatrier sa femme défunte. L'inscription est datée par J.-M. Lassère (1973, p. 134) de l'époque sévérienne. Elle repose sur l'identification du dédicant avec celui de CIL VIII, 2973, où la légion porte les surnoms pia et uindex qui lui furent attribués sous SeptimeSévère. Cette hypothèse est confirmée par l'usage du syntagme a militiis pour désigner le service militaire équestre.

20. ILAlg, II ${ }^{3}, 9109$; $A E$ 1957, 249. Voir Pflaum 1955 (1878). Castellum Arsacalitanum (Numidie).

D(is) M(anibus). / M(arcus) Iul(ius) C(aii) f(ilius) Quir(ina tribu) / Quadratus, / eq(uo) pub(lico), in (quinque) / dec(urias) allecto, / (centurio) leg(ionis) XIII Gem(inae) / in Dacia, / (centurio) leg(ionis) III Aug(ustae) in Afr(ica), / (centurio) leg(ionis) II Aug(ustae) Britta(niae), / def(uncto) Brittaniae (!) / in procinctu ; / u(ixit) a(nnos) XXXVIII. / h(ic) s(itus) e(st).

Ce centurion est mort «sur le front» ou « en première ligne », selon la traduction proposée par H.-G. Pflaum (auquel on se reportera pour un commentaire plus détaillé sur la carrière de ce soldat). Il n'y a pas, dans ce texte, de mention explicite de transfert du corps, mais l'expression $h(i c) s$ (itus) e(st) qui conclut l'épitaphe laisse entendre que Marcus Iulius Quadratus a reçu une sépulture en Afrique (mais voir supra, ${ }^{\circ} 8$ ). 
MEFRA $119 / 1-2007$, p. $149-188$

[21.] CIL X, 8259 ; ILS 8381 ; FIRA ${ }^{2}$, I, 63. Cf. De la Blanchère 1880 ; Mommsen 1881. Trouvée à La Valle, au nord-ouest de Terracine. L'inscription était gravée sur deux piliers monolithes, dressés sur le bord du chemin, peut-être les montants de l'entrée d'un enclos funéraire. Le texte est d'une lecture très difficile.

[D(is)] M(anibus) [s(acrum). / c]ollegi/[u]m pon[ti/fi]cum de/creuit : [si ela ita] sunt que (!) libel(l)o / [c]ontene/ntur, pla/cere per/[ge]re puel(l)a(m) / [de] q(ua) agatu/[r s]acelo (!) // [eximere / et i]ter/[um ex] pra/[escr]ipto / [d]eponer/e et script/uram titu/li at prist/inam for/mam rest/ituere, pia/culo prius / dato operi/s faciend/i oue atra.

L. 8 : pergere Tromp 1921, p. 90 : Mommsen avait proposé permittere, en étant conscient que le verbe était trop long et supposait une omission du lapicide.

Cette inscription fait plus vraisemblablement allusion à la restauration d'un monument funéraire qu'au transfert d'un corps, comme l'avait suggéré Th. Mommsen implicitement au Corpus et comme cela fut souvent repris par la suite (voir, en revanche, Van Haeperen 2002, p. 315).

On notera que sacellum dans un sens funéraire est extrêmement rare, et même sans parallèle épigraphique ou littéraire. Le mot peut désigner un lieu de culte public ou privé, mais n'est guère attesté pour les Mânes. On estime que ce terme renvoie en général à une chapelle (Wissowa 1912, p. 469 n. 1, à partir notamment de la notice de Don., Ad Ter. Ad., 576 ; cf. Dubourdieu - Scheid 2000, p. 77), mais A. Fridh (1990) préfère revenir à la définition donnée par Festus (422, 15 L. : loca dis sacrata sine tecto) qui, selon lui, conviendrait mieux aux réalités désignées par ce mot. Le même auteur note par ailleurs que ce mot semble disparaître de l'usage - au moins littéraire - après le $\mathrm{I}^{\mathrm{er}} \mathrm{s}$. Si la restitution de Mommsen n'est pas entièrement satisfaisante, on voit mal cependant quelle autre proposition pourrait être adoptée.

R. de la Blanchère (1880) propose de dater ce texte du III $^{\mathrm{e}} \mathrm{s}$. en raison essentiellement de la paléographie. Néanmoins, cet argument, à lui seul, ne saurait être décisif, et on restera prudent sur la datation ${ }^{182}$.

${ }^{182}$ J'ai exclu de ce catalogue deux textes qui auraient pu être rattachés, par la mention des pontifes, au transfert de sépulture. Il s'agit de deux inscriptions fragmentaires de Rome, qui posent des problèmes de restitutions auxquels on n'a proposé aucune solution satisfaisante. La première est une inscription vue au XIX $^{\mathrm{e}}$ siècle, et perdue depuis (CIL VI, 30578 ; Geraci 1975, $\mathrm{n}^{\circ}$ 78) où l'on a lu : [- - - ex here]ditate Carfa / [- - de]creto pontif(icum) / [ - - ] a ad duas (hedera) / [- - libertis li]bertabusque / [posterisque e]orum. On ignore la taille de la lacune à gauche, et Mommsen a suggéré [translat]a ad duas / [sorores]. Toutefois, les compétences des pontifes ne se limitaient pas à cette seule autorisation, comme le fait remarquer G. Geraci (1975, p. 123), et d'autres solutions sont possibles. Le second texte ( $A E$ 1926, 48), republié récemment par Cr. Lo Giudice (Libitina 2004, p. 253-255, n 85 et p. 280, notamment n. 368), est plus long, mais tout aussi mal conservé pour la partie qui nous intéresse. La 1. 4 contient la séquence ---Jntificum, dont la restitution la plus vraisemblable est en effet [permissu po]ntificum (decreto, proposé par le premier éditeur, P. Mingazzini, est plus rare). L'hypothèse d'un transfert est séduisante, mais je n'ai pu trouver aucune restitution satisfaisante du texte, tenant compte de la longueur des lacunes. Il paraît plus difficile de penser à une restauration de monument, dans la mesure où on lit, sans équivoque, à la 1. 6, ce qui doit probablement être complété [mea pecu]nia feci. Je dois avouer ne pas être convaincu par la proposition de la dernière éditrice, et plus particulièrement par la restitution [et permissu po]ntificum [a fundamentis] / [sepulcrum siue m] unimentum [cum ustrina], etc. Nous n'avons en effet aucune attestation explicite du contrôle des pontifes dans l'installation d'ustrina, qui était d'ailleurs plutôt du ressort du droit civil (voir supra, la lex Vrsonensis et les remarques que nous avons faites à ce propos) et aucun élément du texte conservé n'autorise cette restitution. 
MEFRA $119 / 1$ - 2007, p. 149-188

Faute de pouvoir examiner de nouveau la pierre, qui est perdue, on se gardera donc de formuler une conclusion sur cette inscription. 


\section{Références bibliographiques}

AD : A. Allmer, P. Dissard, Inscriptions antiques du musée de Lyon, 5 vol., Lyon, 18881893.

Allara 1995 : A. Allara, Corpus et cadauer. La " gestion » d'un nouveau corps, dans Hinard 1995, p. 69-79.

Ando - Rüpke 2006 : C. Ando, J. Rüpke (dir.), Religion and Law in classical and Christian Rome, Stuttgart, 2006 (Postdamer Altertumswissenschaftliche Beiträge, 15).

Belayche 1995 : N. Belayche, La neuvaine funéraire à Rome ou "la mort impossible », dans Hinard 1995, p. 155-169.

Benveniste 1960 : É. Benveniste, Profanus et profanare, Hommages à G. Dumézil, Bruxelles, 1960 (coll. Latomus, 45), p. 46-53.

Berrens 2004 : St. Berrens, Sonnenkult und Kaisertum von den Severen bis zu Constantin I (193-337 n. Chr.), Stuttgart, 2004 (Historia Einzelschriften 185).

Bodel 1986 [1994] : J. Bodel, Graveyards and groves. A study of the lex Lucerina, Cambridge, Mass., 1994 (AJAH, 11, 1986).

Bouché-Leclercq 1871 : A. Bouché-Leclercq, Les pontifes de l'ancienne Rome, Paris, 1871.

Boyancé 1952 [1972] : P. Boyancé, Funus acerbum, REA, 54, 1952, p. 275-289 [repr. dans Études sur la religion romaine, Rome, 1972, p. 73-89 (Coll. EFR, 11)].

Broise - Scheid 1993 : H. Broise, J. Scheid, Étude d'un cas : le lucus de Dea Dia à Rome, dans Les bois sacrés (Actes du coll. intern. de Naples), Naples, 1993 (Coll. du centre J. Bérard, 10), p. 145-157.

Bruns 1909-1912 : C. G. Bruns (éd.), Fontes iuris Romani antiqui, Tübingen, 1909-1912 ( $7^{\mathrm{e}}$ éd.).

Camodeca 1996 : G. Camodeca, Una nuova coppia di consoli nel 148 e il proconsul Achaiae M. Calpurnius Longus, ZPE, 112, 1996, p. 235-240.

Camodeca 2004 : G. CAMOdECA, Per la riedizione delle leges libitinariae flegree, dans Libitina 2004, p. 83-104.

Casavola 1958 : F. Casavola, Studi sulle azioni popolari romane, Naples, 1958.

Castagnetti 2004 : S. Castagnetti, La lex Cumana libitinaria nelle sue due redazioni, dans Libitina 2004, p. 133-146. 
MEFRA $119 / 1-2007$, p. 149-188

CLE : Fr. Bücheler (éd.), Anthologia Latina siue poesis Latinae supplementum. II : Carmina Latina epigraphica, Leipzig, 1895-1897.

Constant 2001 : M.-L. Constant, Commentaires et conjectures sur la carrière et la mort d'un affranchi de Trajan: Marcus Ulpius Phaedimus, Cahiers des études anciennes, 37, 2001, p. 65-74.

Cracco Ruggini 1995 : L. Cracco Ruggini, Les morts qui voyagent : le rapatriement, l'exil, la glorification, dans Hinard 1995, p. 117-134.

Cumont 1910 : Fr. Cumont, Sol, dans Ch. Daremberg, Ed. Saglio (dir.), Dictionnaire des antiquités grecques et romaines, Paris, 1877-1919, vol. 5 (1910) s.v., p. 1381-1386.

Cumont 1930 : Fr. Cumont, Un rescrit impérial sur la violation de sépultures, Revue Historique, 163, 1930, p. 241-266.

Cumont 1942 : Fr. Cumont, Cierges et lampes sur les tombeaux, dans Miscellanea G. Mercati, V. Storia ecclesiastica-diritto, Vatican, 1947, p. 41-47.

De la Blanchère 1880 : R. de la Blanchère, Inscriptions inédites de la valle di Terracina, $R A, 40 / 2,1880$, p. 362-373.

De Souza 2004 : M. de Souza, La question de la tripartition des catégories du droit divin dans l'Antiquité romaine, Saint-Étienne, 2004 (Bibliothèque du CERHI, 1).

De Visscher 1963 : F. De Visscher, Le droit des tombeaux romains, Milan, 1963.

Dubourdieu - Scheid 2000 : A. Dubourdieu, J. Scheid, Lieux de culte, lieux sacrés : les usages de la langue, dans A. Vauchez (dir.), Lieux sacrés, lieux de culte, sanctuaires. Approches terminologiques, méthodologiques, historiques et monographiques, Rome, 2000 (Coll. EFR, 273), p. 59-80.

Ducos 1995 : M. Ducos, Le tombeau, locus religiosus, dans Hinard 1995, p. 135- 144.

Dumézil 2000 : G. Dumézil, La religion romaine archaïque, Paris, 2000 (2éd.).

Estiez 1995 : O. Estiez, La translatio cadaueris. Le transport des corps dans l'Antiquité romaine, dans Hinard 1995, p. 101-108.

$F I R A^{2}$ : S. Riccobono, V. Arangio-Ruiz (éd.), Fontes iuris Romani anteiustiniani, Florence, 1940-1943 ( $2^{\mathrm{e}}$ éd.), 3 vol.

Flambard 1987 : J.-M. Flambard, Éléments pour une approche financière de la mort dans les classes populaires du Haut-Empire: analyse du budget de quelques collèges funéraires de Rome et d'Italie, dans Hinard 1987, p. 209-244. 
MEFRA $119 / 1-2007$, p. 149-188

Freis 1967 : H. Freis, Die cohortes urbanae, Cologne, 1967 (Epigraphische Studien, 2).

Fridh 1990 : A. Fridh, Sacellum, sacrarium, fanum and related terms, dans St. Teodorson (dir.), Greek and Latin studies in memory of Cajus Fabricius, Göteborg, 1990 (Studia Graeca et Latina Gothoburgensia, 54), p. 173-187.

Gabba - Tibiletti 1960 : E. Gabba, G. Tibiletti, Una signora di Trevi sepolta a Pavia, Athenaeum, 38, 1960, p. 253-262.

Gaudemet 1964 : J. Gaudemet, La juridiction provinciale d'après la correspondance entre Pline et Trajan, RIDA, ser. 3, 11, 1964, p. 335-353.

Geraci 1975 : G. Geraci, La collezione di Bagno : le iscrizioni greche e latine, Faenza, 1975 (Epigrafia e antichità, 4).

Giorgi 1910 : G. Giorgi, Le multe sepolcrali in diritto romano, Bologne, 1910.

Giovannini - Hirt 1999 : A. Giovannini, M. Hirt, L'inscription de Nazareth. Nouvelle interprétation, ZPE, 124, 1999, p. 107-132.

Halsberghe 1984 : G.H. Halsberghe, Le culte de Deus Sol Inuictus à Rome au III s. ap. J.C., dans $A N R W$, II, 17/4, 1984, p. 2181-2200.

Herzog 1993 : R. Herzog, (dir.), Nouvelle histoire de la littérature latine, 5. Restauration et renouveau (284-374), Turnhout, 1993.

Herzog 2000 : R. Herzog (dir.), Nouvelle histoire de la littérature latine, 4. L'âge de transition, de la littérature romaine à la littérature chrétienne (117-284), Turnhout, 2000 .

Hinard 1987 : Fr. Hinard, (dir.), La mort, les morts et l'au-delà dans le monde romain (Actes du coll. de Caen, 20-22 nov. 1985), Caen, 1987.

Hinard 1995 : Fr. Hinard (dir.), La mort au quotidien dans le monde romain (Actes du coll. organisé par l'Université de Paris IV, 7-9 octobre 1993), Paris, 1995.

Hinard - Dumont 2003 : Fr. Hinard, J.-Chr. Dumont (dir.), Libitina. Pompes funèbres et supplices en Campanie à l'époque d'Auguste, Paris, 2003.

IDR : Inscriptiones Daciae Romanae, Bucarest, 1975 - (Inscripţiile antice..., seria I).

ILAlg : Inscriptions latines de l'Algérie, Paris, puis Alger, $1922-$

IL Alpes Grées : B. Rémy, Inscriptions latines des Alpes. I. Alpes Graies, ChambéryGrenoble, 1998 (Bibliothèque des études savoisiennes, 5). 
MEFRA $119 / 1-2007$, p. 149-188

ILCV : E. Diehl, Inscriptiones Latinae Christianae Veteres, Berlin-Dublin-Zurich, 19251967.

ILS : H. Dessau, Inscriptiones Latinae Selectae, Berlin, 1982-1916.

ILTun: A. Merlin, Inscriptions latines de la Tunisie, Paris, 1944.

InscrIt : Inscriptiones Italiae, Rome, 1931 -

Jörs 1894 : P. Jörs, M. Antistius Labeo, RE, I,2, 1894, p. 2548-2557.

Kaser 1978 : M. Kaser, Zum römischen Grabrecht, Zeitschrift des Savigny-Stiftung für Rechtgeschichte, Röm. Abt., 95, 1978, p. 15-92.

Kubitschek 1889 : J.W. Kubitschek, Imperium Romanum tributim discriptum,Vienne, 1889.

Kübler 1903 : B. Kübler, Privatrechtliche Competenzen der Volkstribunen in der Kaiserzeit, dans Festschrift zu Otto Hirschfeld sechzigstem Geburtstage, Berlin, 1903, p. 50-60.

Lassère 1973 : J.-M. Lassère, Recherches sur la chronologie des épitaphes païennes de l'Africa, Antiquités Africaines, 7, 1973, p. 7-152.

Latte 1960 : K. Latte, Römische Religionsgeschichte, Munich, 1960 (Handbuch der Altertumswissenschaft, V, 4).

Lex Vrsonensis 1997 : La lex Vrsonensis, Salamanque, 1997 (Studia historica-Historia antigua, 15).

Libitina 2004 : Libitina $e$ dintorni (Atti dell'XI Rencontre franco-italienne sur l'épigraphie), Rome, 2004 (Libitina, 3).

Longo 1964 : G. Longo, Sul diritto sepolcrale romano, IVRA, 15, 1964, p. 137-158.

Lopéz-Melero 1997 : R. Lopéz-Melero, Enterrar en Urso, dans Lex Vrsonensis 1997, p. $105-118$.

Magdelain 1976 [1990] : A. Magdelain, Le pomerium archaïque et le mundus, REL, 54, 1976-77, p. 71-109 [repr. dans Jus Imperium Auctoritas. Études de droit romain, Rome, 1990 (Coll. EFR, 133), p. 155-191.].

Magister 1998 : S. Magister, Pomponio Leto collezionista di antichità. Note sulla tradizione manoscrita di una raccolta epigrafica nella Roma del tardo Quattrocento, Xenia Antiqua, 7, 1998, p. 167-196.

Marbach 1927 : E. Marbach, Sol, RE, II, 5, 1927, p. 901-913. 
MEFRA $119 / 1-2007$, p. 149-188

Marquardt 1881-1886 : J. Marquardt, Römische Staatsverwaltung, 3 vol., Leipzig, 18811886 ( $2^{\mathrm{e}}$ éd.).

Merlin 1903 : A. Merlin, Inscriptions inédites de Khamissa (Thubursicum Numidarum), Mélanges d'Archéologie et d'Histoire, 23, 1903, p. 116-130.

Millar 1977 : F. Millar, The Emperor in the Roman world (31 B.C.-A.D. 337), Londres, 1977.

Mommsen 1876 : Th. Mommsen, Der Begriff des Pomerium, Hermes, 40, 1876, p. 40-50.

Mommsen 1877 [1905] : Th. Mommsen, Lex coloniae Iuliae Genetiuae Urbanorum siue Ursonis, EE, 3, 1877, p. 91-112 [repr. dans Gesammelte Schriften, I. Juristische Schriften, 1, Berlin 1905, p. 240-264].

Mommsen 1881 : Th. Mommsen, Iscrizione di Terracina, Bulletin de l'Institut de correspondance archéologique, 1881, p. 63-64.

Mommsen 1889-1896 : Th. Mommsen, Le droit public romain, Paris, 1889-1896.

Negroni 2001 : A. Negroni, Aggiunte e correzioni al CIL VI. Alcune revisioni nella galeria Lapidaria (settori 6, 8, 10, 12), BMMP, 21, 2001, p. 171-180.

OGIS : W. Dittenberger, Orientis Graeci inscriptiones selectae, Leipzig, 1903-1905.

OPEL : Onomasticon Provinciarum Europae Latinarum, 4 vol. Vol. 1 : B. Lörincz, Fr. Redő (éd.), Budapest, 1994. Vol. 2-4 : B. Lőrincz (éd.), Vienne, 1999-2001.

Panciera et alii 1987 : S. Panciera (dir.), La collezione epigrafica dei Musei Capitolini. Inediti, revisioni, contributi al riordino, Rome, 1987 (Tituli, 6).

Panciera 2000 : S. Panciera, Netteza urbana a Roma. Organizzazione e responsabili, dans X. Dupré-Raventos, J.A. Remola (dir.), La eliminación de residuos en la ciudad romana (Act. de la reunión de Roma, 15-16 de nov. 1996), Rome, 2000 (Bibl. Italica : monografias de la Escuela española de historia y arqueología en Roma, 24), p. 95-105.

Pflaum 1948 : H.-G. Pflaum, Le marbre de Thorigny, Paris, 1948 (Bibliothèque de l'École des Hautes Études, 292).

Pflaum 1955 [1978] : H.-G. Pflaum, Une inscription de Castellum Arsacalitanum, Recueil des notices et Mémoires de la société archéologique de Constantine, 79, 1955, p. 147-172 [repr. dans Scripta Varia I. L'Afrique romaine, Paris, 1978, p. 124-149].

Pikhaus 1994 : D. Pikhaus, Répertoire des inscriptions latines versifiées de l'Afrique romaine ( $I^{\text {er }}-V I^{e}$ siècles). I: Tripolitaine, Byzacène, Afrique Proconsulaire, Bruxelles, 1994 (Epigraphica Bruxellensia, 2). 
MEFRA $119 / 1-2007$, p. 149-188

PIR : Prosopographia Imperii Romani. Saec. I. II. III., Berlin, 1897-1898.

PIR² : Prosopographia Imperii Romani. Saec. I. II. III., Berlin, 1933 - (2 éd.).

Premerstein 1926 : A. von Premerstein, Libellus, $R E, 25,1926$, p. 26-61.

RE : Realencyclopädie der classischen Altertumswissenschaft, Stuttgart, 1894-1980.

Rebillard 2003 : É. Rebillard, Religion et sépulture. L'Église, les vivants et les morts dans l'Antiquité tardive, Paris, 2003.

Ricci 2001 : C. Ricci, Memoria e rappresentazione di sé nel cenotafio antico, dans G. Alföldy, S. Panciera (dir.), Inschriftliche Denkmäler als Medien der Selbstsdarstellung in der römischen Welt, Stuttgart, 2001 (Heidelberger Althistor. Beiträge und epigrapische Studien, Band 36), p. 149-161.

Ricci 2006 : C. Ricci, Qui non riposa. Cenotafi antichi e moderni fra memoria e rappresentazione, Rome, 2006 (Libitina, 4).

Rose 1923 : H.J. Rose, Nocturnal funerals in Rome, CQ, 17, 1923, p. 191-195.

Rossi 1975 : A.M. Rossi, Ricerche sulle multe sepolcrali Romane, Rivista Storica dell'Antichità, 5, 1975, p. 111-159.

Rüpke 2006 : J. Rüpke, Religion in the lex Vrsonensis, dans Ando - Rüpke 2006, p. 34-46.

RS : M.H. Crawford (dir.), Roman Statutes, Londres, 1996 (Bulletin of the Institute of Classical Studies, Suppl. 64).

Salvadore 1996 : M. Salvadore, Il contatto con la terra, AFLM, 29, 1996, p. 129-151.

Scheid 1981 : J. Scheid, Le délit religieux dans la Rome tardo-républicaine, dans Le délit religieux dans la cité antique (table ronde, Rome, 6-7 avril 1978), Rome, 1981 (Coll. EFR, 48), p. 117-171.

Scheid 1984 : J. Scheid, Contraria facere : renversements et déplacements dans les rites funéraires, AION Archéologie, 6, 1984, p. 117-139.

Scheid 1990 : J. Scheid, Romulus et ses frères. Le collège des frères arvales, modèle du culte public dans la Rome des empereurs, Rome, 1990 (BEFAR, 275).

Scheid 2005 : J. Scheid, Quand croire, c'est faire. Les rites sacrificiels des Romains, Paris, 2005.

Scheid 2006 : J. Scheid, Oral tradition and written tradition in the formation of sacred law in Rome, dans Ando-Rüpke 2006, p. 14-33 
MEFRA $119 / 1-2007$, p. 149-188

Sherwin-White 1985 : A.N. Sherwin-White, The letters of Pliny. A historical and social commentary, Oxford, 1985 ( $2^{\mathrm{e}}$ éd.).

Simonelli 2001 : A. Simonelli, Considerazioni sull'origine, la natura e l'evoluzione del pomerium, Aevum, 75/1, 2001, p. 119-162.

Sinn 1987 : Fr. Sinn, Stadtrömische Marmorurnen, Mayence, 1987 (Beiträge zur Erschließung hellenistischer Skulptur und Architektur, 8).

Solin 2003 : H. Solin, Die griechischen Personennamen in Rom. Ein Namenbuch. Zweite, völlig neu bearbeitete Auflage, Berlin-New York, 2003, 3 vol. (CIL Auctarium, Series nova 2).

SupplIt : Supplementa Italica. Nuova series, Rome, 1981 -

Tarpin 2002 : M. Tarpin, Vici et pagi dans l'Occident romain, Rome, 2002 (Coll. EFR, 299).

Thomas 1999 : Y. Thomas, Corpus aut ossa aut cineres. La chose religieuse et le commerce, Micrologus, 7, 1999, p. 73-112.

Thomas 2002 : Y. Thomas, La valeur des choses : le droit romain hors la religion, Annales HSS, 6, 2002, p. 1431-1462.

TLL : Thesaurus Linguae Latinae, Leipzig, $1900-$

Torelli 1963 : M. Torelli, Trebula Mutuesca : iscrizioni corrette ed inedite, Atti della Accademia nazionale dei Lincei, Rendiconti, ser. 8, 18, 1963, p. 230-284.

Tromp 1921 : S.P.C. Tromp, De Romanorum piaculis, Amsterdam, 1921.

Tsalampouni 2001 : E. Tsalampouni, The Nazareth inscription : a controversal piece of Palestinian epigraphy (1930-1999), Tekmeria, 6, 2001, p. 70-120.

Van Haeperen 2002 : Fr. Van Haeperen, Le collège pontifical ( $\left.3^{e} s . a C .-4^{e} s p C\right)$. Contribution à l'étude de la religion publique romaine, Bruxelles-Rome, 2002 (Institut historique belge de Rome. Études de philologie, d'archéologie et d'histoire anciennes, 39).

Veyne 1983 [1991] : P. Veyne, Le folklore à Rome et les droits de la conscience individuelle, Latomus, 43, 1983, p. 3-30 [repr. sous le titre Les droits de la conscience publique sur la conduite individuelle : un constat ethnologique, dans La société romaine, Paris, 1991, p. 57-87].

Vidman 1960 : L. Vidman, Étude sur la correspondance de Pline le Jeune avec Trajan, Prague, 1960 (Studia Historica, 109). 
MEFRA $119 / 1-2007$, p. 149-188

Virno Bugno 1971 : L. Virno Bugno, M. Barronio Sura e l'industria della porpora ad Aquino, Atti della Accademia nazionale dei Lincei, Rendiconti, ser. 8, 26, 1971, p. 680-695.

Wagenvoort 1949 : H. Wagenvoort, Profanus, profanare, Mnemosyne, ser. 4, 8, 1949, p. 319-332.

Walser 1993 : G. Walser, Römische Inschriftkunst. Römische Inschriften für den akademischen Unterricht und als Einführung in die lateinische Epigraphik ausgewählt, photographiert und erlaütert von G. W., Stuttgart, 1993 ( $2^{\mathrm{e}}$ éd.).

Weaver 1972 : P. R. C. Weaver, Familia Caesaris. A social study of the emperor's freedmen and slaves, Cambridge, 1972.

Wissowa 1912 : G. Wissowa, Religion und Kultus der Römer, Munich, 1912, (2 éd.) (Handbuch der klassichen Altertumswissenschaft, V, 4). 